\title{
Evaluación y seguimiento del primer bienio de aplicación del I Plan Integral para la inmigración en Andalucía
}

\author{
Concha Aprell Lasagabaster \\ Profesora Titular de Derecho Administrativo \\ Universidad de Málaga
}

SUMARIO: LOS DOCUMENTOS TÉCNICOS DE SEGUIMIENTO $0 / 1 \mathrm{Y}$ 0/2. INTRODUCCIÓN. I. ANÁLISIS DE LA REALIDAD. II. MARCO JURÍDICO. III. ANÁLISIS Y VALORACIÓN DEL ESTADO DE EJECUCIÓN DE LAS MEDIDAS DESARROLLADAS EN EL PERIODO 2001 Y 2002: ÁREAS DE INTERVENCIÓN. IV. CONCLUSIONES.

La Comisión Interdepartamental de Políticas Migratorias creada como órgano de asesoramiento de la Junta de Andalucía y adscrita a la Consejería de Gobernación tiene entre sus funciones la promover la coordinación e impulso de las actuaciones en materia de inmigración, proponer y elaborar medidas, e informar sobre las repercusiones de la normativa vigente en materia de inmigración. Este conjunto de funciones le atribuye desde sus inicios un importante papel en la elaboración, ejecución, seguimiento y evaluación del Primer Plan Integral para la Inmigración en Andalucía.

\section{LOS DOCUMENTOS TÉCNICOS DE SEGUIMIENTO $0 / 1$ y 0/2.}

Los Documentos Técnicos de Seguimiento 0/1 y 0/2, publicados en el año 2003 y $2004^{1}$, se enmarca en el ámbito de competencias atribuidas a la Comisión Interdepartamental y son un magnifico instrumento para conocer la realidad de la aplicación del Plan durante su primer Bienio de realización, ya

\footnotetext{
${ }^{1}$ Documento Técnico de Seguimiento 0/1. (DTS 0/1) Edición Junta de Andalucía, Consejería de Gobernación. Dirección General de Políticas Migratoria, 2003. Documento Técnico de Seguimiento 02 (DTS 0/2). Edición Junta de Andalucía, Consejería de Gobernación. Dirección General de Políticas Migratoria, 2004.
} 
que son fruto de una de las principales líneas de actuación del propio Plan, su procedimiento de evaluación continua que permite ofrecer una información actualizada de la realidad del hecho migratorio.

El Documento Técnico de Seguimiento $0 / 1^{2}$ (en adelante DTS 0/1) realiza el seguimiento del Plan a lo largo de su primer año vigencia, esto es el año $2001^{3}$, mientras que el Documento Técnico de Seguimiento 0/2, hace lo propio con el año $2002^{4}$. Siguiendo la propia estructura del Plan, ambos Documentos Técnicos se articulan en una Introducción y en diferentes Capítulos no totalmente coincidentes en ambos Documentos, siendo el Documento Técnico de Seguimiento 0/2 (en adelante, DTS 0/2) mucho más completo en cuanto a datos que el DTS $0 / 1$ y al que, por consiguiente, seguiremos en su esquema de desarrollo, haciendo referencia puntual a los datos aportados en el DTS $0 / 1$.

\section{INTRODUCCIÓN}

Tanto el DTS $0 / 1$ como el DTS $0 / 2$ se inician con una pequeña Introducción en la que exponen el proceso de elaboración de ambos Documentos, en la que participan también los miembros de la Comisión Técnica Interdepartamental quienes aportaron los resultados de la evaluación de las medidas ejecutadas durante los años 2001 y 2002.

Respondiendo al prioritario Principio de Integralidad, las medidas evaluadas están basadas en tres líneas estratégicas de intervención, como son prevención, atención y promoción, lo que unido al carácter abierto y flexible del Plan, permiten que se coordinen entre los distintos órganos de la Administración Andaluza, gestores del Plan, la aplicación de nuevas medidas y la modificación de las ya aplicadas y consideradas mejorables por el DTS 0/1. Carácter

\footnotetext{
${ }^{2}$ Una vez finalizado su proceso de elaboración, fue aprobado por la Comisión Interdepartamental de Políticas Migratorias el 30 de septiembre de 2002. Posteriormente fue presentado para su consideración en el Parlamento Andaluz el día 21 de noviembre de 2002 y en el Foro Andaluz de la Inmigración el 19 de diciembre del mismo año. Vid. DTS 0/2, pág. 8.

${ }^{3}$ Como ya hemos señalado al inicio de este trabajo, el Plan se aprobó por Decreto de 9 de enero de 2002, aunque el Documento Marco fue aprobado el 14 de febrero de 2001.

${ }^{4}$ El DTS 0/2 se elabora durante el año 2003, pero no se pueden aportar datos sobre la fecha de aprobación y, en su caso, presentación, al Parlamento y al Foro Andaluz de la Inmigración.
} 
abierto y flexible que unido a «su proceso de evaluación continuada permiten introducir matizaciones y modificaciones que aseguren una óptima utilización de los recursos, la eficacia de los resultados que se prenden y una adecuada coordinación entre los diferentes organismos intervinientes» ${ }^{5}$.

\section{ANÁLISIS DE LA REALIDAD}

Siguiendo la tónica del Plan, ambos Documentos ${ }^{6}$, pero especialmente el DTS $0 / 2$, realizan amplio análisis estadístico de la realidad de la inmigración en Andalucía, bien es verdad que con los inconvenientes derivados de la imposibilidad de acceder a datos estadísticos en tiempo real, cuestión que no deja de ser un importante handicap en una realidad tan movible como es la inmigración en Andalucía en los albores del siglo XXI.

Para la realización del análisis estadístico, se han seleccionado, de entre las fuentes de datos disponibles, las siguientes:

- Instituto Nacional de Estadística

- Registro de Extranjeros Residentes del Ministerio del Interior

- Datos aportados por la Dirección General de Extranjería e Inmigración

- Anuario de Migraciones que edita el Ministerio de Trabajo y Asuntos Sociales.

- Anuario de Estadísticas Laborales y Asuntos Sociales que edita el Ministerio de Trabajo y Asuntos Sociales.

- Instituto de Estadística de Andalucía.

La relación de fuentes de datos permite apreciar una sensible mejora en el acceso a los mismos ${ }^{7}$, como se puede apreciar comparando las fuentes utilizadas en la elaboración del Plan, que eran el Observatorio Permanente de la Inmigración, del Instituto Nacional de Estadística, así como de fuentes propias de las Consejerías de la Junta de Andalucía ${ }^{8}$.

\footnotetext{
${ }^{5}$ DTS 0/2, pág. 8.

${ }^{6}$ Que se corresponden con el Capítulo II del DTS 0/1 y Capítulo I del DTS 0/2.

${ }^{7}$ DTS 0/2, pág. 13.

${ }^{8}$ Vid. DTS 0/2, pág. 6.
} 
No obstante, los Documentos de Seguimiento se enfrentan al mismo problema que el Plan, la falta de información referente a personas en situación irregular, ya que los datos estadísticos al proceder de fuentes oficiales no tienen en cuenta los extranjeros en situación irregular, colectivo del que es muy difícil obtener datos fiables, sobre todo en una Comunidad como la Andaluza, que ejerce de frontera de la Unión Europea. Motivo por el cual, ambos DTS, siguiendo la tónica del Plan apenas hacen mención a ese grupo de población.

A la hora de analizar los datos disponibles, los Documentos Técnicos de Seguimiento tienen en cuenta que la población extranjera residente en España se acoge a distintas formulas administrativas para determinar su permiso de residencia, teniendo en cuenta factores como el país de procedencia o la situación familiar. Por tanto, el grupo de análisis está formado por las personas extranjeras que legalmente residen en España al estar en posesión de un permiso de residencia en vigor, que pueden ser de dos tipos:

- Régimen comunitario: contempla a los nacionales de los Estados de la Unión Europea y del Espacio Económico Europeo (EEE) y Suiza.

- Régimen General: contempla a los no nacionales de la Unión Europea y del EEE.

Es importante tener en cuenta estas categorías, ya que el tipo de permiso de residencia condiciona el permiso de trabajo y los extranjeros del Régimen Comunitario al ser ciudadanos de la Unión Europea, tienen derechos similares a los de nacionalidad española. Por ello, ambos DTS procuran ofrecer información tanto de la población extranjera de Régimen General como de Régimen Comunitario. Por otro lado, también se tiene en cuenta la situación familiar, ya que es posible que extranjeros no nacionales de la UE ni del EEE, pueden disponer de un permiso de residencia de Régimen Comunitario, al ser familiares de ciudadanos comunitarios.

Datos Generales de la población extranjera residente en Andalucía y resto de España $^{9}$.

Los datos aportados por la Dirección General de Extranjería e Inmigración en Andalucía, a finales de 1999, permiten apreciar que tenían permiso de

\footnotetext{
${ }^{9}$ DTS 0/1, págs. 17; DTS 0/2, págs. 15-16.
} 
residencia comunitario o general 109.329 personas, mientras que el año 2000 ascendían a 132.428, en el año 2001 a 157.157, y en año 2002 a 163.942, en esos mismos años, en España el número de extranjeros en situación regular ascendía a 801.329, 895.720, 1.109 .060 y 1.324 .001 personas, respectivamente. En esos mismos años, los extranjeros residentes legales en Cataluña eran 183.736, 214.996, 280.167 y 328.461 y en la Comunidad de Madrid, 158.885, $162.985,231.295$ y 272.692 respectivamente.

El balance porcentual de estos datos nos permite apreciar que el incremento de la población de extranjeros regulares en Andalucía del año 2000 frente al del 1999 fue de un 21,35\% frente al 11,78\% de media nacional, año que coincidió con los principales procesos de regularización. El año siguiente el 2001 el incremento en Andalucía fue similar, concretamente del 18,67\%, pero menor a la media nacional que se elevó al 23,82\%. Finalmente el año 2002 ha supuesto un incremento de un 2,32\% respecto a 2001, frente al 19, $38 \%$ de la media nacional.

El porcentaje de población extranjera residente regular en Andalucía representaba el año 1999 el 13,62\% del total de la población residentes regulares en España, el 14,78\% en el año 2000, el 14,17\% en el 2001 y el $12,38 \%$ en el 2002. Mientras las Comunidades con mayor presencia de extranjeros como son Cataluña o la Comunidad de Madrid representaban el $22,93 \%, 24 \%, 25,26 \%$ y $24,81 \%$, y el $19,83 \%, 18,20 \%, 20,86 \%$ y $29,69 \%$ respectivamente.

Estos datos nos permiten extraer dos importantes conclusiones:

1) Como constataba el Plan, la inmigración en Andalucía es un fenómeno ya consolidado, seguimos siendo la tercera Comunidad Autónoma con mayor número de extranjeros residentes, por detrás de Cataluña y Madrid y por delante de la Comunidad Valenciana.

2) En comparación con el resto de España y concretamente con otras Comunidades Autónomas, Andalucía no es de los territorios donde mayor incremento se está produciendo en términos de personas con permiso de residencia, ralentizándose el proceso desde el año 1999.

¿Cuáles son los motivos para esta ralentización? El DTS 0/2 alega tres principales motivos:

- La ausencia de procesos de regularización 
- La peculiar composición de la población extranjera en Andalucía respecto al resto de España, que gira en torno a una población comunitaria muy importante con un crecimiento más lento.

- Unos flujos migratorios interiores de la población de nacionalidad extranjera hacia la zona de Murcia, Comunidad Valenciana, Cataluña y Madrid.

La ausencia de procesos de regularización estimo que no puede ser alegada como causa de la ralentización, ya que al ser procedimientos de ámbito nacional afectan por igual a todas las Comunidades Autónomas, no sólo a Andalucía. Por el contrario, la peculiar composición de la inmigración en Andalucía con una importante presencia de ciudadanos comunitarios así como los flujos migratorios a zonas económicamente más dinámicas si pueden influir en esta disminución del ritmo de llegada de inmigrantes a la Comunidad Andaluza.

El Censo de 2001 aporta datos complementarios a los de la Dirección General de Extranjería e Inmigración. Los Censos de Población y Vivienda se realizan n España, por imperativo legal, cada diez años. «Su objetivo principal, es determinar el número de habitantes, viviendas y edificios del Estado y de sus diversas áreas geográficas y administrativas, y obtener una descripción de la estructura del país desde distintos puntos de vista para permitir la elaboración y evaluación de políticas demográficas, sanitarias, educativas, asistenciales, medioambientales, etc.».

«El análisis de los datos aportados por el Censo en sus distintos avances, nos encontramos con que la población cuyo país de nacimiento no es España, residente a 1 de enero de 2002, ascendía a 1.572.017 personas; número superior a los datos aportados por la Dirección General de Extranjería e Inmigración que, a 31 de diciembre de 2001, señaló que los residentes extranjeros en España ascendían a 1.109.060. El motivo de esta disparidad de datos puede deberse a varias causas:

- Que algunos residentes no se hayan inscrito.

- Que algunos residentes extranjeros hayan inscrito a familiares que realmente no residan en la vivienda.

- O simplemente a que algunos residentes están en situación administrativa irregular por lo que no constan en los archivos de la Dirección General de Extranjería e Inmigración» ${ }^{10}$

${ }^{10}$ DTS 0/2 pág. 19 y 20. 
Motivos todos ellos perfectamente válidos y reales, como se ha podido comprobar con la apertura del procedimiento de regularización del año 2005, con los considerables problemas que ha planteado el procedimiento de empadronamiento para los distintos Ayuntamientos ${ }^{11}$.

El análisis de los datos aportados por el avance del Censo 2001 permite observar cómo el porcentaje de población extranjera respecto al total de la población en el ámbito nacional es de 3,85\%. «Comparando estos datos con la tendencia señala por los datos aportados por la Dirección General de Extranjería e Inmigración, muestran que las Comunidad Autónomas con mayor presencia de población pueden dividirse en cuatro grupos»:

a) «Aquellos que tienen un alto porcentaje de población y siguen creciendo a un ritmo por encima de la media: Murcia, Valencia, Navarra, La Rioja y Baleares» ${ }^{12}$.

b) «Aquellas que tiene un alto porcentaje de población respecto a la media y que han ralentizado su crecimiento: Madrid, Cataluña, Canarias, y las dos Ciudades Autónomas (Ceuta y Melilla)» ${ }^{13}$

c) «Un tercer grupo estaría constituido por aquellas Comunidades donde el incremento es alto pero aún la población extranjera no se encuentra representad por un número significativo de personas: Castilla la Macha, Cantabria y el País Vasco» ${ }^{14}$.

d) «Finalmente aquellas Comunidades donde el incremento es pequeño y la población extranjera se encuentra representada por un nú-

11 Vid. al respecto LAGO NÚÑEZ, G.: “Los extranjeros y la Administración Local', en El Consultor de los Ayuntamientos y los Juzgados, año 2005, núm. 11, págs. 1819 y ss.

${ }^{12}$ La población extranjera representa el 5,81\% de la población total de Murcia, el 5,23\% de la de la Comunidad Valenciana, el 4,37\% de la población total de Navarra, el 4,65\% de la de La Rioja y el 8,18\% de la población total de Baleares. Vid. DTS 0/2, Tabla 1.4. pág. 21.

${ }^{13}$ La población extranjera representa el 6,72\% de la población total de Madrid, el 4,89\% de la de Cataluña, el 5,78\% de la de Canarias y el 4,54\% y el 10,43\% de las Ciudades de Ceuta y Melilla. Vid. DTS 0/2, Tabla 1.4, pág. 21.

${ }^{14}$ La población extranjera representa el 2,31\% de la población total de Castilla la Mancha, el 1,62\% de la de Cantabria y 1,50\% de la del País Vasco. DTS 0/2, Tabla 1.4, pág. 21. 
mero no levado de personas respecto al total de la población: Andalucía, Aragón, Principado de Asturias, Castilla y León, Extremadura y Galicia» ${ }^{15}$.

«Estos porcentajes, en todos los casos, están muy alejados de los que existen en otros países europeos y señalan, en el caso de la Comunidad Andaluza, una desaceleración del crecimiento de inmigrantes extranjeros con permiso de residencia, debido a diversas causas que inciden en la situación legal de los extranjeros». Al mismo tiempo, «no podemos negar que en Andalucía se encuentran dos de las diez provincias españolas con mayor presencia de residentes extranjeros, como son Almería y Málaga y que en otras provincias, debido a su estructura económica, nos encontramos con poblaciones extranjeras que pueden llegar a multiplicar por cuatro la población residente como sucede en Huelva y Jaén durante las campañas agrícolas».

\section{$\underline{\text { La nacionalidad de los residentes extranjeros }}$}

Los datos aportados al respecto por la Dirección General de Extranjería e Inmigración y referidos al año 2000, 2001 y 2002, confirman el análisis realizado por el Plan para cada una de las provincias andaluzas en lo que se refiere a la irregular distribución de la población extranjera en las distintas provincias andaluzas ${ }^{16}$ y también permiten apreciar que el origen extranjero en Andalucía gira principalmente en torno a 10 países de los cuales 5 corresponden a la Unión Europea (Reino Unido, Alemania, Italia, Francia y Países Bajos 3 corresponden a América del Sur (Ecuador, Colombia y Argentina), 1 al continente Asiático (China) y 1 al continente Africano (Marruecos).

La nacionalidad más representada es la marroquí con un $24,69 \%$ en el año 2002, ligeramente inferior al 24,99\% del año 2001. La población de origen marroquí llegó a representar el 26,92\% de la población extranjera el año 2000. «Ello podría ser debido a que los procesos de regularización llevados a cabo durante ese año supusieron la regularización de miles de personas. Desde ese momento esta población ha ido perdiendo representatividad».

${ }^{15}$ La población extranjera representa el 2,42\% de la población total de Andalucía, el 3,18\% de la de Aragón, el 1,25\% de la población total del Principado de Asturias, el 1,53 de la de Castilla y León, el 1,96\% de la de Extremadura y el 1,30\% de la población total de Galicia. DTS 0/2, Tabla 1.4, pág. 21.

16 Vid. DTS 0/2, págs. 21-31. 
En el caso de Ecuador en el año 2002 se ha producido un descenso de $1,72 \%$, ya que, si en el año 2001, representaba el 4,94\% de la población, en el año 2002 ha descendido al 3,22\%, siendo preciso tener en cuenta que la tendencia general en el territorio español es justamente la inversa, pues entre el año 2001 y el 2002 se ha incrementado su presencia en un 1,07\%, pasando de representar el 7,64\% de los extranjeros residentes en España a un 8,71\% del total. Lo mismo puede decirse de las personas con nacionalidad de Colombia que pasaron de representar el 2,83\% el año 2001 al 2,55\% en el año 2002, mientras que en el territorio nacional sucedía lo contrario, ya que pasó de un $4,39 \%$ a un 5,38\% del año 2001 al año 2002.

Mientras tanto, dos nacionalidades de origen extracomunitario han visto incrementada su peso respecto de la población total de Andalucía. Este es el caso de la población originaria de China que ha pasado de un 2,02\% a representar un 2,61\% y también de los nacionales de Argentina que han pasado de un 2,00\% a un 2,34\% ambos en el periodo de 2001 a 2002, siguiendo, en este caso, la misma tendencia que a nivel nacional.

«Respecto de la población comunitaria, la población originaria del Reino Unido ha pasado del 14,70\% en el año 2001 al 16,37\% en el año 2002, tendencia que ha nivel nacional es totalmente inversa ya que ha pasado de representar el $7,23 \%$ al $6,80 \%$, tendencia decreciente que se viene observando desde el año 1999 donde llego a alcanzar el 9,53\% de la población a nivel nacional».

«Las otras nacionalidades comunitarias señalas (Alemania, Italia, Francia y Países Bajos) tienen un comportamiento similar, moviéndose en porcentajes parecidos al año $2001{ }^{17}$.

\section{La edad de los inmigrantes.}

La distribución de la población según los grupos de edad ha ido evolucionando desde la elaboración del Primer Plan Integral para la Inmigración en Andalucía, según ponen de manifiesto los datos de la Dirección General de Extranjería e Inmigración.

${ }^{17}$ Alemania representa el 5,39\%, Italia el 3,76\%, Francia 3,73\% y los Países Bajos el 2,24\%. Vid. DTS 0/2, pág. 24. 
«Tanto en Andalucía como en el resto de España, la distribución de la población extranjera según grupos de edad, a 31 de diciembre de 2002, muestra una mayor concentración de extranjeros y extranjeras en las edades que son consideradas como Población Activa (entre los 16 y 65 años), sobre todo en el grupo que va de 25 a 44 años».

«Se observa en la mayoría de la provincias un incremento en el grupo de edad que denominamos "menores de 16 años", sobre todo en la provincia de Córdoba donde llegan a representar el 17,20\% de la población extranjera en el año 2002, Cádiz con un 12,37\% y Sevilla, donde llega al 12,23\%; todas, cantidades por encima de la media nacional que se queda en el 11, 24\%». Este hecho obliga «a pensar que los proyectos familiares de los grupos son fuertes y consolidados y contrastan con la situación de las provincias de Huelva y Málaga», que se comentarán más adelante.

«El grupo de "16 a 24" es el que más oscilaciones sufre. Sus incrementos se producen de un lado debido a la incorporación de personas que cumplen los 16 años y de otro número de personas inmigrantes que llegan a Andalucía, por lo que aunque el incremento sigue produciéndose, se produce a un menor ritmo que la incorporación a otros grupos de edad como es el de "25 a 44 años”. A pesar de ello, provincias como Jaén con un 14,88\%, Almería con un $13,20 \%$ y Málaga con un 13,19\% están por encima de la media nacional, que es un $12,13 \%$ ".

«En el grupo de "25 a 44" es en que se produce el mayor numero de incorporaciones, de hecho en todas las provincias se ha incrementado su peso relativo», siguiendo con ello la tendencia detectada durante la elaboración del Plan. «Podemos decir, por lo tanto, que la inmigración en Andalucía se produce, en su mayoría, en personas que tienen menos de 45 y que llegan a nuestro territorio en unas condiciones de salud optimas, dispuestos a incorporarse al mercado laboral. Provincias como Jaén con un 61\%, Almería con un $59,22 \%$ o Huelva con un 57,65 están por encima de la media nacional que es de $53,57 \%$ ».

«En el grupo de "45 a 64" y "mas de 65" se produce un hecho conjunto. Estos dos grupo a nivel del territorio andaluz se comportan de igual forma. Ello puede ser debido a que las provincias donde se produce el fenómeno son provincias que hemos denominado en ocasiones anteriores de turismo residencial y de ocio, con municipios costeros enfocados al turismo, donde residen un gran número de jubilados de edades superiores e inferiores a los 65 años. Málaga con un 31,53\% de la población en el grupo de "45 a 64 " y un 
21,55\% en el grupo de "más de 65" lidera esa clasificación, le sigue Cádiz con un $22,95 \%$ y un $8,45 \%$ respectivamente; finalmente, Granada con un $20,16 \%$ y $9,86 \%$. Si comparamos con la media nacional que es de un $16,90 \%$ para el grupo de 45 a 64 años y de un 6,16\% para el grupo de más de 65 años, podemos comprobar la magnitud de fenómeno del turismo residencial de la Costa del Sol.

Resumiendo, el grupo más importante de residentes extranjeros sigue siendo el colectivo de 25 a 44 años, aunque se ha producido cambios desde la aprobación del Plan en el intervalo de "menores de 16", que ha visto incrementada su presencia, sobre todo en algunas provincias andaluzas como son Córdoba, Cádiz y Sevilla, lo que indica que muchos extranjeros han decidido instalarse permanentemente en nuestra Comunidad.

\section{El tipo de permiso de residencia}

Los datos disponible a 31 de diciembre de 2002 señalan de nuevo una mayor presencia de los extranjeros de Régimen Comunitario que de Régimen General en Andalucía, como ya sucedía en los años 1999 y 2000.

Analizando los datos del Régimen Comunitario, se constata tanto para todo el Estado como para Andalucía una mayor presencia de mujeres, aunque la diferencia es mínima, como ocurría en 1999. Un 50,71\% de la población con Régimen Comunitario son mujeres frente al 48,83\% que representan los varones. Destacan especialmente, Córdoba con un 55,32\% de mujeres frente a un $43,71 \%$ de hombres, seguido de Granada, Málaga, Almería y Sevilla ${ }^{18}$.

La proporción de la población extranjera del Régimen General se invierte respecto del Régimen Comunitario, superando ampliamente el número de hombre al de mujeres, tanto en el Estado como en Andalucía, siendo estos porcentajes de un 64,16\% de varones frente al 35,69\% de mujeres en Andalucía. Estos datos hacen patente que existe todavía una inmigración económica protagonizada sobre todo por hombres, a pesar de las evidencias, existentes en los últimos años, de un incremento constante de la presencia de mujeres inmigrantes, debido tanto a los procesos de reagrupación familiar como a los proyectos migratorios individuales.

\footnotetext{
18 Vid. Tabla 1.18.DTS 0/2, pág. 36.
} 
Las diferencias señalas en la distribución por sexo se constatan también a la hora de contemplar los datos referidos a cada una de las provincias andaluzas. En todas las provincias andaluzas, sin excepción alguna, los hombres son mayoritarios, destacando Almería con un $76,35 \%$, Huelva con un $74,22 \%$ y Jaén con un $72,70 \%$.

\section{La situación de alta laboral en la Seguridad Social de la población extranjera que trabaja en la Comunidad Autónoma de Andalucía.}

«Un dato significativo de la integración de la población extranjera es su situación respecto de la actividad económica. En este sentido, uno de los indicadores a tener en cuenta es el alta a la Seguridad Social. La afiliación al Sistema de Seguridad Social es obligatoria para todas las personas incluidas en el campo de aplicación de la Seguridad Social y única para toda la vida del trabajador o de la trabajadora sin perjuicio de las bajas, altas y demás variaciones que con posterioridad a la afiliación puede producirse».

«Respecto a las cifras de afiliación a los distintos regímenes de la Seguridad Social, es necesario aclarar, como señala el Ministerio de Trabajo en las distintas notas explicativas para este tipo de datos, que no se corresponde necesariamente con el número de trabajadores, sino con las situaciones que general obligación de cotizar. En este sentido una misma persona puede estar contabilizada tantas veces como situaciones de cotización tenga, ya sea porque tiene varias actividades laborales en un mismo régimen o en varios».

La comparación de datos sociolaborales aportados por Ministerio de Trabajo y Seguridad Social para el año 2001 con los del año 2002 permite corroborar las valoraciones iniciales sobre la ralentización del fenómeno migratorio, ya que los trabajadores afiliados a la Seguridad Social en alta laboral representan en ambas fechas el $11,5 \%$ del total nacional ${ }^{19}$.

«En el año 2001, el 31,37\% de los extranjeros afiliados a la Seguridad Social eran mujeres; un año mas tarde ese porcentaje alcanza el 33,13\%, pasando en términos absolutos de 21.941 a 29.422. En el caso de los varones, en el año 2001, representaban el 68,63\% de los extranjeros afiliados a la Seguridad Social; el año siguiente, ese porcentaje disminuyó, alcanzando el $66,87 \%$. En términos absolutos los varones pasaron de 47.995 a 59.385 afiliados».

${ }^{19}$ Vid. Tabla 1.21 y 1.25 . DTS 0/2, pág. 41 y 43. 
Si tenemos en cuenta que los datos aportados por el Plan estimaban que, a 31 de diciembre del año 2000, que el $30 \%$ de todos los trabajadores extranjeros afiliados a la Seguridad en alta eran mujeres, mientras que el 69,34\% eran hombres, podemos comprobar el sostenido incremento de mujeres inmigrantes en Andalucía.

«En cuanto a la distribución por provincias, se pone de manifiesto la alta incidencia de trabajadores y trabajadoras extranjeras en la provincia de Málaga, con el 35,68\% de los afiliados a la Seguridad Social en alta laboral, y Almería, con el 31,63\% en el años 2002.

«La distribución de afilados a la Seguridad Social en alta laboral según el tipo de régimen laboral muestra que, en el Régimen General, está afiliados el 3,12\% de trabajadores extranjeros, mientras que en el Régimen Especial Agrario están afiliados el 33,39\%; y 17,34\% lo están el Régimen Especial de Trabajadores Autónomos. Al mismo tiempo se ha podido comprobar que durante los últimos años se está produciendo una incorporación de mujeres extranjeras al Régimen Especial de Empleados/as de Hogar, así se ha pasado en términos absolutos de 3.357 personas en 2001 a 5.183 en el año 2002, lo que supone pasar de un $4,80 \%$ a un $5,84 \%$ del total de personas en alta laboral afiliados a la Seguridad Social ${ }^{20}$ ».

«Por último, respecto a la distribución según nacionalidades, es interesante destacar que el mayor porcentaje de los trabajadores y trabajadoras extranjeros en alta a a Seguridad Social, el 35,52\%, corresponde a nacionalidades africanas, mientras que el 17,53\% corresponde a trabajadores procedentes de América Central y del Sur. Es importante señalar el hecho de que el $70,45 \%$ son trabajadores de nacionalidades distintas a las del Espacio Económico Europeo».

\section{Los alumnos extranjeros en Andalucía durante el curso 2002-2003}

Los datos aportados por la Consejería de Educación permiten señalar que durante el curso escolar 2002-2003 había un total de 34.775 alumnos extranjeros matriculados en Andalucía. De ellos, el 51,42\% cursan Educación Primaria; el 26,63\% cursa Educación Secundaria; el 19,61\% es alumnado matriculado en Educación para Adultos; el 2,08\% son alumnos del Régimen de

\footnotetext{
${ }^{20}$ Vid. DTS 0/2, pág. 39-48.
} 
Educación Especial y un 0,26 es alumnado extranjero matriculado en P. G. S. El mayor número de alumnos extranjeros se produce en Málaga, donde estudian el 33,29\% de los alumnos extranjeros matriculados en Andalucía, seguido de Almería con un $28,07 \%$ y Granada que representa el $10,32 \%{ }^{21}$.

\section{MARCO JURÍDICO}

El Marco Jurídico en el que se enmarca el Plan es analizado de forma pormenorizada en el DTS 0/2, recogiendo las actualizaciones legislativas que se promulgaron o entraron en vigor durante el año 2001 y que no se incluyeron en el DTS 0/1, así como las normas promulgadas durante el año 2003, que por su trascendencia se consideran oportunas incluir, aunque dicho año no se incluye en el periodo de evaluación ${ }^{22}$.

La actualización legislativa y jurisprudencial respeta el «esquema expuesto en el Marco Jurídico del Plan, al objeto de realizar una exposición desde el punto de vista de los diversos ámbitos competenciales y territoriales: normativa internacional, comunitaria, estatal, autonómica y resoluciones judiciales».

\section{ANÁLISIS Y VALORACIÓN DEL ESTADO DE EJECUCIÓN DE LAS MEDIDAS DESARROLLADAS EN EL PERIODO 2001 Y 2002: ÁREAS DE INTERVENCIÓN ${ }^{23}$.}

Los objetivos generales que propone el I Plan Integral para la Inmigración en Andalucía, expresados en el Capítulo V del mismo son los siguientes:

a) «Favorecer la plena integración social, laboral y personal de la población inmigrante, como sujeto de derechos y deberes, creando las condiciones que favorezcan dicha integración en el seno de la sociedad andaluza».

b) «Asegurar el acceso de la población inmigrantes a los servicios básicos comunes al conjunto de la población, tales como la sanidad, la

\footnotetext{
21 Vid. Síntesis de datos sobre población extranjera en Andalucía. DTS 0/2, pág. 45-47.

${ }^{22}$ Capítulo I del DTS 0/1 y Capítulo II del DTS 0/2.

23 Vid. DTS 0/1, págs. 23-108 y DTS 0/2, págs. 67-307.
} 
educación, la vivienda, los servicios sociales y la atención jurídica, impulsando y realizando estrategias activas que garanticen este acceso».

c) «Cualificar la oferta de bienes y servicios tanto a la población inmigrantes como a la acogida, fomentando la coordinación y cooperación de las actuaciones de los poderes públicos, poniendo en valor los recursos disponibles».

d) «Mejorar permanentemente el conocimiento de la realidad y de las estrategias más adecuadas para el cambio, mediante el mantenimiento sostenido de la actividad de investigación, y de rechazo a toda forma de racismo y xenofobia, y cualquier clase de discriminación».

e) «Fomentar la sensibilización social acerca de los valores positivos del hecho de la inmigración, y de rechazo a toda forma de racismo y xenofobia, y cualquier clase de discriminación»

f) «Contribuir a mejorar las condiciones de vida y de las infraestructuras de los países de origen de la población inmigrante, mediante el conjunto de actuaciones que constituyen la Cooperación al Desarrollo, incidiendo, así en las causas del hecho migratorio».

\section{Introducción ${ }^{24}$}

El DTS 0/2 inicia el análisis y valoración de las distintas Áreas de Intervención con una importante declaración de principios relativa a la importancia de las información de calidad para lograr una buena gobernanza. «El I Plan Integral para la Inmigración en Andalucía, ya en sus inicios, contempla aspectos relativos a los debates que se están desarrollando actualmente acerca de la responsabilidad social, gobernanza, carta de servicios o el concepto de democracia participativa. En definitiva, aspectos relacionados con la gestión, diseño y evaluación de las políticas publicas en el marco de las nuevas relaciones entre los ciudadanos y ciudadanas y las administraciones públicas, que nos afectan a todos y que ahora se pone de actualidad»

«Hablar sobre la calidad de la información, la disponibilidad de los datos, la participación de las estructuras ciudadanas en la toma de decisiones estratégicas, la evaluación continua de las políticas públicas o la datación de éstas a los entornos dinámicos donde se desarrollan, mediante estructuras de coor-

\footnotetext{
${ }^{24}$ Vid. DTS 0/2, págs. 70-71.
} 
dinación abiertas y flexibles que incorporan las mejores actuaciones de las administraciones participantes como modelos a seguir, son algunos de los múltiples aspectos que el presente documento ha tenido en cuenta en su desarrollo; en coherencia con los objetivos planteados por el I Plan Integral para la Inmigración en Andalucía y las acciones propuestas para conseguirlos. Y todo ello, dentro de las distintas recomendaciones que se están haciendo desde la Unión Europea y otros estamentos, acerca de los procesos que se han de seguir para mejorar la Responsabilidad Social Corporativa de las Instituciones y que tienen como uno de sus pilares el de la transparencia informativa».

En este marco el DTS 0/2 plantea las características que debe tener toda información de calidad y que son:

- Fiabilidad: porque en ella se basa la toma de decisiones que se ha realizar.

- Transparencia: permitiendo con ello determinar la fuente.

- Disponibilidad: para que cuando sea necesario su utilización no genere demoras innecesarias.

- Eficiencia: ya que su obtención no debe generar costos innecesarios.

«No siempre más información supone mas valor, alcanzar el punto óptimo ha sido el horizonte que buscado el Plan». «Es dentro de esas características donde hemos trabajado para determinar la calidad de la información que estamos manejando. Esto ha sido fundamental a la hora de realizar los cambios; de nada nos serviría aumentar la cantidad de información puesta de manifiesto en la valoración del año 2002, si esta información no es de calidad»

«A su vez, y tal como ya se recogía en el DTS 0/1, "la necesidad de agilizar y mejorar el sistema de recogida, registro y explotación de datos" de un lado y de otro, "el conocimiento de la realidad obtenido de la forma más rápida y fiable", eran totalmente necesarios en este segundo año del proceso de evaluación. Ello ha permitido que la información disponible para los ciudadanos y ciudadanas, así como para todas las personas que se dedican al estudio del fenómeno de la inmigración en Andalucía, sea mayor y de mejor calidad». No obstante no se puede olvidar algunos factores como son: las diferentes culturas metodológicas, los distintos niveles de recogidas de datos y/o el grado de complejidad de algunas de las actuaciones, que inciden en la consecución de los objetivos, así como en el seguimiento de las medidas.

La elaboración del DTS 0/2 ha supuesto un importante cambio cualitativo y cuantitativo en el análisis de las medidas y objetivos que integran el I Plan 
Integral para la Inmigración en Andalucía. El cambio cuantitativo se deriva del incremento de la cantidad de información recogida y el cambio cualitativo de su mayor calidad, haciéndose posible una comparación de los datos obtenidos con las medidas y objetivos valorados en la evaluación de 2001, así como una mejora en la explotación de los mismos.

La mejora en los Instrumentos utilizados para la elaboración del DTS $0 / 2$, que, en efecto, es mucho más completo como se comprobar por simple comparación con el DTS 0/1, ha llegado de la mano «de una nueva sistemática en la recogida de datos e información». Esta nueva sistemática ha permitido a los autores del DTS 0/2 hacer propuestas de mejora en la recogida de información sobre cada una de las medida, así como, de los indicadores asociados a éstas. «La nueva herramienta utilizada para la recogida de información acerca de las actividades realizadas para la consecución de los objetivo dentro de la planificación anual que contempla ha permitido:

- Obtener información sobre aquellas actividades planificadas y realizadas en el año 2002.

- Recoger información sobre aquellas actividades planificadas para el año 2002 que por diversas causas no han podido realizarse en parte o en su totalidad.

- Determinar, en ambas situaciones, las dificultades encontradas lo que permitirá que en años sucesivos, arbitrar mecanismos que mejoren la eficacia de las medidas, disminuyendo los esfuerzos para conseguir los resultados.

- Proponer nuevas actuaciones para el bienio 2003-2004 por parte de los centros directivos responsables. Ello dentro de la lógica de ofrecer la mayor información acerca de las actuaciones que la Junta de Andalucía va a realizar en los próximos años en materia de inmigración dentro del marco del I Plan Integral para la Inmigración en Andalucía.

Esta información ha determinado la introducción de un apartado bajo el epígrafe "Propuestas para el bienio 2003-2004"»

\section{1. Área de Intervención SOCIO-EDUCATIVA}

El sistema educativo de la Comunidad Autónoma de Andalucía, como el del resto del Estado Español, tiene un carácter universal que garantiza el acceso gratuito a la educación básica obligatoria a toda persona residente en la Comunidad. 
La política educativa practicada ofrece un medio educativo intercultural con la finalidad de que con el transcurso del tiempo mejore y sirva de sustrato para la enseñanza, la transmisión y el ejercicio de valores como el respeto a la diversidad, la tolerancia, la solidaridad y el rechazo a todas las formas de xenofobia y racismo. «Estos valores se encuentran inmersos tanto en la LOGSE como en los diferentes proyectos puestos en marcha desde la Consejería de Educación y Ciencia, como es el Plan Andaluz de Educación para la Paz y la No-violencia y el Plan para la Atención Educativa del Alumnado Inmigrante».

«La asunción de la interculturalidad como elemento definitorio del Área Socio-Educativa, se refleja en el cambio de denominación del Plan de Atención al Alumnado Inmigrante que pasará a denominarse Plan para la Educación Intercultural, siendo este cambio nos sólo nominativo sino también de contenidos, objetivos y medidas. A su vez, el término NO-Violencia, se sustituirá por Noviolencia, debido a ciertas diferencias conceptuales entre ellos».

$\mathrm{Al}$ objeto de lograr una mejor evaluación de las distintas medidas aplicadas se pretende mejorar el sistema de recogida, registro y explotación de datos e información a nivel cualitativo y cuantitativo, mediante las siguientes medidas:

1. La próxima puesta en funcionamiento del nuevas aplicaciones informáticas -fundamentalmente Séneca- hará posible contar en breve plazo con datos ajustados de diversos indicadores, como es la satisfacción de los profesores y de los centros respecto de algunas de las medidas del Plan.

2. El indicador de satisfacción de la comunidad inmigrante se está valorando actualmente de manea interna, aunque en el momento actual no se pueden avanzar conclusiones dada la complejidad del análisis de los datos cualitativos.

3. Se esta preparando un "pliego de prescripciones" para la realización, durante el primer trimestre del curso 2003/04, de una amplia evaluación externa del desarrollo del Plan de Atención al alumnado Inmigrante, en conexión con el Área Socio-Educativa del Plan Integral. Con esta evaluación se pretende poder desarrollar todos los indicadores previstos para la evaluación del mismo que hasta ahora, por motivos técnicos, no se podido implementar.

4. La Consejería de Educación y Ciencia, como órgano responsable del la ejecución de las medidas que componen esta área cuenta con la colaboración de diversos órganos gestores como son las diferentes Delegaciones Provinciales, Centros Educativos, Asociaciones de Madres y Padres de Alumnos y Alumnas, Entidades sin ánimo de lucros, etc. 
Las actuaciones que componen esta área -y que van dirigidas a la población de menores, jóvenes y adultos inmigrantes escolarizados en cualquiera de los diversos ámbitos educativos, al profesorado implicado, a los padres y madres del alumnado inmigrante, así como a la comunidad educativa-, se encuentran destinadas a la consecución de seis objetivos, con los que se pretende, como se recogía en el I Plan y se ratificaba en el DTS 0/1:

- la escolarización en igualdad de condiciones;

- la puesta en macha de programas que faciliten y promuevan la interculturalidad;

- el aprendizaje de la lengua española así como de la lengua de origen para favores, de un lado, su integración en el ámbito escolar, y por otro, para mantener sus referentes culturales;

- la difusión de valores democráticos en la comunidad educativa y en el entorno social con objeto de favorece un clima social de convivencia, respeto y tolerancia;

- la participación de madres, padres y alumnos/as inmigrantes y la promoción educativa, social y laboral de las personas adultas inmigrantes par que los adultos puedan desarrollar el máximo de sus capacidades a la hora de escoger su itinerario de desarrollo personal, formativo, laboral y social".

No obstante hay que hacer una importante matización en uno de estos objetivos, «la promoción de la lengua y cultura del origen, sin dejar de se considerados elemento importantes en el Área Socio-Educativa, no se van a considerar núcleos esenciales del desarrollo y evaluación de la misma, para lo que se propondrá modificar, en cierta forma, algunos d los objetivos y medidas del Plan o se matizarán algunos elementos del mismo».

Finalmente, dado que los cursos académicos no se corresponde con los años naturales, es preciso señalar que la evaluación del Área Socio-Educativa corresponde a las medidas desarrolladas durante el curso académico 2001/ 2002 y 2002/03.

Objetivo Específico 1.1. Facilitar la escolarización, en cualquier época del año, de todas las niñas y niños pertenecientes a familias inmigrantes, en las mismas condiciones que el alumnado andaluz.

ÓRGANO RESPONSABLE: CONSEJERÍA DE EDUCACIÓN Y GIENGIA. 


\section{MEDIDA}

1.1.1. Divulgación, entre las familias y colectivos de inmigrantes, de los aspectos básicos del proceso de escolarización y organización del sistema educativo y de las convocatorias de becas y ayudas al estudio, mediante la publicación de folletos explicativos.

- Con objeto de facilitar la escolarización de la población inmigrante en el curso 2002/03,se ha realizado el diseño y distribución del folleto "La Escuela empieza en Abril", en español, francés, inglés y árabe.

- Se ha elaborado un enlace en la página de la Consejería de Educación y Ciencia de la Junta de Andalucía con los contenidos relacionados en la materia.

- No se ha llegado a realizar la publicación de folletos explicativos de las convocatorias de becas y ayudas al estudio en diferentes idiomas, ya que la mayoría son competencia del Ministerio de Educación, Cultura y Deporte, y no se considera necesaria, habida cuenta que los objetivos se alcanzan desde el momento en que el alumno está escolarizado, momento en el que el alumno/a recibe información sobre cualquier tipo de ayuda en igualdad de condiciones que el resto del alumnado.

- La evaluación de la medida permite señalar que la campaña de escolarización ha sido un rotundo éxito, lo que se demuestra en el diferencial de escolarización. A 30 de octubre de 2003, había 12.281 alumnos y alumnas más que durante el curso 2001/2002, lo que supone un incremento porcentual de un $54,60 \% \mathrm{Si}$ desglosamos estas cifras por provincias podemos comprobar cómo las provincias de Málaga y Almería con 11.576 y 9.769 alumnos/as son las que en números absolutos escolarizan más alumnado ${ }^{25}$. Sin embargo, al comprobar los datos, podemos observar como el diferencial de escolarización ha tenido un comportamiento que pude ser señalado de tres formas distintas ${ }^{26}$ :

- En primer lugar, se observan provincias donde la diferencia de escolarización está entre un $69 \%$ y un $79 \%$ de incremento res-

\footnotetext{
${ }^{25}$ Vid. Tabla 1.1.1.2: DIFERENCIAL DE ESCOLARIZACIÓN CURSO 2002/2003, en DTS 0/2, pág. 77.

26 Vid. Gráfico 1.1.1.1: PESO DEL DIFERENCIAL DE ESCOLARIZACIÓN, en DTS 0/2, pág. 78.
} 
pecto del curso 2001/2002. Estas provincias son Córdoba, (79,37\%), Huelva (78,36\%), Almería $(78,17 \%)$, Jaén $(72,14 \%$ y Granada $(69,01 \%)$.

- En segundo lugar, estarían aquellas provincias que rondan el $45 \%$ de incremento y que son Málaga $(44,30 \%)$ y Sevilla $(44,15 \%)$.

- Finalmente, la provincia de Cádiz que apenas ha tenido variaciones, ya que su incremento ha sido inferior al $1 \%(0,42 \%)$.

- Dentro de estos datos que describen el incremento del diferencial de escolarización, se ha de señalar el incremento en términos absolutos de las provincias de Almería y Málaga, que han aumentado 4.282 y 3.554 alumnos/as, respectivamente, de hecho el porcentaje acumulado de estas dos provincias supone el $63,81 \%$, lo que es un dato muy importante a tener en cuenta, ya que no sólo hay que tener en cuenta el aumento porcentual respecto del año anterior sino también el número de alumnos y alumnas que son atendidos en el curso 2002/2003.

- Respecto a la distribución por enseñanzas, es preciso tener en cuenta diversos aspectos ${ }^{27}$ :

- Por un lado, en las provincias de Almería y Huelva más del 30\% de los alumnos/as están escolarizados en el Programa de Formación de Adultos. Al mismo tiempo, Almería representa el 44,16\% de toda Andalucía, de la población escolarizada bajo la modalidad Educación de Adultos.

- Por otro, en la mitad de las provincias andaluzas (Málaga, Sevilla, Córdoba y Jaén) la población extranjera escolarizada en la Educación Infantil y primaria representa más del 50\% del total que tiene la provincia.

- Finalmente, los Programas de Garantía Social no representan en comparación con el resto de las opciones educativas una opción relevante.

- Respecto al número de AMPAs ${ }^{28}$ y entidades públicas y privadas colaboradoras en la difusión de los folletos y publicaciones:

${ }^{27}$ Vid. Gráfico 1.1.1.2: ALUMNOS/AS ESCOLARIZADOS CURSO 2002/03, POR PROVINCIAS, en DTS 0/2, pág. 79.

28 Asociaciones de Madres y Padres de Alumnos. Vid. Tabla 1.1.14: AMPAS COLABORADORAS POR PROVINCIA, en DTS 0/2, pág. 80. 
- Según datos estimados por CODAPA, 344 AMPAs han participado en la distribución de los folletos realizados. De modo especial ha colaborado las diferentes asociaciones provinciales "Acoge".

- Los municipios de las Comunidad Andaluza han colaborado en la distribución del material, en especial los de Vícar, El Ejido, Níjar, Roquetas de Mar, Lepe, Cartaya y San Juan de Aznalfarache.

- En definitiva, 94 AMPAs más que el curso anterior han colaborado en relación con el número de centros en el que ha aumentado significativamente el número de alumnos y alumnas inmigrantes.

MEDIDA

1.1.2. Campañas de sensibilización entre la población inmigrante para la escolarización de los niños y niñas en la Etapa de Educación Infantil.

- Las actuaciones que se realizaron han servido para cumplir los objetivos propuestos, ya que tanto los folletos "La Escuela empieza en Abril" como la elaboración y publicación del enlace a la página web de la Consejería de Educación y Ciencia también comprendía información destinada a los padres de alumnos y alumnas de esta etapa escolar.

- Por otro lado y de modo específico se han realizado actuaciones en este ámbito, tales como la realización de 1.000 .000 de dípticos en español, así como 5.000 carteles y la difusión de un spot televisivo y cuñas radiofónicas en castellano. Asimismo se ha abierto una línea 900 en castellano que ha contribuido a solventar consultas ${ }^{29}$.

- Propuesta para el bienio 2003-2004: con la entrada en funcionamiento de la línea 900 se prevee una recogida de datos sobre la incidencia en el teléfono gratuito de atención a la escolarización, en relación al alumnado inmigrante: ello permitirá una mejora del servicio y por tanto, una mayor aproximación y conocimiento de la utilidad de la medida y la satisfacción de la comunidad educativa, lo se podrá traducir en campañas de sensibilización más adaptadas a las necesidades ${ }^{30}$.

\footnotetext{
${ }^{29}$ La campaña fue presentada por la Consejera de Educación y Ciencia con la presencia de los principales medios de comunicación y agencias de información. Vid. también Tabla 1.1.2.1 DISTRIBUCIÓN DE DÍPTICOS Y CARTELES EN CASTELLANO. CAMPAÑA DE ESCOLARIZACIÓN 2002/03, en DTS 0/2, pág. 81.

${ }^{30}$ DTS 0/2, pág. 285.
} 


\section{MEDIDA}

1.1.3. Dotación de recursos humanos y materiales extraordinarios a los centros que escolaricen un número significativo de alumnado inmigrante.

- Se ha realizado una dotación de 162 nuevos profesores para atender necesidades de los centros en relación con medidas de compensación educativa y de atención al alumnado inmigrantes y de minorías étnicas y culturales, de los cuales 119 son Profesorado ATAL mientras 43 son Profesorado de APOYO COMPENSATO$\mathrm{RIO}^{31}$, lo que representa un incremento de 67 profesores/as ATAL +COMPENSATORIA respecto del año $2001^{32}$.

- La dotación de estas plazas ha supuesto una dotación de 295.586,47 € en concepto de gastos de funcionamiento extraordinarios, para la realización de medidas de compensación educativa, y otra dotación de $269.419 €$ en concepto de gastos de funcionamiento extraordinarios, para la realización de medidas de atención al colectivo de alumnado inmigrantes y de minorías étnicas y culturales (Plan de Atención al Alumnado Inmigrante, ahora Plan para la Educación Intercultural ${ }^{33}$, de los que casi mas de la tercera parte se han destinado a la Provincia de Almería. Dotación presupuestaria que supone un incremento de $210.877,00 €$ en créditos extraordinarios respecto del año $2001^{34}$.

\section{MEDIDA}

1.1.4. Autorización por parte de la Consejería de Educación y Ciencia de la disminución de la ratio establecida con carácter general en los Centros que escolaricen alumnado inmigrantes, en función del número de alumnos, características del Centro y plantillas, de acuerdo con el art. 14.2 de la Ley de Solidaridad en la Educación.

\footnotetext{
${ }^{31}$ Vid Tabla 1.1.3.1 CUPO DE POFESORADO PARA PROGRAMAS EDUCATIVOS (RÉGIMEN NO ORDINARIO DE PROVISIÓN), en DTS 0/2, pág. 82.

32 Vid. Tabla 1.1.3.3 EVOLUCIÓN DEL CUPO DE PROFESORADO PARA PROGRAMAS EDUCATIVOS (REG. NO ORDINARIO DE PROVISIÓN), en DTS 0/2, pág. 82.

${ }^{33}$ Vid. Tabla 1.1.3.2 PRESUPUESTO DE GASTOS PARA ACTUACIONES, PROGRAMAS DE COMPENSACIÓN EDUCATIVA Y PLAN DE INMIGRANTE, A REALIZAR EN LOS PROPIOS CENTROS DOCENTES PÚBLICOS, en DTS 0/2, pág. 83.

${ }^{34}$ Distribuidos $123.866 €$ en Actuaciones de compensación educativa y $185.408 €$ en medidas de atención al colectivo de alumnado inmigrantes y minorías étnicas (Plan de atención al Alumnado Inmigrante). Vid. también Tabla 1.1.3.2, citada en nota anterior, en DTS 0/2, pág. 83.
} 
- Las Actuaciones Realizadas para el cumplimiento de esta medida han ido encaminadas a aumentar la dotación de la plantilla de los centros que atiende a este alumnado extranjero. Concretamente el aumento ha sido, como ya indicamos en el punto anterior, 119 profesores, lo que ha dado lugar a una ratio en Educación Secundaria 2002/03 de 26,70. Con esta medida no se ha tratado de disminuir "estrictamente" el número de alumnos /aula cuando existe un número significativo de alumnado inmigrantes en el centro, sino de adecuar de forma autónoma por cada centro sus recursos humanos y materiales para la correcta atención del alumnado. Esto puede significar, la reducción temporal del número de alumnos en un grupo, pero no implica que los grupos, como tales disminuyan sus número de forma general. El conjunto de centros atendidos en Andalucía por profesorado ATAL es 152, si desglosamos estos datos por provincias, vemos que Almería es la provincia con mayor número de centros atendidos por profesorado ATAL, en concreto 152; le sigue a bastante distancia Huelva con 49; Málaga y Sevilla con 40 cada una de ellas; Jaén con 31; Granada con 25; Córdoba con 21 y finalmente Cádiz con $8^{35}$.

- Se ha producido un aumento del número de profesores destinados a la atención del alumnado inmigrante, correlativo al aumento del número de alumnos inmigrantes. Aunque el aumento de porcentaje de alumnos es mayor que el de profesores, es preciso señalar que el número de alumnos/as que puede atender un profesor puede ser sensiblemente superior al de años anteriores sin que esto signifique disminución de la calidad de la atención.

- Respecto del año 2001 se ha producido un aumento de 60 profesores/as ATAL en total. La ratio general no se ha modificado sensiblemente por esta medida, lo que es lógico, pues es un indicador general del sistema educativo ${ }^{36}$.

- Ratio en Educación Primaria: 21.30 (2001/2002).

- Ratio en Educación Secundaria: 26.72 (curso 2001/02)

- Ratio en Educación Primaria: 2002/03: 21,30

- Ratio en Educación Secundaria. 2002/2003: 26,79

35 Vid. Tabla 1.1.4.2: CENTROS ATENDIDOS POR PROFESORADO ADSCRITO A LAS ATAL, POR PROVINCIAS 2002/2003, en DTS 0/2, pág. 85.

${ }^{36}$ Vid. DTS 0/2, pág. 85. 
- Todo ello lleva a señalar que es necesario mantener la dotación de recursos humanos y materiales en el ámbito de acciones descritas en esta medida y en la medida anterior. Por ello, se propone que en los próximos años se doten los incrementos de profesorado necesarios para la atención del alumnado inmigrante, en relación con su crecimiento porcentual.

\section{MEDIDA}

1.1.5. Acceso a los servicios complementarios de comedores, transporte escolar, así como el de Residencias Escolares para que el alumnado inmigrante pueda continuar sus estudios después de cursar las enseñanzas obligatorias.

- El acceso a los servicios complementarios de comedores, transporte escolar así como de Residencias escolares, se va a mantener en la misma línea de actuación, ya que el acceso se realiza en la mismas condiciones que los alumnos/a españoles. Según las previsiones presupuestarias en función de los datos de matrícula, durante el curso 2002/03 ha utilizado estos servicios:

- Comedor escolar: 1.400 alumnos, lo que representa 200 alumnos/as más que en el curso 2001/2002. Siendo la provincia de Málaga, con 490 alumnos la que más hace uso del comedor escolar, seguido por Almería con 180; Cádiz, Granada y Sevilla con 140; y Córdoba, Huelva y Jaén con $70^{37}$.

- Transporte escolar: 1.200 alumnos, lo que implica 400 alumnos más que el curso 2001/2002. Siendo la provincia de Málaga con 420 alumnos la que mayor número de alumnos utiliza este medio, seguida de Almería con 240; Cádiz, Granada y Sevilla con 120 y Córdoba, Huelva y Jaén con 60 cada una de ellas ${ }^{38}$.

- Residencia escolar: 238 alumnos, de los cuales 226 son alumnos y 12 alumnas $^{39}$.

\footnotetext{
${ }^{37}$ Vid. Tabla 1.1.5.3: EVOLUCIÓN DE LA ESTIMACIÓN DE ALUMNOS/AS EMIGRANTES QUE UTILIZAN LOS SERVICIOS DE COMEDOR ESCOLAR Y TRANSPORTE ESCOLAR DURANTE EL CURSO 2002/2003, en DTS 0/2, pág. 87.

${ }^{38}$ Vid nota anterior.

${ }^{39}$ Vid. Tabla 1.1.5.2: ESTIMACIÓN DE ALUMNOS/AS INMIGRANTES QUE UTILIZAN EL SERVICIO DE RESIDENCIAS ESCOLARES DURANTE EL CURSO 2002/03, en DTS 0/2, pág. 87.
} 


\section{MEDIDA}

\subsubsection{Fomento de la participación del alumnado inmigrante en las activida-} des extraescolares.

El fomento de la participación de los alumnos/as inmigrantes en actividades extraescolares durante le curso 2002/2003 se puesto en marcha a través de dos medidas distintas:

1) Las actividades realizadas dentro del Plan de Familia (extensión del horario de apertura de los centros...) de los que debido a su dinámica no se pueden dar datos sobre el alumnado inmigrante participante.

2) También se han distribuido créditos mediante una Orden de Convocatoria para Proyectos de Actividades Extraescolares, proyectos que han podido ser presentados por los centros, las AMPAs o las Asociaciones de Alumnos/as:

a. Existen ciertas dificultades para determinar la participación efectiva del alumnado inmigrante. La existencia de actividades específicas de desarrollo intercultural corresponderán a una parte de las realizadas en el centro, estando abiertas a la participación de todos los alumnos y profesores, que frecuentemente participan en más de una actividad.

b. Podemos, por tanto, hablar de actividades específicas de promoción de la interculturalidad medidas a partir del análisis de los proyectos presentados por los centros en el ámbito de la Orden de Convocatoria para Proyectos de Actividades Extraescolares.

c. Por otra parte, se estima a partir de estos datos, la participación en cualquier tipo de actividad de alumnos y alumnas inmigrantes, de manera que se establece en proporción al porcentaje de este alumnado respeto al total suponiendo que un alumnos inmigrante participa en igual grado en este tipo de actividades. Ya que dada su naturaleza la realización de muchas de estas actividades no necesita "registrarse" para tener acceso a ellas.

d. Desde el curso 2002/03, dentro de la Convocatoria para Proyectos de Actividades Extraescolares aparece, un apartado específico denominado "Promoción de valores", cuya finalidad es fomentar la tolerancia, la interculturalidad... en los centros escolares. A esta convocatoria se han presentado un total de 1967 actividades proyectadas por los centros para el curso 2002/2003. Los resultados se obtiene del análisis de los proyectos presentados. En base a todos estos datos se estima que ha participado un total de 
3.268 alumnos/as inmigrantes de un total de 126.797 (sin los datos de la provincia de Huelva). El número de profesores implicado se estima en $5.852^{40}$.

e. Finalmente, del total de créditos aplicados a Actividades Extraescolares por esta Orden de Convocatoria para el curso 2002/2003, que es de 75.265,00€, se estima que un total de 125.210,00€ para las actividades referidas ${ }^{41}$.

- Propuestas para el Binomio 2003-2004: A partir del curso 2002703, la Consejería puso en marcha, dentro de las convocatorias de ayudas públicas de actividades extraescolares, un nuevo apartado denominado "Escuela: Espacio de paz". Por tanto, esta Consejería se compromete a seguir promoviendo esta nueva iniciativa mediante créditos extraordinarios y seguir promoviendo el desarrollo de actividades y proyectos específicos de tipo intercultural (como los que se derivan de la convocatoria "Escuela: Espacio de paz"), así como la integración del alumnado inmigrantes en todas las actividades -curriculares o no- que se realicen en el centro donde se encuentre matriculado.

\section{MEDIDA}

1.1.7. Formalización de convenios con entidades sin ánimo de lucro para establecer la figura del mediador intercultural.

- Se han suscrito 4 convenios que incluyen la figura del mediador / ra cultural en distintas provincias andaluzas ${ }^{42}$. Concretamente:

- Provincia de Huelva: se ha suscrito un convenio con los Ayuntamientos de Cartaya, Lepe, Isla Cristina, Moguer y la Asociación Huelva Acoge para prevenir el absentismo escolar. Dicho convenio ha permitido contratar a 4 mediadores/ras interculturales. La intervención, además de la puntual a la demanda de los cen-

${ }^{40}$ Vid. Tabla 1.1.6.1: ESTIMACIÓN DE ACTIVIDADES EXTRAESCOLARES REALIZADAS AL AMPARO DE LA CONVOCATORIA ANUAL QUE REALIZA LA CONSEJERÍA DE EDUCACIÓN Y CIENCIA DURANTE EL CURSO 2002/2003, en DTS 0/2, pág. 89.

${ }^{41}$ Vid. DTS 0/2, págs. 88-89.

${ }^{42}$ Para el año anterior el DTS 0/1 señala que se han ejecutado convenios con Andalucía Acoge, pero a la fecha de la realización del Documento se desconocen los datos relativos al número de mediadores/as, centros que disponen de este servicio y el grado de satisfacción de la comunidad educativa. Vid. DTS 0/1, pág. 3. 
tros, se ha distribuido de la siguiente forma: 4 centros en Cartaya, 9 en Lepe, 2 en Isla Cristina y 3 en Moguer.

- Provincia de Jaén: se ha firmado dos convenios con Jaén Acoge y las Asociación Siloé. En total se han contratado a 3 mediadores/as, que atienden a 25 centros.

- Provincia de Sevilla: Se ha firmado un convenio con Sevilla Acoge. Se han contratado 2 mediadores/as para las barriadas sevillanas de Bellavista, Macarena, Pino Montano, atendiendo a demanda a los centros.

- Los mediadores contratados han atendido la demanda de, al menos, 43 centros educativos. Como acabo de señalar, la atención no se realiza en punto fijo, sino que en la mayoría de los casos se establece una comunicación fluida entre los mediadores/as y los distintos centros de una zona, lo que permite una atención a la demanda.

- En cuanto a la contratación y formación de estos mediadores, el DTS $0 / 2$ es consciente que pueden plantear problemas en el futuro si no se actúa con tiento. En efecto, existe una demanda generalizada en el sistema educativo y en la sociedad de mediadores/as, por lo tanto, «es necesario desarrollar una figura que favorezca la integración en la comunidad educativa del colectivo objeto de Plan Integral para la Inmigración en Andalucía, pero evitando al mismo tiempo, que no se convierta en un elemento de aislamiento de diferentes colectivos en razón de su procedencia o de su cultura de origen, sino que dependan de esta figura como elemento de conexión con la realidad cotidiana del país de acogida».

- Propuesta para el binomio 2003-2004: La definición de un perfil, la selección de mediadores/as y su dependencia funcional -sobre todo cara al futuro de esta figura- son elementos que dificultan el desarrollo de esta medida en el nivel general de Andalucía, por lo que en general se están realizando convenios a nivel provincial. Teniendo en cuenta esto y lo expuesto en el DTS 0/1, se propone entrar a fondo en la definición de un perfil profesional del mediador /a y de su situación dentro del sistema educativo, como medio de avanzar en la atención al alumnado inmigrante, desde la propia perspectiva de la Administración en General, y de la Administración Educativa en particular.

\section{MEDIDA}

1.1.8. Incremento de la oferta de Programas de Garantía Social tanto en Institutos de Educación Secundaria como a través de Convenios con Ayun- 
tamientos y Asociaciones con objeto de favorecer la integración social y laboral del alumnado inmigrante.

- La matriculación de los alumnos/as inmigrantes en los Programas de Garantía Salarial se ha producido sin más limitaciones que las impuestas por los requisitos académicos y la edad, establecidos por la normativa en vigor. El acceso a los mismo se derivará de su escolarización "normalizada", en función de las necesidades y demandas individuales y de la orientación profesional y vocacional realizada en los centros, como sucede con cualquier alumno/a.

- Durante el curso 2002/03 se han matriculado en los Programas de Garantía Salarial 75 alumnos/as inmigrantes en IES y 11 en PGS derivados de convenios con Ayuntamientos o Entidades sin animo de lucro, lo que implica un aumento de 7 alumnos/as inmigrantes en los PGS impartidos por los IES.

Objetivo 1. 2. Favorecer que los centros elaboren Proyectos de Centro interculturales que faciliten y promuevan procesos de intercambio, interacción y cooperación entre las cultura.

\section{ÓRGANO RESPONSABLE: CONSEJERÍA DE EDUCACIÓN Y CIENCIA.}

\section{MEDIDA}

1.2.1. Formación y asesoramiento específico al profesorado de los centros que atiendan al alumnado perteneciente a las familias inmigrantes.

- Se cuantifican solamente los cursos y otras actividades similares de formación formalmente constituidos como tales y de los que por lo tanto se dispone de datos remitidos desde la Dirección General de Evaluación Educativa y Formación de Profesorado de la Consejería de Educación y Ciencia.

- Se ha producido un crecimiento en la demanda de este tipo de actividades formativas que se ha visto reflejada en un importante aumento de las mismas. En concreto se ha realizado 52 actividades de formación directamente relacionadas con la medida descrita, 20 más que en el curso 2001/2002, sin embargo, ha disminuido el número de profesores participantes, ya que han participado 1.347 profesores, mientras que el curso 2001/2002 participaron 1552 (sin datos de la provincia de Málaga). El DTS 0/2 estima que este descenso en la participación de los profesores viene motivado por el tipo de actividades, que han sido mucho más especializados en el curso 2002/03, que en año anterior y también al proceso norma de for- 
mación del profesorado que ya suma 2.899 asistentes acumulados en los dos años de vigencia de esta medida ${ }^{43}$.

- La zonificación de las actividades responde a las necesidades específicas de las diferentes áreas geográficas en las que se ubican los distintos Centros de Profesorado, en concreto, en la provincia de Almería se han realizado 16 actividades, con la participación de 387 profesores; en la de Cádiz, 6 en las que han intervenido 122 profesores; en la provincia de Córdoba, 6 actividades con 71 profesores; en la de Granada 5 actividades en la que han participado 144 profesores; en la provincia de Huelva 8 actividades con 314 profesores, en la de Jaén 3 actividades en la que han participado 189 profesores; en la de Málaga 3 actividades y 24 profesores y finalmente, en la provincia de Sevilla han intervenido 105 profesores en 5 actividades ${ }^{44}$.

- Propuesta para el bienio 2003-2004: Fomentar este tipo de asociaciones formativas, en relación con lo recogido en el Plan de Cultura de Paz y Noviolencia y en el Plan de Educación Intercultural, ya que la evolución de las actuaciones indica una correcta ejecución de los objetivos ${ }^{45}$.

MEDIDA

1.2.2. Publicación de materiales de apoyo y asesoramiento para los centros y el profesorado.

- Se ha editado, por la Delegación Provincial de Almería con colaboración de Unicaja, un CD denominado "Español para ti", concretamente 2000 ejemplares. Asimismo, el la página web se ha incluida el contenido del CD-Rom "Acogida y atención al alumnado inmigrantes" y más de 50 materiales relacionados con la Interculturalidad.

- Respecto de las visitas, descargas de material y otros aspectos relacionados con la página web, no ha sido posible cuantificarlas durante el año 2002, aunque se espera poder hacerlo en el año 2003.

43 Vid. TABLA 1.2.1.1: ACTIVIDADES DE FORMACIÓN RELACIONADAS, DURANTE EL CURSO 2002/03, en DTS 0/2, pág. 92.

${ }^{44}$ Vid. Nota anterior.

${ }^{45}$ DTS 0/2, pág. 285. 
- Propuesta para el binomio 2003-2004: Dentro del marco de las Nuevas Tecnologías de la Información, se pretende seguir con la selección y publicación de materiales que se consideren de interés para el profesorado que atiende al alumnado inmigrantes, pero utilizando, sobre todo, la página web de la Consejería ${ }^{46}$.

Objetivo 1.3. Potenciar programas para el aprendizaje de la lengua española. ÓRGANO RESPONSABLE: CONSEJERÍA DE EDUCACIÓN Y GIENGIA.

\section{MEDIDA}

1.3.1. Implantación progresiva de Aulas de Adaptación Lingüística en función de las necesidades de cada una de las zonas y centros que escolarizan alumnado inmigrante con su equipamiento y profesorado correspondiente.

- La implantación de Aulas de Adaptación Lingüística (ATAL) se inició en el primer año de aplicación del I Plan Integral para Inmigración en Andalucía.

- Pese a que la movilidad geográfica del alumnado a lo largo el curso dificulta enormemente la utilización de los recursos humanos y materiales relacionados con las ATAL, a lo largo del curso 2002/03 se han contado con un total de 119 de estas aulas ( 7 de carácter fijo y 112 itinerantes) con un/a profesor/a al frente de cada una de ellas. Han recibido formación en las mismas 430 alumnos/as.

- La distribución geográfica de estas aulas ha sido la siguiente: En la provincia de Almería 44 ATAL, 7 fijas y 37 itinerantes; en la de Cádiz 6, todas ellas itinerantes; en la provincia de Córdoba 17 itinerantes; en la de Granada 6 itinerantes; en la de Huelva 15 itinerantes; en la provincia de Jaén 5 itinerantes; en la Málaga 11 itinerantes y finalmente, en la provincia de Sevilla 15 aulas itinerantes.

- En total se ha producido un aumento de 60 ATAL con su correspondiente profesor respecto del curso 2001/02.

- «Respecto del grado de adquisición por parte del alumnado de la lengua española y el grado de satisfacción de la comunidad educativa en relación con la ejecución de esta medida», en la actualidad se está realizando el "primer estudio piloto de carácter interno cuyos datos estarán disponibles para finales de año 2003», por lo que suponemos que será incluido en el DTS $0 / 3^{47}$.

\footnotetext{
46 Vid. DTS 0/2 pág. 285.

47 Vid. DTS 0/2 págs. 94-95.
} 
MEDIDA

1.3.2. Formalización de convenios con entidades sin ánimo de lucro para apoyar el aprendizaje de la lengua de acogida, con personal cualificado que conozca la lengua propia del alumnado.

- Durante el año 2002, se han suscrito 5 convenios (lo que supone 3 más que el año 200) con diversas Asociaciones sin ánimo de lucro, concretamente en la provincias de Huelva, Jaén y Sevilla.

- En la provincia de Almería, los mediadores/as contratados/as desde la Consejería de Asuntos Sociales, a través de su coordinación con el Equipo Técnico Provincial, realizan actuaciones en diferentes centros educativos.

- En la provincia de Huelva, los ayuntamientos que participan en el convenio firmado -Cartaya, Lepe, Isla Cristina- contratan a los/las mediadores/as directamente y en la provincia de Jaén existen 4 aulas de apoyo gestionadas por Jaén Acoge y la Asociación Siloé que complementan la oferta de cursos aprendizaje. En la provincia de Sevilla se ha firmado un convenio con Sevilla Acoge y otro con la Asociación "Esperanza de Nuestra Tierra.

- Estos convenios han permitido atender a 361 alumnos/as y han intervenido 74 profesores/as, 69 de ellos voluntarios en las Asociaciones de la Provincia de Sevilla ${ }^{48}$.

- Propuestas para el bienio 2003-2004: Se realizará un análisis de los convenios para establecer su validez y mejorar su ejecución, como medida que redunde en beneficio del alumnado inmigrante. Por otro lado, se iniciará el estudio de un perfil profesional -en el ámbito de los Ciclos Formativos de Grado Superior- para establecer una cualificación de "mediación cultural", que permita a la Administración educativa desarrollar con mayor eficacia este tipo de actuaciones ${ }^{49}$.

Objetivo 1.4. Mantener y valorar la cultura de origen del alumnado. ÓRGANO RESPONSABLE: CONSEJERÍA DE EDUCACIÓN Y CIENCIA.

\section{MEDIDA}

1.4.1. Apoyo a programas para el aprendizaje y desarrollo de la lengua y cultura maternas.

48 Vid. TABLA 1.3.2.1 CONVENIOS PARA EL APOYO DEL APRENDIZAJE DE LA LENGUA ESPAÑOLA REALIZADOS DURANTE EL CURSO 2002/03, en DTS 0/2, pág. 95.

${ }^{49}$ Vid. DTS 0/2 pág. 285. 
- A fin de dar ejecución a esta medida, en el año 2002 se han realizado gestiones con la Fundación Hassan II de Marruecos a través de la Consejería de Presidencia.

- Se ha suscrito un convenio con la asociación Huelva Acoge. Aunque se encuentran sería dificultades para poder encontrar profesores nativos con el perfil adecuado, a través de este convenio se ha logrado contrata un profesor nativo.

- No se dispone de datos sobre el número total de alumnos/as a los /las que se les imparte clases y el grado de competencia adquirida en la lengua materna por parte del alumnado. Se está trabajando en la articulación del instrumento de análisis cualitativo adecuado para ello ${ }^{50}$.

Objetivo 1.5. La difusión de los valores democráticos en la comunidad educativa y en el entorno social: Favorecer un clima social de convivencia, respeto y tolerancia, en especial en las zonas que acogen inmigrantes fomentando que los centros educativos sean un núcleo de encuentro y difusión de los valores $\underline{\text { democráticos no sólo de la comunidad educativa sino del propio barrio }}^{51}$.

\section{ÓRGANO RESPONSABLE: CONSEJERÍA DE EDUCACIÓN Y CIENCIA.}

MEDIDA

1.5.1. Apoyo a los centros para que pongan en marcha procesos de reflexión y contraste sobre la perspectiva intercultural que impliquen a todos los sectores del barrio, pueblo o zona educativa en la que encuentre en centro.

- Las actuaciones realizadas durante el año 2002 han sido las siguientes:

- Jornadas "Análisis de conflictos y formación en Cultura de la Paz", en Granada, 28 a 31 de enero de 2002.

- Dotación de 269.419,00 € en concepto de gastos de funcionamiento extraordinarios para la realización de medidas de atención al colectivo de alumnado inmigrantes y de minorías étnicas y culturales, aunque han sido contabilizadas en los presupuestos asignados a la medida 1.1.3.

\footnotetext{
${ }^{50}$ DTS 0/2, pág. 96.

${ }^{51}$ DTS 0/2, pág. 96-99.
} 
- Dotación de 292.586,47 € en concepto de gastos de funcionamiento extraordinario para la realización de medidas de comprensión educativa, contabilizadas en el presupuesto de la medida 1.1.3.

- Actuaciones de los Gabinetes de Asesoramiento de la Convivencia y la Cultura de Paz, con una dotación de 121. 731,74€

- Convocatoria de Actividades Extraescolares y Complementarias, contabilizadas en la medida 1.1.6. Esta es una de las medidas que mejor acogida tiene en los centros docentes, junto con las actuaciones en materia de formación. Del total de los créditos aplicados a Actividades Extraescolares por esta Orden de Convocatoria, para el curso 2002/03 751.265,00 €, se estima un total de $125.210,00 €$ para el total para las actividades referidas.

- Publicación de la convocatoria para el curso 2002/2003 de "Escuela: Espacio de Paz", con créditos totales de 360.606,00€ para los cursos 2002/03 y 2003/04. Al momento de cerrar el DTS 0/2 y debido a la lógica del año escolar sólo se conoce el número de proyectos presentados que han sido 80, con créditos por valor de 24.040,40 €. Siendo el desglose por provincias: Almería 7, Cádiz 11, Córdoba 13, Granada 7, Huelva 4, Jaén 9, Málaga 10 y Sevilla $19^{52}$. Dado que este tipo de proyecto se aplica por primera vez en el curso 2002/2003, no existen datos comparables con el año anterior.

- Según los datos aportados y en base a los créditos extraordinarios, el diferencial entre los cursos 2001/2002 y 2002/2003 es de $207.877,00 €$. Esta aumento está en relación con el mayor número de alumnos/as inmigrantes matriculados/as en los centros andaluces. Este incremento, así como la posible distribución de los alumnos en los diferentes centros es muy difícil de prever, como también la demanda de realización de actividades por centros.

- De cara al próximo bienio se pretende mantener la línea de actuaciones seguida con la publicación de diferentes convocatorias en las que se incluyan elementos de educación intercultural, bien derivados del Plan de Educación Intercultural del Plan de Cultura de Paz y Noviolencia.

52 Vid. Tabla 1.5.1.1: PROYECTOS DE REFLEXIÓN Y CONTRASTE SOBRE PERSPECTIVA INTERCULTURAL EN LOS CENTROS EDUCATIVOS (Basados en los Proyectos presentados al amparo de la Orden "Escuela: Espacio de Paz"), en DTS 0/2, pág. 97. 


\section{MEDIDA}

1.5.2. Impulso a la participación de las madres y padres del alumnado inmigrante en los centro docentes.

- En el curso 2002/03 se ha realizado por primera ver un convocatoria de ayudas a Federaciones y Confederaciones de Madres y Padres de Alumnas y Alumnos en la que para la realización de los objetivos se han establecido bloques de actividades de educación intercultural y para la convivencia.

- Las actividades son realizadas por las AMPAs, pero en el ámbito de organizaciones de carácter supraprovincial o provincial.

- Para el año 2002 se han concedido ayudas por valor e $14.700,00 €$, datos extraídos del análisis de los proyectos presentados a la convocatoria de ayudas para el curso 2002/03 para actividades de las confederaciones de Madres y Padres de Alumnos y alumnas.

- Durante el año 2002 se han realizado 6 actividades-marco entre las diferentes Confederaciones y Federaciones de Madres y Padres de Alumnos y Alumnas

- Se ha producido un aumento de 3.600,00 € respecto del año 2001. No se pueden aportar más datos comparativos ya que éste es el primer año en el que se realiza el análisis e estas medidas ${ }^{53}$.

\section{MEDIDA}

1.5.3. Fomento de la participación del alumnado inmigrante en las Asociaciones de Alumnos y Alumnas.

- La convocatoria de ayudas de alumnos/as se ha realizado en bloques de actividades. Estas actividades están gestionadas en el ámbito provincial a través de las Delegaciones Provinciales, que son las encargadas de realizar el seguimiento de las mismas. También se realizan actividades a nivel supraprovincial gestionadas por las Federaciones de alumnos/as, aunque se desarrollan en cada uno de los centros por las asociaciones que forman parte de aquellas.

- En el análisis de la actividades se ha detectado cierta dificultad para obtener información cuantificada de las memorias, ya que se trata de una gestión provincializada y además, se trata de pequeñas ayudas para un numero elevado de actividades de carácter concreto o puntual realizadas por estas asociaciones en el marco de proyectos más amplios.

${ }^{53}$ DTS 0/2, pág. 98. 
- Se estima que de los 6.040,00 € destinados a la Confederación sindicato de Estudiantes de Andalucía, unos 1800,00 € han ido a la realización de estas actividades realizadas en el marco del Proyecto "Campaña contra el racismo y la xenofobia en los Centros de Educativos"

- $\quad$ El DTS 0/2 considera primordial seguir fomentado este tipo de actividades al considerar que la promoción del asociacionismo estudiantil es esencial en el desarrollo de la sociedad para promover el respeto y la tolerancia ${ }^{54}$.

MEDIDA

1.5.4. Fomento de la participación de las madres y padres del alumnado inmigrante en las Escuelas de Madres y Padres para garantizar la integración y prevenir el fracaso y absentismo escolar.

- Aunque se considera esencial por aparte de profesores y asociaciones de madres y padres, resulta difícil conseguir la participación e implicación de los padres y madres en actividades de relación con el centro en donde estén matriculados sus hijos. Influyen condiciones sociolaborales (horarios, desplazamientos a los centros escolares...) así como -en el caso de algunas familias inmigrantes- el desconocimiento de la lengua.

- No obstante, no existen diferencias notables entre la implicación del colectivo de familias inmigrantes con el resto de familias de alumnos/as.

- Se ha realizado una actividad marco contabilizada en el la medida 1.5.2.

- Propuesta para el bienio 2003-2004: se propone modificar el término Escuela de Madres y Padres asociado a esta medida y a sus indicadores, puesto que actualmente se está produciendo un debate sobre la redefinición de este concepto ${ }^{55}$.

Objetivo 1.6. La promoción educativa, social laboral de las personas adultas inmigrantes: Potenciar el desarrollo de acciones de formación integral de los alumnos y alumnas inmigrantes adultos, interviniendo de forma especial sobre los padres y madres cuyos hijos estén escolarizados en las enseñanza básica.

\footnotetext{
${ }^{54}$ DTS 0/2, pág. 99.

55 Vid. DTS 0/2, pág. 286.
} 


\section{ÓRGANO RESPONSABLE: CONSEJERÍA DE EDUCACIÓN Y CIENCIA.}

\section{MEDIDA}

1.6.1. Integración de la población inmigrante en la formación básica de Adultos.

- La campaña iniciada en el curso 2001/02 tuvo unos resultados aceptables, por lo que se a continuado durante el curso 2002/03 con la distribución de un folleto divulgativo en español, francés, inglés, chino y árabe que ya fue objeto de divulgación el curso anterior. Para aprovechar las sinergias derivadas de la campaña institucional se optó por distribuir los 200.000 ejemplares del folleto junto con la campaña de escolarización de menores en edad escolar. También se creó un enlace a la página web de la Consejería de Educación y Ciencia.

- Respecto de los resultados obtenidos, aunque este es el primer año del que se disponen de datos desagregados para la Educación de Adultos, el DTS 0/2 estima que en curso 2002/03 se han escolarizado al menos tres veces más alumnos/as que en el curso 2001/02. Por provincias, Almería con un $44,16 \%$ del total del alumnado, es la provincia andaluza donde mayor número de personas extranjeras se encuentran escolarizadas, seguida a gran distancia por Granada con un $14,09 \%$, Málaga con un 12,49\% y Huelva con un $11,66 \%$.

- Se está procediendo a elaborar un estudio de satisfacción y grado de difusión de las medidas programadas.

\section{MEDIDA}

1.6.2. Desarrollo de planes educativos en los Centros de Adultos dirigidos a la población inmigrante.

- Durante el curso 2002/03 se han realizado 98 planes específicos, encuadrado dentro de un solo programa denominado "Educación Intercultural", lo que ha permitido una mayor fiabilidad y validez en la obtención de datos referentes a los planes educativos dirigidos a los adultos extranjeros.

- Las provincias de Almería y Huelva son las que, con 30 y 21 planes respectivamente, han realizado el mayor número de actuaciones, lo que supone el $30,61 \%$ y $21,43 \%$ respectivamente ${ }^{56}$. Han intervenido 49 profesores/as, 15 de ellos, que representan el 30,61\%, en Almería y 10 , el 10,20\%, en Huelva.

\footnotetext{
${ }^{56}$ En Cádiz se han llevado a cabo 11 planes, Córdoba 2, en Granada 9, en Jaén 6, en Málaga 12 y en Sevilla 7. DTS 0/2, pág. 102.
} 
- El número de alumnos que han participado depende de muchos factores, no siendo directamente proporcional al número de planes ni de profesores. En concreto han participado 2078 alumnos, destacando Almería con 658 y Huelva con 507.

- Propuesta para el bienio 2003-2004: Se propone que se desarrollen los citados planes en función de las demandas en las diferentes zonas geográficas andaluzas. Así mismo consideramos que será objetivo de análisis de esta medida los planes que se ejecuten dentro del programa denominado "Educación Intercultural". Por lo tanto se propone modificar la redacción de la medida que quedaría de la siguiente forma: "Desarrollo de planes educativos, dentro del programa de Educación Intercultural, en los Centros de Adultos dirigidos a la población inmigrantes".

\section{MEDIDA}

1.6.3. Formación específica del profesorado de Educación de la Personas Adultas que trabajen con la población inmigrante.

- Según los datos remitidos desde la Dirección General de Evaluación Educativa y Formación del Profesorado, durante año 2002 se ha producido un aumento considerable de la demanda de este tipo de acciones formativas. Se trata, pues, de una medida de amplia difusión entre el profesorado, que demanda este tipo de actividades a través de los planes de formación de los distintos centro educativos. En concreto se han realizado 6 actuaciones formativas específicamente destinadas a la Educación de Adultos, en las que han participado directamente 173 profesores ${ }^{57}$.

- Para próximos cursos se pretende potenciar aquellos cursos que reciben mejor calificación por parte de los participantes.

\section{MEDIDA}

1.6.4. Establecimiento de convenios con asociaciones, organizaciones o instituciones que trabajen con la población inmigrante.

- Se han suscrito convenios con distintas entidades y asociaciones, tanto de ámbito regional como provincial. Así todas las provincias, excepto Almería, Córdoba y Málaga, han suscrito convenios específicos para actuaciones en la provincia. Éstas han determinado actuaciones en la provincia, a través de los convenios regionales ${ }^{58}$.

\footnotetext{
57 "Acciones Formativas en relación con actividades de Interculturalidad para educación permanente de adultos". Vid. DTS / 02, pág. 103.

${ }^{58}$ Se han suscrito en total 9 convenios, 7 más que el año anterior. Vid. DTS/02, pág. 104.
} 


\section{MEDIDA}

1.6.1. Promoción de la participación de las personas inmigrantes adultas en asociaciones de alumnos y alumnas, de vecinos, culturales etc,...

- Se han realizado Planes de Animación Sociocultural y Desarrollo Comunitario en las que participan inmigrantes a través de los centros que escolarizan alumnado inmigrante. Sin embargo, no se disponen datos sobre la cuantificación provincial exacta de dichos planes, aunque todos los centro que escolarizan inmigrantes disponen de dichos planes desarrollados, por lo que puede ser incluidos en la cuantificación de la medida ${ }^{59}$.

\section{MEDIDA}

\subsubsection{Impulsar Planes de Acción Comunitaria que permitan el desarrollo de} acciones de integración social.

Durante el año 2002, se han suscrito 704 convenios para el desarrollo de Planes de Desarrollo Comunitario que incluyen la atención al alumnado inmigrante. De los convenios firmados, 7 tienen un ámbito territorial que incluyen comarcas de diferentes provincias. Asimismo, se han firmado 2 convenios a nivel andaluz ${ }^{60}$.

\section{2. Área de Intervención SOCIO-LABORAL ${ }^{61}$}

El acceso al mercado laboral es una de las demandas sociales que la población inmigrante también presenta. A su vez la incorporación laboral de este colectivo presenta algunas dificultades, que nacen, en la mayoría de los casos, de la situación de irregularidad del inmigrante en nuestro país. Esta situación de irregularidad conduce bien a una situación de desempleo o bien acceder al empleo sumergido, como mano de obra a un precio inferior al del mercado normalizado. Por consiguiente, sus posibilidades de progresar hacia la inclusión social se encuentran mermadas al carecer de empleo, que es la vía principal para lograr el progreso, la integración y la cohesión social.

59 Centros que escolarizan alumnado inmigrante: Almería (50), Cádiz (34), Córdoba (26), Granada (46); Huelva (41), Jaén (31), Málaga (49) y Sevilla (49). Vid. DTS/02, pág. 104.

${ }^{60}$ Respecto del año 2001, ha aumentado el número de convenios comarcales (7), se han mantenido los autonómicos (2) y han aumentado en 140 el d venios en virtud de la Orden de 29 de enero de 10991 y de la Orden de 26 de febrero de 1991. Vid. DTS/02, pág. 104.

${ }^{61}$ Vid. DTS 0/1, págs. 39-50 y DTS 0/2 págs. 107-133. 
Partiendo de esa premisa los diferentes órganos responsable de esta área de intervención Socio-Laboral han puesto en marcha una serie de actuaciones para mejorar el acceso de la población inmigrante al mercado laboral y a los servicios básicos comunes a la población en su conjunto.

En este contexto es preciso tener en cuenta una serie de aspectos competenciales, que siguen obstaculizado el desarrollo de algunas actuaciones en esa área durante los años 2001 y 2002, como son las Políticas Activas de Empleo, no transferidas aún por el Estado; las competencias sobre inspección laboral y la tipología de estancia regular e irregular del inmigrante dependiente de su situación administrativa.

Durante el año 2002, se ha producido una de las novedades más importante en el ámbito sociolaboral del Servicio Andaluz de Empleo, aprobado por Ley 4/2002, de 16 de diciembre. "Su valor social se ha puesto de manifiesto a través del amplísimo consenso alcanzado para la aprobación de la Ley por la que se crea”.

Las actuaciones relativas a la inserción de los inmigrantes en el mundo laboral son de evidente importancia lo que supone la más alta expectativa de esta población. En esta materia, la Consejería de Asuntos Sociales ha despenado una labor orientada a la formación y capitación profesional de los inmigrantes.

Finalmente, debe señalarse la importancia que tiene la incorporación al mercado laboral de las mueres en condiciones de igualdad y más aún cuando hablamos de mujeres inmigrantes. El Instituto Andaluz de la Mujer colabora en el desarrollo del Proyecto EQUAL ARENA que tiene como objetivo "fomentar la participación en igualdad de la población inmigrante residente en Andalucía, especialmente en el ámbito laboral”.

Objetivo específico 2.1. Abordar desde el ámbito de las relaciones laborales las problemáticas que genera la incorporación de inmigrantes al mercado de trabajo.

\section{ÓRGANO RESPONSABLE: CONSEJERÍA DE EMPLEO Y DESARROLLO TEGNOLÓGICO. DIRECGIÓN GENERAL DE EMPLEO E INSERCIÓN.}

MEDIDA

2.1.1. Crear una Comisión de Migraciones en el Consejo Andaluz de Relaciones Laborales. 
- Esta Comisión se ha reunido desde su constitución el 24 de julio de 2001 en 9 ocasiones, 7 de las cuales se han producido en el año 2002.

- Su labor se ha centrado en el desarrollo de un estudio sobre "Negociación Colectiva en Andalucía y condición de nacionalidad de los trabajadores" A partir del mismo, se pretende la elaboración de unas recomendaciones dirigidas a las personas que componen las distintas mesas de negociación de convenios colectivos andaluces, al objeto de tener presente el fenómeno de la inmigración al elaborar y firmar tales convenios. Asimismo y durante las sesiones se discutieron aspectos diversos sobre la situación de los temporeros extranjeros en Huelva y Jaén, los métodos de trabajo que permitan detectar las situaciones de discriminación encubierta y otras ${ }^{62}$.

- Propuestas para el bienio 2003-2004: Se va a realizar y publicar el estudio sobre la Negociación Colectiva en Andalucía y la condición de nacionalidad de los trabajadores ${ }^{63}$.

Objetivo específico 2.3. Favorecer el acceso de la población inmigrante a las acciones de Formación Profesional Ocupacional (FPO)

\section{MEDIDA}

2.3.1. Realización de acciones formativas en zonas con población inmigrante.

- Al objeto de ofrece una formación profesional cualificada, durante el año 2002 se ha realizado cursos en las 8 provincias andaluzas, destacando Málaga con 215 personas participantes $(29,57 \%)$ y Sevilla con $122(16,78 \%)$, en relación a toda la población extranjera.

- En relación a la población de origen extracomunitario, los cursos de formación se ha realizado en su mayor parte en las provincias de Cádiz con 59 personas participantes $(27,19 \%)$ y Málaga con 55 personas $(25 \%, 37 \%)$.

- El número total de trabajadores comunitarios y no comunitarios que han participado en los cursos de F.P.O. asciende a $727^{64}$. Lo que representa un importante aumento respecto del año anterior en el que participaron 156 trabajadores ${ }^{65}$.

\footnotetext{
${ }^{62}$ Vid. DTS/02, pág. 111.

${ }^{63}$ Vid. DTS 0/2 pág. 287.

${ }^{64}$ Tabla 2.3.1.1. ALUMNOS/ALUMNAS EXTRANJEROS/AS QUE RECIBIERON CURSOS DE FPO. Vid. DTS /02, pág. 112.
}

${ }^{65}$ Vid. DTS/01, pág. 42. 
- El índice de feminización ha sido el $51,86 \%$, ya que de 727 participantes; 377 son mujeres. Proporción que varía respecto de la población no comunitaria, se puede observar cómo los porcentajes respecto a la población total sufren una pequeña variación: así de 217 personas, 115 son hombres, es decir, el 53\% y 102 son mujeres, lo que supone el $47 \% 66$.

- En lo que se refiere a la edad de los participantes, 203 son menores de 25 años (27,92\%), 456 inmigrantes tienen edades comprendidas entre 25 y 45 años $(62,72 \%)$ y 68 tienen edades superiores a 45 años $(9,36 \%)$. Estos datos referidos a la población no comunitaria arrojan resultados similares $(33,18 \%, 57,14 \% \text { y } 9,68 \%)^{67}$.

- Los datos aportados permiten apreciar que la FPO de la población inmigrantes se produce dentro de unos parámetros similares respecto de toda la población andaluza, con una cada vez mayor participación de la mujeres.

- Propuestas para el bienio 2003-2004: En el bienio anterior, la difusión de la campaña de cursos de formación se ha hecho de forma general y en el próximo bienio se realizará de forma específica para la población inmigrante ${ }^{68}$.

Objetivo específico 2.4.: Facilitar el acceso de la población inmigrantes al programa de apoyo al Autoempleo.

ÓRGANO RESPONSABLE: CONSEJERÍA DE EMPLEO Y DESARROLLO TECNOLÓGICO. DIRECGIÓN GENERAL DE EMPLEO E INSERCIÓN.

MEDIDA

2.4.1. Ayudas a proyectos de autoempleo.

- Durante el año 2002 se han concedido 126 ayudas para la ejecución de proyectos de autoempleo presentado por extranjeros con un coste total de $429.723,56 €$. El mayor número de proyectos concedidos corresponde a Almería (18), Cádiz (26), Málaga (48) y Sevilla (17), datos que se corresponden con las tendencias que mostraban los

\footnotetext{
66 Tabla 2.3.1.2. ALUMNOS/ALUMNAS EXTRANJEROS/AS DE PROCEDENCIA EXTRACOMUNITARIA QUE RECIBIERON CURSOS FPO. Vid. DTS /02, pág. 113.

${ }^{67}$ Tabla 2.3.1.1. y 2.3.1.2. Vid. DTS /02, págs. 113-114.

${ }^{68}$ Vid. DTS 0/2 pág. 287.
} 
datos acerca de la situación laboral de los inmigrantes en Andalucía (Capítulo 1 del Análisis de la Realidad) ${ }^{69}$.

- Los proyectos concedidos a extranjeros no comunitarios mayores de 30 años ha sido 33, siendo la provincia de Málaga la más dinámica con 13 ayudas concedidas, Sevilla y Almería con 6 y 5 ayudas, respectivamente, le siguen a gran distancia. Respecto a los menores de 30 años, los datos siguen la misma tendencia, destacando Málaga con 8 ayudas concedidas sobre un total de 25 en toda Andalucía ${ }^{70}$.

- Los proyectos concedidos a extranjeros comunitarios mayores de 30 años han sido 51, siendo también la provincia de Málaga la más dinámica con 22 ayudas concedidas. En este grupo Cádiz presenta un mayor dinamismo respecto de otras provincias, ya que le fueron concedidas 15 ayudas. Respecto de las personas con menos de 30 años, los datos muestran un reparto más homogéneo, ya que se concedieron 5 ayudas en Málaga y 4 en Sevilla y Cádiz, 1 en Granada y ninguna en Jaén y Córdoba ${ }^{71}$.

- Respecto de los sectores económicos y siguiendo la clasificación C.N.A.E, se ha concedido ayudas destinadas a impulsar proyectos viables en Construcción (4); Actividades recreativas (7); Educación (7); Actividades diversas de servicios personales (9); Otras actividades empresariales (12); Hostelería (24), Comercio al por menos (35); Proyectos encuadrados en otras actividades $(28)^{72}$.

- Atendiendo al sexo de los solicitantes, tenemos que las mujeres con 68 ayudas obtenidas representan el 53,97\% de los proyectos subvencionados, mientras que los hombres han recibido subvenciones para el $46,03 \%$ de los proyectos señalados ${ }^{73}$.

${ }^{69}$ Tabla 2.4.1.1.AYUDAS AL AUTOEMPLEO EN ANDALUCÍA. SEGÚN PROCEDENCIA. Vid. DTS /02, pág. 115.

${ }^{70}$ Almería, Cádiz y Sevilla obtuvieron 4 ayudas cada una; Jaén sólo 3 ayudas y Granada ninguna. Vid. Tabla 2.4.1.2 AYUDAS AL AUTOEMPLEO EN ANDALUCÍA CONCEDIDAS A PERSONAS DE ORIGEN EXTRACOMUNITARIO. Vid. DTS/02, pág. 116.

${ }^{71}$ Tabla 2.4.1.3. AYUDAS AL AUTOEMPLEO EN ANDALUCÍA CONCEDIDAS A PERSONAS DE ORIGEN COMUNITARIO. Vid. DTS/02, pág. 116.

72 Tabla 2.4.1.4 AYUDAS AL AUTOEMPLEO EN ANDALUCÍA. ACTIVIDADES ECONÓMICAS. Vid. DTS/02, pág. 117.

73 Tabla 2.4.1.5 AYUDAS AL AUTOEMPLEO EN ANDALUCÍA. CONCEDIDAS A PERSONAS DE ORIGEN EXTRANJERO, POR SEXO Y EDAD. Vid. DTS/02, pág. 117. 
- Propuestas para el bienio 2003-2004. Se propone incorporar un nuevo indicador relativo a la actividad económica a la que se destina las ayudas al autoempleo ${ }^{74}$.

Objetivo específico 2.5. Favorecer el acceso de la población inmigrante a las acciones de Orientación Profesional.

ÓRGANO RESPONSABLE: CONSEJERÍA DE EMPLEO Y DESARROLLO TECNOLÓGICO. DIRECGIÓN GENERAL DE EMPLEO E INSERCIÓN

MEDIDA

2.5.1. Ubicación de los Servicios de Orientación en zonas con elevado número de población inmigrante.

2.5.2. Desarrollo de Acciones de Orientación en Zonas de Población Inmigrante.

2.5.3. Difusión específica de las acciones de orientación entre la población inmigrante.

- Acogida a la Orden de 7 de mayo de 2001, por la que se regulan y convocan ayudas al desarrollo de Medidas Complementarias de Apoyo al Empleo, se ha realizado la implantación de Servicios de Orientación para la Inserción Laboral, estableciéndose procesos de orientación y asesoramiento que permitan a los inmigrantes demandantes de empleo aumentar sus posibilidades de inserción profesional. En concreto se han ubicado 8 servicios de orientación laboral en Cuevas de Almanzora, La Mojonera, Almería, Roquetas de Mar y Vícar, todas ellas en la provincia de Almería; Algeciras (Cádiz) y Cartaya y Mancomunidad Islantilla en la provincia de Huelva ${ }^{75}$.

- Además de los servicios de orientación específicamente dirigidos al colectivo de inmigrantes, en el resto de los Servicios de Orientación de la Red Andalucía Orienta también se ha prestado atención a este colectivo.

- El número de inmigrantes que ha recibido atenciones en los Servicios de Orientación asciende a 929, de los que 444 eran hombres y 485 mujeres, el número de atenciones han sido 1724, lo que representa multiplicar por 4 las actuaciones realizadas en el año 2001, que afectaron a 231 extranjeros $^{76}$. El índice de feminización es de

\footnotetext{
${ }^{74}$ Vid. DTS 0/2 pág. 288.

${ }^{75}$ Vid. DTS/02, pág. 118.

${ }^{76}$ Vid. DTS/02, pág. 120.
} 
$52,20 \%$. Donde mayor número de actuaciones se viene realizando son las provincias de Almería, Málaga y Sevilla, ya que son las provincias con mayor población extranjera ${ }^{77}$.

- Los mayores de 25 años son el grupo con el que se realiza el mayor número de actuaciones, lo que es lógico ya que en los datos de la población en el año 2002, se ha señalado que los mayores incrementos de población se están dado en el tramo de edad que tiene entre 25 y 45 años. Todas las provincias tienen un $75 \%$ de actuaciones en ese grupo de mayores de 25 años, salvo Cádiz donde alcanza el $94 \%$ y Córdoba donde no alcanza el $70 \% 78$.

- Los Servicios de Orientación han difundido diversos folletos en varia lenguas destinados al colectivo inmigrante, intentado con ello un asesoramiento especializado y personalizado para la búsqueda de empleo. El diseño de los formatos, texto e idiomas se realizó en el año $2001^{79}$.

- Propuestas para el bienio 2003.2004: Se procederá a verificar el funcionamiento y efectividad de estos servicios y ampliar, si procede, a otras zonas que tengan un alto porcentaje de población residente extranjera ${ }^{80}$.

Objetivo específico 2.6. Facilitar a través del Programa, ayuda al empleo en proyectos de interés social, cooperación para la dotación de Mediadores Interculturales.

ÓRGANO RESPONSABLE: CONSEJERÍA DE EMPLEO Y DESARROLLO TECNOLÓGICO. DIRECCIÓN GENERAL DE EMPLEO E INSERCIÓN.

MEDIDA

2.6.1. Posibilidad de subvencionar la contratación de mediadores culturales a través de estas ayudas.

- Dentro de las ayudas a la contratación en Proyectos de Interés Social se ha subvencionado a la FEDERACIÓN ANDALUCÍA ACOGE

77 Tabla 2.5.2.1 ACCIONES DE ORIENTACIÓN CUYOS BENEFICIARIOS ERAN PERSONAS DE ORIGEN EXTRANJERO. POR SEXO Y PROVINCIA. Vid. DTS/02, pág. 119.

${ }^{78}$ Tabla 2.5.2.2 ACCIONES DE ORIENTACIÓN CUYOS BENEFICIARIOS ERAN PERSONAS DE ORIGEN EXTRANJERO. POR EDAD Y PROVINCIA. Vid. DTS/02, pág. 120.

${ }^{79}$ Vid. DTS/02, pág. 121.

${ }^{80}$ Vid. DTS 0/2 pág. 288. 
y al MOVIMIENTO PARA LA PAZ Y EL DESARME Y LA LIBERTAD DE ANDALUCÍA para la contratación de Mediadores/as Interculturales. Su distribución provincial no puede quedar determinada ya que son las propias organizaciones las que determinan su ubicación basándose en su sistemas de información. No obstante de las memorias presentadas se deduce que la mayoría de actuaciones se han llevado a cabo en las provincias de Almería, Huelva, Jaén y Málaga. El número de mediadores contratados en el año 2002 han sido 20, mientras que en el año 2001 fueron 12, lo que supone un aumento del $66,66 \%{ }^{81}$.

Objetivo específico 2.8. Mejorar la cualificación profesional de los inmigrantes en los perfiles profesionales que precisa el sector agrario y pesquero.

\title{
ÓRGANO RESPONSABLE: CONSEJERÍA DE AGRICULTURA Y PESCA
}

\author{
MEDIDA
}

2.8.1. Impartición de cursos de formación agraria y pesquera.

2.8.2. Realización de jornadas y seminarios

2.8.3. Elaboración de material didáctico y de carácter divulgativo.

- Durante el curso 2002 se impartieron 119 cursos, lo que supone un importante aumento respecto de los 43 que se impartieron en año 2001. De ellos, 6 han sido dirigidos exclusivamente a trabajadores inmigrantes y el resto han sido cursos programados para agricultores y pescadores a los que se han incorporado alumnos/as inmigrantes ${ }^{82}$.

- Han participado un total de 263 alumnos, de los cuales el 30,80\% procedían de la provincia de Málaga, le sigue Cádiz con un 13,73\% del total ${ }^{83}$.

- Respecto de la satisfacción de los/las usuarios/as, ésta ha sido buena, con algunos matices en cuanto a la comprensión de lenguaje y conceptos manejados en las clases teóricas, ya que si bien la mayo-

\footnotetext{
${ }^{81}$ Vid. DTS/02, pág. 121.

82 Tabla 2.8.1.1 GURSOS DE CAPACITACIÓN AGRARIA CUYOS BENEFICIARIOS ERAN PERSONAS DE ORIGEN EXTRACOMUNITARIO POR PROVINCIAS. Vid. DTS/02, pág. 122 y DTS/01 pág. 47.

83 Tabla 2.8.1.2 RELACIÓN DE CURSOS CON PRESENCIA DE ALUMNOS INMIGRANTES. Vid. DTS/02, pág. 123.
} 
ría tiene una buen compresión oral del lenguaje presenta más dificultades en cuanto a la compresión escrita.

- Se han realizado 2 jornadas con participación de alumnos inmigrantes: una sobre cultivo de cítricos realizado en Palma del Río (Córdoba) y otra, sobre semilleros hortícolas celebrado en Almería 84 .

- Durante el año 2002 se ha iniciado la realización de una hoja divulgativa en varios idiomas relativa a la correcta aplicación de los productos fitosanitarios, que va a estar destinado al colectivo de los trabajadores inmigrantes que trabajan aplicando estos productos. Durante el año 2003 se finalizará la elaboración de la publicación y se procederá a su distribución ${ }^{85}$.

- Propuestas para el bienio 2003-2004 Se propone realizar unas serie de mejoras: Mejorar la coordinación entre los distintos Centros Directivos que permita diseñar un itinerario de formación adaptado a las necesidades de las personas inmigrantes. Diseño de un manual de conceptos y símbolos que permitan identificar el significado de las actividades agrarias y pesqueras, independientemente de la cultura de origen. Incremento del número de cursos en sectores de actividad agraria y pesquera y en el ámbito provincial si la demanda lo requiere $^{86}$.

Objetivo específico 2.9. Desarrollar actuaciones específicas de orientación, formación e inserción sociolaboral para inmigrantes en Andalucía.

ÓRGANO RESPONSABLE: CONSEJERÍA DE ASUNTOS SOCIALES. D. G. DE BIENESTAR SOCIAL.

MEDIDA

2.9.1. Financiación de programas de Formación Compensatoria.

- La Formación Compensatoria Básica que desarrolla la Dirección General de Bienestar Social es una actuación complementaria del Sistema de Servicios Sociales que tiene un gran importancia al permitir la adquisición de habilidades que permitan crear una base que favorezca el acceso a otros ámbitos sociales y culturales.

\footnotetext{
${ }^{84}$ Vid. DTS/02, pág. 125.

${ }^{85}$ Vid. DTS/02, pág. 125.
} 
- En el año 2001 se desarrollaron, mediante convenios con Asociaciones, Corporaciones Locales, Sindicatos y la implicación de Recursos Humanos de las distintas Administraciones 36 programas de Formación Compensatoria cuyo conste ascendió a $110.646,32^{87}$.

- Durante el año 2002 se produce un cambio en la metodología de ayudas, pasando a ser subvencionadas en vez de conveniadas. En ese contexto, se han subvencionado cuatro actuaciones por un importe de 38.012,98 €. Aunque al cierre del DTS/02 todavía no se conocía el número cursos realizados y de participantes en los $\operatorname{mismos}^{88}$.

MEDIDA

2.9.2. Fomento del autoempleo.

- Durante el año 2002 se ha realizado 3 actuaciones que han sido subvencionadas con $12.015,18^{89}$, aunque estos datos no son definitivos pues al cerrar el DTS/02 todavía no se disponía de todas las memorias de la ejecución de las diferentes actuaciones, aunque en contrapartida se conocen datos de las actuaciones realizadas durante el año 2001, en el que se contabilizaron 2058 participantes $^{90}$.

- Finalmente, dentro de este apartado hay que señalar la firma del convenio de colaboración entre la D. G de Bienestar Social y la Entidad IMFE con el fin de prestar asesoramiento para el autempleo en las Zonas de Necesidades de Transformación Social.

${ }^{86}$ Vid. DTS 0/2 pág. 289.

87 Vid. DTS/01, pág. 48.

${ }^{88}$ Programa de alfabetización de inmigrantes, realizado por el Ayuntamiento de Adra (Almería), con 12.200 €; Apoyo a la escolarización, realizado por el Ayuntamiento de Roquetas (Almería) 4.712,98 €; Programa para facilitar la integración de mujeres inmigrantes y sus hijos, realizado por la Asociación para la Igualdad y Solidaridad en la provincia del Granada $12.000 €$; Alfabetización de inmigrantes, realizado por el Ayuntamiento de Marbella, con 9.100€.Vid. DTS/02, pág. 126.

${ }^{89}$ Realizado por la Asoc. de Mujeres Progresistas de Sevilla, subvencionada con $3000 €$; Agencia de colocación solidaria, realizado por la Asociación juvenil Luso-Africana en Sevilla, con $6.010 €$ y Bolsa de empleo para inmigrantes, realizada por ATIME en Sevilla, con 3.005 €. Vid. DTS/02, pág. 127.

90 Vid. DTS/02, pág. 127. 


\section{MEDIDA}

2.9.3. Promoción de cursos de enseñanza del español.

- $\mathrm{Al}$ igual que la medida 2.9.2., la enseñanza de español que desarrolla la Dirección General de Bienestar Social es una actuación complementaria del Sistema de Servicios Sociales.

- Se han concedido subvenciones a 4 cursos realizados en las provincias de Almería, Huelva y Sevilla por un importe total de 22.382,14 € Los datos de participación que se disponen son del año 2001 contabilizándose un total de 1.432 alumnos.

- Por último, desde las actuaciones que se realizan en las Zonas de Necesidades de Transformación Social también se ha informado y derivado a la población inmigrante hacia programas de enseñanza de español.

\section{MEDIDA}

2.9.4. Promoción de cursos de orientación sociolaboral para inmigrantes.

- Durante el año 2002 se han realizado 11 actuaciones en materia de cursos de orientación sociolaboral para inmigrantes por un importe subvencionado de 149.059,60 €, en las provincias de Almería, Cádiz, Granada, Huelva y Sevilla. El número de participante no se pudo contabilizar al cierre del DTS/02 por estar las medidas en ejecución. De forma similar, si se puede facilitar los datos del año 2001, año en el que participaron 115 personas $^{91}$.

- De forma complementaria, también se deben contabilizar las actuaciones de información y derivación llevadas desde las distintas Zonas de Necesidades de Transformación Social, en concreto, fueron informados 559 inmigrantes en toda Andalucía para asistencia a diferentes servicios de orientación sociolaboral. Dichos servicios son gestionados por varias entidades ${ }^{92}$.

\section{MEDIDA}

2.9.5. Realización de cursos de formación profesional.

- Durante el año 2002, la D.G. de Bienestar Social promueve la realización de diversos cursos de Formación Profesional como una actuación complementaria del Sistema de Servicios Sociales, teniendo en cuenta que la responsabilidad y competencia recae sobre la Con-

\footnotetext{
91 Vid. DTS/02, pág. 129.

92 Vid. DTS/02, pág. 129.
} 
sejería de Educación y Ciencia, al estar enmarcada, dicha formación, dentro del Sistema Educativo Andaluz.

- Se han realizado 4 actuaciones que se han desarrollado en las provincias de Córdoba y Sevilla por un importe total de 27.045,48€ d. ${ }^{93}$.

- Como en las actuaciones anteriores, desde las distintas Zonas de Necesidades de Transformación Social, de las provincias de Almería, Cádiz, Granada, Jaén, Málaga y Sevilla se informó y asesoró a 34 inmigrantes para que asistieran a diversos cursos de FPO gestionados por diversas entidades.

OBJETIVO 2.10. Facilitar el acceso y la reincorporación al mercado de trabajo de las personas que sufren dificultades para reintegrarse o integrarse en un mercado de trabajo, que debe estar abierto a todos, y combatir las actitudes racistas y xenófobas en relación con el mercado de trabajo.

ÓRGANO RESPONSABLE: CONSEJERÍA DE GOBERNACIÓN, CONSEJERÍA DE ASUNTOS SOCIALES, CONSEJERÍA DE EMPLEO Y DESARROLLO TECNOLÓGICO, INSTITUTO ANDALUZ DE LA MUJER.

MEDIDA

2.10.1. Presentación de la solicitud. Las actuaciones que inicialmente se pretenden desarrollar una vez conseguida la aprobación de la Iniciativa comunitaria.

- El proyecto, presentado en el marco de la Iniciativa Comunitaria EQUAL del Fondo Social Europeo para "combatir las actuaciones racistas y xenófobas en relación con el mercado de trabajo", ha sido denominado ARENA y fue elaborado y aprobado en el año $2001^{94}$.

- Nace con el objetivo de fomentar la participación inigualdad de la población inmigrante residente en Andalucía, especialmente en el ámbito laboral. Se estima que los beneficiarios (directos e indirectos) del proyecto EQUAL ARENA serán unos 18.000, de los cuales

\footnotetext{
${ }^{93}$ Las actuaciones fueron: Diseño capilar creativo africano, realizado por Asociación de Mujeres Africanas "Asoma”, en la provincia de Córdoba, Centro de formación, orientación laboral y jurídica al inmigrante, puesto en marcha por "La Voz del Inmigrante" en la provincia de Sevilla. Integración laboral de las mujer inmigrante, llevado a cabo por la Asociación "Mujeres entre mundos", en Sevilla y Orientación Profesional para la integración en el mercado laboral, realizada por MPDL en Sevilla. Vid. DTS/02, pág. 130.

${ }^{94}$ DTS/01, pág. 49-50.
} 
el $37 \%$ serán mujeres. La cuantía total del proyecto será de $3.119 .685 €^{95}$.

- Tras su aprobación, se inició la puesta en marcha de la fase denominada Acción 1 que se desarrolla en la primera mitad del año 2002 e implica llevar a cabo distintas actividades encaminadas a redefinir el proyecto, que volvió a ser presentado para su nueva aprobación. Se requirieron actividades de coordinación y organización del trabajo muy específicas, teniendo en cuenta que en el proyecto participan 20 entidades de Andalucía ${ }^{96}$ y que, además, era necesario entrar en contacto con entidades de otros países europeos.

- Se establecieron grupos de trabajo por áreas, se celebraron reuniones con los posibles socios de los otros países y se llego a un Acuerdo de Cooperación Transnacional con dos Agrupaciones de Desarrollo: una de la región Valona en Bélgica, y otra de Lombardía, Italia. Se tradujeron y firmaron el acuerdo nacional (AD ES-333. MOSAICO) y el acuerdo transnacional (ACT 941, ALAMEDA). Con la firma de estos acuerdos se dio por concluida la Acción 1.

- DESARROLLO DEL PROYECTO EQUAL ARENA. En el Acuerdo de la Agrupación de Desarrollo nacional MOSAICO, se establecen las medidas que se irán implantando durante la Acción, cuyo periodo elegible de gastos se inició el 12 de julio de 2002 y terminará el 12 de julio de 2004. Dentro de esta Acción, desde la Consejería de Gobernación, se han ido desarrollando diferentes medidas de las contempladas en el proyecto EQUAL ARENA:

- Inicio del Diseño de la Herramienta de Gestión de Usuarios desde los Servicios de Recepción y orientación creados por el proyecto.

- Contratación de personal laboral para la coordinación y seguimiento del proyecto.

- Taller formativo.

- Actividades de Coordinación y seguimientos de las medidas del proyecto.

- Reunión de Coordinación de la Agrupación de Desarrollo.

${ }^{95}$ DTS/01, pág. 49.

${ }^{96}$ En concreto: Consejerías de Empleo y Desarrollo Tecnológico; Asuntos Sociales; Gobernación; Instituto Andaluz de la Mujer; Dip. Prov. de Almería; Ayuntamientos de Almería, la Mojonera, Vícar, Roquetas del Mar, Algeciras y Moguer, Lepe y Cartaya; CCOO; UGT; Plataforma de Inmigrantes; Federación Andalucía ACOGE; UAGA; Universidades de Almería y Granada Vid. DTS/01, pág. 49. 
- Diseño de la imagen corporativa del proyecto ARENA. Manual corporativo.

- Reproducción y encuadernación de 126 ejemplares del proyecto

- Puesta en marcha del Sistema de información (Portal EQUAL ARENA) ${ }^{97}$.

- DESARROLLO DEL PROYECTO TRANSNACIONAL EQUALALAMEDA. Para el desarrollo de las actividades y productos del Proyecto Transnacional ALAMEDA se mantuvieron distintas reuniones con los socios transnacionales, tanto del Grupo de Coordinación de la Transnacionalidad, como de los Grupos de Trabajo Temáticos. Ambos tipos de acuerdos trabajar en el desarrollo de las siguientes actividades y productos:

- Indicadores de Inserción Socio profesional: selección y definición de los mismos así como su desagregación según diversas variantes.

- Página Web: Desarrollo estructura y contenidos.

- Repertorio de Buenas Prácticas: organizada la estructura de recogida de información sobre experiencias en los ámbitos de integración social, nuevos nichos de empleo y cooperación al desarrollo con participación de inmigrantes.

- Fórum de Proyectos EQUAL con medidas dirigidas a los inmigrantes: Planteamientos del producto, que formaría parte de la Página Web.

- Biblioteca Virtual Hermes: Se realizaron previsiones para la alimentación de este producto.

- Intercambios: Se planificó la actividad de Intercambios de Beneficiarios, Profesionales y Responsabilidades del Proyecto EQUAL-ARENA

- Perfil del Mediador/a Intercultural: Se planifica el encuentro e intercambio de documentación entre investigadores de los países socios para el desarrollo del producto ${ }^{98}$.

- La D. G. de Bienestar Social es el socio responsable, dentro de la agrupación de desarrollo, de la realización de la evaluación externa del proyecto, para lo cual se ha concedido a la Universidad de Sevi-

\footnotetext{
${ }^{97}$ DTS/02 pág. 131.

98 DTS/02 pág. 132.
} 
lla, Departamento de Psicología Social, una subvención de $10.517,50 €^{99}$.

\section{3. Área de Intervención SOCIO-SANITARIA}

"El Plan Integral para la Inmigración en Andalucía recoge entre sus Principios Rectores el de Igualdad, como principio básico, según el cual la incorporación de las personas de origen extranjero en la sociedad andaluza ha de producirse en condiciones de igualdad con la población autóctona”. Partiendo de esa premisa y teniendo en cuenta el carácter universal del Sistema Sanitario Público Andaluz, desde el Área de Intervención SOCIO-SANITARIA se pretende acercar los recursos existentes a la población inmigrante incidiendo de manera especial en las situaciones que puedan suponer un riesgo para la salud individual o colectiva. En ese contexto, los órganos responsables de esta área, Consejería de Salud, Instituto Andaluz de la Mujer y Comisionado para las Drogodependencias desarrolla medidas destinadas a la consecución de los objetivos previstos.

Objetivo específico 3.1. Potenciar la captación de la población inmigrante para atender los problemas de salud que presentan, al objeto de preservar la salud individual y colectiva, por medio de la atención individualizada.

\section{ÓRGANO RESPONSABLE: CONSEJERÍA DE SALUD}

\section{MEDIDA}

3.1.1. Captación activa de la población inmigrante desde las Zonas Básicas de Salud, a través de mapa del riesgo, para incluirlas en los Programas de Salud.

- La Consejería de Salud, mediante sus recursos propios y con la colaboración de diversas entidades como Cruz roja, Andalucía Acoge, CARDINJ, APIC, Acoge, Médicos del Mundo, MPDL, U.G.T. y CC.OO. potencia la captación activa de población inmigrantes con dificultades en el acceso a los Servicios Sanitarios mediante el documento normalizado de derivación.

- Durante el año 2002 se han tramitado un total de 38.577 documentos de derivación hacia los Servicios Sanitarios, lo que supone un descenso de 3.676 documentos de derivación respecto los 42.253 tramitados en el año 2001. La causa de este descenso hay que atri-

${ }^{99}$ DTS/02 pág. 132. 
buirla a la mejora en la gestión de los documentos de derivación lo que evita la duplicación de los mismos, así como de las tarjetas sanitarias.

- Almería y Málaga son las provincias donde mayor número de documentos se han tramitado en el año 2002 (14.644 y 11.802 respectivamente), muy de lejos les siguen Sevilla (3.883), Granada (2.813), Cádiz (1.995), Jaén (1.691), Huelva (913) y Córdoba (836). Respecto del año 2001, la principal diferencia estriba en el aumento de Málaga (que pasó de 8.182 a los 11.802 citados) y la disminución de Almería (de 22.118 a 14.644)

- La entidad que mayor numero de derivaciones ha realizado, con un $28 \%$ del total, seguida de Andalucía Acoge con 25\%, aunque en cada provincia es una entidad diferente la que mayor número de derivaciones realiza ${ }^{100}$.

Objetivo específico 3.2. Promover la captación de inmigrantes y determinar las necesidades de salud de cada persona que lo precise.

ÓRGANO RESPONSABLE: CONSEJERÍA DE SALUD

MEDIDA

3.2.1. Las contempladas en el Convenio de Colaboración entre la Consejería de Salud, ONGs, Centrales Sindicales y Fundación Progreso y Salud que $\underline{\text { se encuentra abierto a toda organización que exponga su voluntad de }}$ suscribirlo.

- La Consejería de Salud, a través de distintos convenios de Colaboración suscritos con ONGs, Centrales Sindicales y Fundación Progreso y Salud ejecuta distintas medidas destinadas a la captación de, asesoramiento y acompañamiento y atención sanitaria de del colectivo inmigrante.

- Como resultados de dichas medidas se han elaborado en el año 2002 un total de 38.863 Tarjetas de Reconocimiento de Asistencia Temporal, de las cuales 38.577 fueron emitidas tras la derivación del servicio sanitario pertinente y las 286 restantes como resultado de acceso directo al Sistema Sanitario sin requerir azoramiento previo alguno, datos que suponen un descenso de 18.809 respecto las 57.386 Tarjetas emitidas en el año 2001.

${ }^{100}$ Vid. DTS/01, pág. 52 y DTS/02, págs. 135-136. 
- Desde el Sistema Sanitario Público Andaluz se está intentado canaliza la emisión de todas las Tarjetas de Reconocimiento de Asistencia Temporal a través de las actuaciones de acompañamiento y derivación que realizan las ONGS, mediante convenio suscrito a tal fin, para ejercer control sobre el uso correcto de las mismas. Este propósito explica la reducción progresiva de la diferencia entre el numero de documentos de derivación y el número de Tarjetas de Reconocimiento que se puede comprobar entre los años 2001 y $2002^{101}$.

- El número de Tarjeta Reconocimiento de Asistencia Temporal emitidas en los años 2001 y 2002 sigue la siguiente evolución por provincias: Almería con 24.013 Tarjetas emitidas en el año 2001 pasa a 16.613 en el año 2002, le sigue Málaga con 11.204 que disminuye a 4.918 en el año 2002, Córdoba de 5.166 a 3.827, Huelva 4.345 a 3.616, Sevilla de 5.590 a 2.966, Granada de 3.107 a 2.820 y finalmente, Cádiz de 2.415 Tarjetas en el año 2001 a 2.212 emitidas en el año $2002^{102}$.

- En los que se refiere a la Asistencia en Atención Primaria, incluidas las asistencias prestadas por enfermería, en el años 2002 se han prestado 182.545 asistencias, que implica un aumento del 42,09\% respecto del año 2001 donde se llevaron a cabo 128.467 asistencias. Destaca Almería, tanto en el año 2001 como en el 2002 que representa casi el $45 \%$ de las asistencias, seguida de Málaga con cerca del $18 \%{ }^{103}$.

- En Atención Especializada, en el año 2002 se ha prestado asistencia a 59.724 inmigrantes de los cuales 32.138 se han realizado en la provincia de Almería, lo que supone el $53,81 \%$ de las atenciones realizadas en Andalucía. Estos datos, además suponen un incremento del 31,13\% respecto del año 2001 en que se realizaron 30.464, aumento que se distribuye de la siguiente forma: Almería pasa de 30.464 asistencias en el año 2001 a 32.138 en el año 2002, Málaga de 3.709 a 7.056, Granada de 2.736 a 5.409, Sevilla de 1.473 a 5.027 , Córdoba de 702 a 3.112, Jaén de 2.067 a 2917, Cádiz de 1.518 a

101 Vid. para ello los datos aportados en la medida 3.1.1 y 3.2.1.

102 Vid. Gráfico 3.2.1.2 EVOLUCIÓN DE TARJETAS DE ASISTENCIA TEMPORAL 2002/200, POR PROVINCIAS, en DTS/02, pág. 138.

103 Vid. Gráfico 3.2.1.4, EVOLUCIÓN DE ATENCIONES PRIMARIAS 2002/2001, POR PROVINCIAS en DTS/02, pág. 139. 
1.683 y finalmente Huelva que es la única provincia en donde disminuye el número de se asistencias prestado al pasar de 2.265 en el año 2001 a 238 en el año $2002^{104}$.

- El número de partos atendidos por el Sistema Sanitario Público Andaluz han aumentado más de un 75\% del año 2001 al año 2002, ya que mientras en el año 2001 se atendieron 613 en el año 2002 se han atendido 1.074 partos, de los que el 50,37\%, corresponde a la provincia de Almería, seguido de Sevilla que representa el 16,01\% de los partos ${ }^{105}$.

- En colaboración con la Dirección General de Infancia y Familia de la Consejería de Asuntos Sociales corresponde al Sistema Sanitario Público Andaluz la realización de pruebas radiológicas para determinar la edad de los supuestos menores. Los datos aportado permiten apreciar un importante aumento de dichas pruebas, pues mientras en el año 2001 se realizaron 84 estudios en el año 2002 se han realizado 1.256 pruebas radiológicas ${ }^{106}$.

Objetivo específico 3.3. Posibilitar a la población inmigrantes que lo requiera intérpretes que faciliten el encuentro con el Sistema Sanitario Público Andaluz.

ÓRGANO RESPONSABLE: CONSEJERÍA DE SALUD

MEDIDA

3.3.1. Servicio de Intérpretes Traductores a través de las ONGs y Centrales Sindicales firmantes del Convenio de Colaboración.

- Con el objeto de solventar el desconocimiento del idioma existente en muchas de las relaciones del colectivo inmigrante con el Sistema Sanitario Público Andaluz, la Consejería de Salud proporciona un servicio de interpretes y traductores a través de la suscripción de convenios de colaboración con entidades tales como la Cruz Roja o Andalucía Acoge.

${ }^{104}$ Vid. Gráfico 3.2.1.6, EVOLUCIÓN DE ATENCIONES ESPECIALIZADAS 2002/2001, POR PROVINCIAS, en DTS/02, pág. 140.

105 Vid. Gráfico 3.2.1.8, EVOLUCIÓN DE LOS PARTOS ATENDIDOS 2002/2001, POR PROVINCIAS, en DTS/02, pág. 141.

106 Vid. DTS/01, págs. 53-54 y DTS/02, págs. 137-142. 
- Los resultados de la ejecución de este servicio permiten apreciar un importante aumento en la interpretaciones prestadas entre el año 2001 y el año 2002, pues mientras en el año 2001 se prestaron 138 servicios en el año 2002 han sido un total de 208 el número de interpretaciones, lo indica un aumento de mas de 70. Del total de estos 208 servicios, 183 fueron prestados por Andalucía Acoge y las 25 restantes por la Cruz Roja.

- No se puede indicar el grado de satisfacción de usuarios y profesionales sanitarios ya que no existen encuestas especificas ${ }^{107}$.

Objetivo específico 3.4. Mejorar la información de los inmigrantes sobre el Sistema Sanitario Público Andaluz, sus programas de prevención y las vías de acceso al mismo.

ÓRGANO RESPONSABLE: CONSEJERÍA DE SALUD

MEDIDA

3.4.1. Elaboración, edición y distribución de "carpetas de mano" con historia clínica portátil.

- Mediante convocatoria anual de ayudas públicas en los años 2001 y 2002 se subvencionaron proyectos destinados a la elaboración, edición y distribución de "carpetas de mano" que contienen la historial clínica portátil, entregándose 80.000 carpetas en el año 2001 y 29.530 en el año 2002, lo que ha supuesto un descenso de 50.470 carpetas.

- En el año 2001, la provincia en la que mayor número de carpetas se entregaron fue Almería con 34.961, seguido por Málaga con 17.679, posición que mantienen en el año 2002 si bien como ya se ha indicado con un importante descenso ${ }^{108}$.

\section{MEDIDA}

3.4.2. Edición y distribución de trípticos informativos sobre el Convenio de Colaboración (ver Medidas del Objetivo 3.2) y acceso a la asistencia sanitaria en distintas lenguas.

- Se ha financiado la edición y distribución de trípticos informativos sobre los convenios de colaboración suscritos con las distintas enti-

\footnotetext{
107 Vid. DTS/01, pág. 55 y DTS/02, pág. 142.

108 Vid. Gráfico 3.4.1.2 EVOLUCIÓN DE LAS CARPETAS DE MANO DISTRIBUIDAS 2002/2001, POR PROVINCIAS, en DTS/02, pág. 143.
} 
dades y el acceso a la asistencia sanitaria. En el año 2002 se han distribuido 30.413 trípticos, lo que supone una disminución de 49.587 trípticos respecto al año $2001^{109}$.

MEDIDA

3.4.3. Elaboración y distribución de dípticos sobre vacunaciones y medidas preventivas en Andalucía.

- Mediante convocatoria de ayudas públicas anual se subvenciona también la elaboración, edición y distribución de dípticos sobre vacunaciones y medidas preventivas, distribuyéndose en el año 2002 un total de 17.661 dípticos informativos, lo que supone un descenso significativo de 62.339 dípticos menos ${ }^{110}$.

Objetivo específico 3.5. Mejorar la información de los profesionales sociosanitarios sobre la atención sanitaria a inmigrantes.

ÓRGANO RESPONSABLE: CONSEJERÍA DE SALUD

MEDIDA

3.5.1. Elaboración edición y distribución de una guía de atención sanitaria a inmigrantes, dirigida a los profesionales sanitarios.

- En el año 2001 se diseño y elaboró la guía informativa para ofrecer a los profesionales sanitarios un mejor conocimiento de las características culturales, sociales, sanitarias y religiosas de los diferentes colectivos de población inmigrante, con objeto de favorecer la calidad del servicio sanitario prestado.

- En el año 2002 se han editado y distribuido un total de 23.906 guías informativas, remitiéndolas a todos los Centros de Salud y Servicios de Urgencias del Sistema Sanitario Público andaluz ${ }^{111}$.

Objetivo específico 3.6 Facilitar el acceso de las mujeres inmigrantes a los programas de educación sexual y salud reproductiva para mejorar la salud.

ÓRGANO RESPONSABLE: CONSEJERÍA DE SALUD

\footnotetext{
${ }^{109}$ Vid. DTS/02, pág. 144.

${ }^{110}$ Vid. DTS/02, pág. 144.

111 Vid. DTS/02, pág. 145.
} 


\section{MEDIDAS}

3.6.1. Elaboración de una Guía de Información socio-sanitaria para las mujeres inmigrantes.

3.6.2. Campaña de información.

- En el año 2001 se procedió al diseño del contenido de la Guía informativa socio sanitaria para mujeres inmigrantes y durante el año 2002 se procedió a su elaboración y distribución. En total, se editaron 21.568 guías y se contactaron con 16.974 mujeres inmigrantes, a las que se les ha ofrecido una información más detallada ${ }^{112}$.

- El Instituto Andaluz de la Mujer ha colaborado, en el desarrollo de esta medida, con la Consejería de Salud, a través de la Fundación Progreso y Salud en la elaboración de un folleto informativo sobre "Salud y Derecho de las Mujeres inmigrantes" donde se ofrece información sobre los principios y derechos que les protegen y los servicios sanitarios y sociales a los que pueden acceder.

- Del total de los folletos editados el Instituto Andaluz de la Mujer ha distribuido de 5.000 folleto $^{113}$.

Objetivo específico 3.7 Impulsar programas orientados a la promoción de la salud y dirigidos especialmente a los drogodependientes inmigrantes.

ÓRGANO RESPONSABLE: CONSEJERÍA DE ASUNTOS SOCIALES. COMISIONADO PARA LAS DROGODEPENDENCIAS.

\section{MEDIDA}

3.7.1. Elaboración de un protocolo específico adaptado a la necesidad de los drogodependientes.

- No ha sido posible diseñar un protocolo específico adaptado a las necesidades de este colectivo.

- No obstante, desde la Red Andaluza de Atención a las Drogodependencias se atiende a la población inmigrante que demanda este servicio.

- El número de inmigrantes atendidos en los Cetros Provinciales de Tratamiento Ambulatorio durante el año 2002 han sido 390, lo que supone un descenso respecto al año 2001 en que se atendiendo a 498, siendo las provincias de Huelva, Málaga y Sevilla este descenso ha sido más acusado ${ }^{114}$.

\footnotetext{
112 Vid. DTS/02, pág. 146.

113 Vid. DTS/02, pág. 147.

114 Vid. datos desagregados en DTS/02, págs. 146-147.
} 
Objetivo específico 3.8 Reducir los riesgos derivados del consumo de drogas, a través de la incorporación del Programa de Intercambio de Jeringuillas y de la distribución de preservativos.

\section{ÓRGANOS RESPONSABLE: CONSEJERÍA DE SALUD}

MEDIDA

3.8.1. Distribución de jeringuillas y preservativos en los Albergues para inmigrantes, Centros de Primera Acogida, ONGs específicas y en los que se detecte que exista consumo por vía intravenosa.

- Desde la Consejería de Salud se puso en marcha el Programa de Intercambio de Jeringuillas y de distribución de preservativos, pero dada las características del mismo, no es posible determinar el número exacto de personas de origen extranjero que hacen uso de este programa $^{115}$.

Propuesta para el bienio 2003-2004: Creación de un nuevo objetivo específico 3.9 Reducir los riesgos y daños del consumo de drogas mediante la elaboración y difusión de campañas de sensibilización, en materia de prevención dirigidas a personas de origen extranjero. Órgano responsable: Consejería de Asuntos Sociales. Comisionado para las drogodependencias ${ }^{116}$.

\section{4. Área de Intervención de RECURSOS SOCIALES}

El fin último del I Plan para la Inmigración en Andalucía es la integración de los inmigrantes como sujetos de derechos y deberes. Para ello, desde esta área se establecen una serie de medidas encaminadas a la consecución de objetivos tales como favorecer el acceso de esta población a los servicios básicos existentes en nuestra sociedad, como la vivienda, la asistencia jurídica, los servicios sociales, etc.; atender a los menores extranjeros no acompañados para garantizar sus derechos reconocidos; fomentar el asociacionismo y la participación social de mujeres y jóvenes inmigrantes, así como fomentar la práctica del deporte como medio de integración social; y asesorar, informar y acoger a mujeres y menores víctimas de la explotación sexual.

\footnotetext{
115 Vid. DTS/02, pág. 148.

116 Vid. DTS 0/2 pág. 291.
} 
Objetivo específico 4.1. Informar, orientar y asesorar a los inmigrantes en materia laboral, jurídica, social y educativa, que facilite su integración.

ÓRGANO RESPONSABLE: CONSEJERÍA DE ASUNTOS SOGIALES. D.G. DE BIENESTAR SOCIAL.

MEDIDA

4.1.1. Programas gestionados por Corporaciones Locales y Entidades Privadas sin ánimo de lucro.

- Ante todo hay que señalar que desde la convocatoria de ayudas públicas de a Consejería de Asuntos Sociales se cubren diferentes programas que se pueden enmarcar en distintas medidas de esta área.

- Durante los años 2001 y 2002 los Programas de Información gestionados por las Corporaciones Locales y Entidades Privadas sin ánimo de lucro, a través de la Red de Servicios Sociales y la convocatoria de de subvenciones de la Consejería de Asuntos Sociales, ha ofrecido asesoramiento a la población inmigrante en materia jurídico-leal, empleo, sanidad, reagrupación familiar, escolarización, etc ${ }^{117}$.

- En el año 2002 han sido subvencionadas 7 asociaciones inmigrantes y 27 asociaciones proinmigrantes, con un total de 42 proyectos dedicados a la información, orientación y asesoramiento de las personas inmigrantes en diversas materias como son, la laboral, jurídica, social, etc., siendo la cuantía total subvencionada de $168.278,31 €$., para la las asociaciones de inmigrantes y $516,508,49 €$ para las asociaciones de proinmigrantes. Las organizaciones sindicales, a su vez, han percibido un total de $359.104,73 €$ de subvención para llevar acabo Programas de Información a Inmigrantes. Por último son 35 corporaciones Locales las que cuentan con programas de atención inmigrantes, percibiendo un total de 814.353,12 € como financiación específica.

- Puestos en relación estos datos con los resultados del ejercicio anterior podemos decir que el año 2001 fueron subvencionados 12 asociaciones de inmigrantes y 34 proinmigrantes. La cuantía de la subvención ascendía a $120.502,93 €$ y $586.978,47 €$ respectivamente. Las organizaciones sindicales recibieron un total de $315.531,35 €$ y fueron 25 Corporaciones Locales las que contaron con programas de atención a inmigrantes, cuya financiación ascendió a 349.037,78 €

${ }^{117}$ Para ver la relación de todos los programas por provincias, vid. DTS/02, págs. 151-156. 
- Como resultado global podemos indicar que se ha subvencionado en el año 20025 asociaciones de inmigrantes y 7 proinmigrantes menos que el año 2001. Presupuestariamente se ha incrementado el importe económico subvencionado en $47.775,38 €$ para las asociaciones de inmigrantes y ha descendido en $70.470,07 €$ la cuantía par alas asociaciones proinmigrantes. En cuanto a la cuantía subvencionada a las organizaciones sindicales, se detecta un incremento de $43.573,38 €$ respecto del año anterior. Por último, se han incrementado en 10 las Corporaciones Locales que cuentan con Programas de atención a inmigrantes, lo que ha requerido un aumento de 465.315,34 € respecto al año 201 para su financiación.

- Complementariamente, en el año 2002 el número de inmigrantes atendidos desde los Servicios Sociales comunitarios ascendió a 26.288 ${ }^{118}$.

\section{MEDIDA}

4.1.2. Mantenimiento y potenciación de la Red de Mediadores Interculturales.

- Durante el año 2002 se ha ampliado la red de mediadores/as interculturales en nuestra región, que pasado a ser de 34 , lo que supone un incremento de 6 respecto del año 2001.

- La provincia que cuanta con el mayor número de mediadores/as es Almería (35,29\%), seguido de Huelva (20,59\%), Granada $(11,76 \%)$, Sevilla (11,76\%), Jaén $(8,82 \%)$, Cádiz $(5,88 \%)$, Córdoba $(2,94 \%)$ y Málaga $(2,94 \%)^{119}$.

MEDIDA

4.1.3. Mantenimiento y potenciación de la Red de Información. Orientación y Asistencia Sociolaboral.

- En el año 2002 la Red de Información, Orientación y Asistencia Sociolaboral ha estado presente en todas las provincias andaluzas ${ }^{120}$.

- En total han sido 75 puntos de la Red lo que supone un descenso de 5 punto respecto del año 2001 en que fueron 80 puntos de información. Estos e debe a que entidades que solicitaron el año an-

\footnotetext{
118 Vid. DTS/02, págs. 156-158.

119 Vid. DTS/02, págs. 158-159.

120 Vid. Datos concretos de los programas y cuantía de los mismos, así como la distribución geográfica de la Red de Información, en DTS/02, págs. 160-164.
} 
terior subvención no lo ha hecho en el año 2002 y han pedido financiación para otros programas.

MEDIDA

4.1.4. Convenios con los sindicatos.

- Para el desarrollo de programas específicos de información y asesoramiento a inmigrantes en el año 2002, como en el 2001, se han suscrito convenios entre la Consejería de Asuntos sociales y las siguientes Organizaciones Sindicales:

- CC.OO. ANDALUCÍA para la Atención a Inmigrantes Extranjeros residentes en el territorio andaluz con una subvención de $154,009,35 €$

- U.G.T. ANDALUCÍA para la Atención e Información y asesoramiento laboral al inmigrante no comunitario, con una ayuda de $154.009,35 €$.

- En el año 2001 fueron asesorados 29.808 inmigrantes por los sindicatos subvencionados: 11.962 por U.G.T. y 17.846 por CC.OO. No se disponen de datos relativos al año 2002, porque al cierre del DTS/02 no se deponía de las memorias de las actuaciones realizadas ${ }^{121}$.

Objetivo específico 4.2. Promover la participación social y el asociacionismo de los inmigrante, así como su agrupamiento en federaciones, redes y otras estructuras análogas.

ÓRGANO RESPONSABLE: CONSEJERÍA DE ASUNTOS SOGIALES. D.G. DE BIENESTAR SOCIAL.

MEDIDA

4.2.1. Subvenciones a ONGs de inmigrantes y proinmigrantes.

- El fomento del movimiento asociativo y la participación social de los inmigrantes es una de las líneas prioritarias de actuación desde hace años ante la debilidad de dicho tejido asociativo.

- En el año 2002 desde la D. G. de Bienestar Social se han realizado actuaciones que se extraen de otra medidas pero que por tratarse de subvenciones a ONGs también se analizan en este apartad, ya que favorecen el movimiento asociativo de los inmigrantes.

121 Vid. DTS/02, págs. 165-166. 
- En el año 2002 se han concedido subvenciones a 20 asociaciones de inmigrantes y 47 proinmigrantes. El importe global de la subvención ha sido de $1.852 .460,87 €$ que se han destinado a financiar 120 proyectos, asimismo se ha financiado por primera vez una asociaron "Mujeres entre Mundos" con una subvención de 6.010,12 € para la ejecución del programa "Integración laboral de la mujer inmigrante".

- En el año 2001 se subvencionaron 18 proyectos para el fomento del asociacionismo, por lo que esta año esta cifra ha aumentado considerablemente ya que se ha subvencionado 42 proyectos. Fueron beneficiarios de estas subvenciones 33 asociaciones de inmigrantes y 44 proinmigrantes, lo que supone un descenso de 13 asociaciones de inmigrantes subvencionadas respecto del año 2001, mientras que han aumento en 3 el número de asociaciones proinmigrantes. También aumento el volumen global de la subvención que en el año 2001 fue de $1.765 .779,50 €^{122}$.

\section{MEDIDA}

\subsubsection{Mantenimiento y equipamiento de dichas ONGs.}

- Mediante Convocatoria de ayudas de la D.G. de Bienestar Social se han otorgado subvenciones para mantenimiento y equipamiento a las 6 asociaciones de inmigrantes y 5 proinmigrantes para mantenimiento de sus sedes e infraestructuras, por un importe total de $118.681,81 €$, lo que supone un leve descenso respeto del año 2001, en el que se subvencionaron 8 asociaciones de inmigrantes y 10 proinmigrantes, por una cuantía total de $128.075,65 €$.

- Además, la D.G. de Coordinación de Políticas Migratorias complementa esta medida subvencionados dos acciones:

- Equipamiento General (informática, mobiliario y ofimática).

- Reforma y adaptación de locales ${ }^{123}$.

- Propuestas para el bienio 2003-2004. Incluir una nueva medida (4.2.5) que recoja las actuaciones especificas que realiza la Dirección General en el seno de esta medida ${ }^{124}$.

\footnotetext{
122 Vid. DTS/01, pág. 61 y DTS/02, págs. 167-172.

${ }^{123}$ Vid. DTS/02, págs. 173-174.

124 Vid. DTS 0/2 pág. 291.
} 


\section{MEDIDA}

\subsubsection{Encuentros y Jornadas entre Asociaciones.}

- En el año 2002 se celebró una Jornada sobre "Movimientos Migratorios" en Adra (Almería), dirigida a Asociaciones de Inmigrantes y de Emigrantes y Ayuntamientos, con el objetivo de ofrecer conocimientos actualizados sobre la realidad migratoria a la vez que se pretendía fomentar el asociacionismo y el intercambio de experiencias del colectivo inmigrantes y emigrantes. Dicha jornada fue organizada por la Delegación Provincial de la Consejería de Asuntos Sociales, en colaboración con el Ayuntamiento de Adra. Estaba dirigido a personas que trabajan en temas relacionados con la inmigración. Contó con 90 participantes de un abanico muy amplio: técnicos de Ayuntamientos, responsables de ONGs y sindicatos, mediadores7as interculturales etc., y supuso un coste total de $2.000,00 €^{125}$.

\section{MEDIDA}

4.2.4. Fomento del voluntariado social entre la población inmigrantes como herramienta y apoyo para su participación en asociaciones.

- La D.G. de Bienestar Social, a través de su convocatoria de ayudas públicas, ha subvencionado diversas asociaciones de inmigrantes para desarrollar programas que permitan fomentar el voluntariado social entre la población inmigrante.

- No se pueden ofrecer datos sobre asociaciones de inmigrantes que han incorporado voluntariado social inmigrantes, aunque, en el año 2001 fueron 6 y en el 2002 han sido 8 las asociaciones subvencionadas para poner en marcha esta iniciativa de incorporación. Los programas se han llevado acabo en las provincias de Cádiz, Jaén, Málaga y Sevilla ${ }^{126}$.

Objetivo específico 4.3. Ofrecer atención inmediata y ejercer la tutela de los menores extranjeros no acompañados.

ÓRGANO RESPONSABLE: CONSEJERÍA DE ASUNTOS SOCIALES. D.G. DE INFANCIA Y FAMILIA.

\footnotetext{
125 Vid. DTS/02, pág. 174.

126 Vid. DTS/02, pág. 175.
} 


\section{MEDIDA}

4.3.1. Confirmación previa y científicamente fiable de la presunta minoría de edad.

- Se ha producido un total de 1676 actuaciones de acogida inmediata a supuestos menores extranjeros no acompañados y se realizaron pruebas radiológicas para confirmar la minoría de edad de 1.256 de estas acogidas. En 420 de los casos no se práctico esta prueba debido a que, o bien se encontraban documentados y por tanto se confirma su edad sin necesidad de prueba alguna, o bien abandonaron voluntariamente el programa de acogida inmediata antes de que se les realizase la prueba.

- Del total de 1.676 acogidas inmediatas realizadas durante el año 2002, su distribución geográfica es la siguiente: en Almería se realizaron 146, en Cádiz 271; en Córdoba 123; en Granada 385; en Huelva 3; 42 en Jaén; en Málaga 516 y en Sevilla 190. Esta actuación es la primera asistencia para estos menores y se les apertura expediente administrativo. La media de edad de estos menores acogidos es de 15,6 años.

- En cuanto a la nacionalidad, predomina la Marroquí en un $85 \%$ de los casos, es decir, de los 1.676 nuevos expedientes aperturados en el año 2002, 1,425 corresponden a la nacionalidad Marroquí, 224 a menores procedentes de otros países africanos, 21 a países del Este y 6 Latinoamericanos. A su vez son mayoritariamente varones, tan sólo 34 de los expedientes corresponden a menores del sexo femenino.

- Este año se han realizado 282 actuaciones de acogida inmediata más que el año 2001, ya que de 1.394 practicadas en el año 2001 se ha pasado en este año a realizar 1.676 acogidas inmediatas. En cuanto a la media de edad se ha incrementado un año, pasando de 14,6 en 2001 a 15,6 de media de edad en $2002^{127}$.

\section{MEDIDA}

4.3.2. Atención inmediata del menor en un centro de primera acogida.

- La atención inmediata al menos en un centro de primera acogida supone la primera asistencia y atención del menos extranjero no acompañado. Dentro de este programa, desde que el menor es localizado y se ha comprobado su minoría de edad es la Junta de Andalucía la que asume la guarda administrativa del menor. Esta guar-

127 Vid. DTS/02, págs. 178-179. 
da no requiere declaración de desamparo previa, simplemente garantiza, de forma inmediata, la cobertura de las necesidades básicas del mismo en base a la Ley 1/1998 de los derecho y la atención al menor.

- El número total de atenciones realizadas en el año 2002 ha sido de $1.801,1676$ nuevas y 125 de menores que a 1 de enero de 2002 se encontraban en estos centros ${ }^{128}$. La estadía media en estos centros de acogida ha sido de 15 a 30 días. Comparando estos datos con los de el año 2001, se comprueba un descenso importante en las atenciones desde este programa, en la que se realizaron 2.929 atenciones. El descenso se debe a la mayor fluidez existente en la tramitación de otros programas, como es el de acogida en centro residencial básico.

- El año 2002 se realizaron 282 nuevas actuaciones más que en el 2001, ya que de 1.394 acogidas inmediatas en 2001 se ha pasado a $1676^{129}$.

- Propuesta para el bienio 2003-2004. Mejorar la Red de Acogida Básica, a través del Programa Europeo Interreg II cuya vigencia comprende hasta el año 2006. De forma más específica se pretende mejorar el equipamiento de los centros de acogida inmediata existente, ofrecer cursos de formación a los profesionales e introducir la figura del Mediador/a. También se pretende introducir mejoras en la guarda y atención de los menores, mediante la agilización de los trámites administrativo pertinentes, a lo que contribuirá el desarrollo del Protocolo de Menores No Acompañados ${ }^{130}$.

\section{MEDIDA}

\subsubsection{Apertura de un expediente de protección de menores.}

- Las actuaciones de acogida inmediata realizadas desde la Junta de Andalucía requieren un trámite administrativo. Se trata de la apertura del expediente de protección al menor, en el que se recogen todos los datos disponibles del menor y en le que se adjunta la prueba radiológica, si se le ha practicado, el centro en el que ingresa,

\footnotetext{
${ }^{128}$ En Almería se realizaron 162 atenciones a menores, en Cádiz 288, en Córdoba 126, en Granada 414, en Huelva 54, en Málaga 558 y en Sevilla 190.Vid. DTS/02, pág. 178.

${ }^{129}$ Vid. DTS/02, pág. 178.

${ }^{130}$ Vid. DTS/02, pág. 292.
} 
programas que se le aplican etc.; así como posibles abandonos voluntarios, reagrupación familiar, etc.

- El número de expedientes de protección de menores extranjeros no acompañados en el año 2002 coincide, como es lógico, con el numero de nuevas atenciones a menores, es decir, 1.676, lo que implica un aumento de 282 respecto del año 2001.

- La comparativa de estos resultados respecto a variaciones de nacionalidad, edad y sexo no se detectan cambios importantes ${ }^{131}$.

\section{MEDIDA}

4.3.4. Presentación personal del menor ante la Oficina Consular para su identificación y localización de su familia.

- Es preciso señalar que no todos los menores son presentados ante la Oficina Consular para su identificación y localización de su familia pues abandonan de forma voluntaria los Centros antes de proceder a este trámite. A estos hay que añadir los que cumplen la mayoría de edad antes de realizarlo y los que han comunicado en el momento de su ingreso que son menores y posteriormente se comprueba su mayoría de edad.

- En el año 2002 se han realizado 1.138 identificaciones, lo que supone un incremento respecto las 1.023 del año $2001^{132}$.

MEDIDA

4.3.5. Cuando sea posible la reagrupación del menor con su familia.

- Las actuaciones de la medida anterior tienen como finalidad la reagrupación del menor con su familia. La ejecución de esta medida corresponde a la Administración General del Estado, pero la Junta de Andalucía, como guardadora de los menores puede ofrecer datos de la reagrupación familiar que les consta según los expedientes administrativos.

- El total de las reagrupaciones familiares de menores tutelados por la Junta de Andalucía en el año 2002 ha sido de 181, algunos se ha reagrupado en su país de origen y otros en nuestro país dependiendo donde se encuentre la familia ${ }^{133}$.

${ }^{131}$ Vid. DTS/01, págs. 62 y DTS/02, pág. 179.

132 Vid. DTS/01, págs. 62 y DTS/02, pág. 179.

${ }^{133}$ La mayoría se ha reagrupado en España. Vid. datos sobre distribución geográfica de las reagrupación geográfica en Gráfico 4.3.5.1 PROVINCIAS DESDE LAS QUE SE REALIZARON LA REAGRUPACIÓN y Gráfico 4.3.5.2 TERRITORIOS DONDE SE PRODUJO LA REAGRUPACIÓN FAMILIAR. DTS/02, pág. 180. 


\section{MEDIDA}

4.3.6. Declaración formal de desamparo y la resolución de tutela.

- El en proceso de atención y guarda del menor, una vez que éste ha sido presentado ante la Oficina Consular para su identificación y se ha confirmado su situación de desamparo, la Junta de Andalucía procede a tramitar la declaración de desamparo y tutela. Trámite muy laborioso y que requiere la intervención de distintos profesionales que elaboren Informes preceptivos para emisión de la resolución administrativa.

- De un total de 1801 atenciones a menores durante el año 2002, se han emitido un total de 665 declaraciones de desamparo y resoluciones de tutela, que no se dicta por separado. El plazo para la emisión de estas resoluciones ha sido en general de dos a tres meses. Los datos señalados indican un descenso de 67 resoluciones de desamparo respecto del año 2001. las causan de esta disminución son varias. Agrupación familiar, abandonos voluntarios, adquisición de la mayoría de edad, edad ${ }^{134}$.

- Propuestas para el bienio 2003-2004: Desarrollo del Protocolo MENA (Menores Extranjeros No Acompañados) del Observatorio Nacional de la Información ${ }^{135}$.

Objetivo específico 4.4. Ejercicio de la guarda legal de los menores extranjeros no acompañados en los centros de protección de acogimiento residencial.

ÓRGANO RESPONSABLE: CONSEJERÍA DE ASUNTOS SOGIALES. D.G. DE INFANCIA Y FAMILIA

MEDIDA

4.4.1. Ejercicio de la guarda legal de los menores extranjeros no acompañados.

- El ejercicio de la guarda legal del menor por la Junta de Andalucía se inicia con la resolución administrativa de desamparo y tutela, resoluciones que como ya hemos señalado en la medida 4.3.6 ascendieron a 665. La media de edad de estos menores es de 15,6 años y su nacionalidad es marroquí en el $65 \%$ de los casos, datos muy similares al año 2001 en el que la edad media era 14,6\% años y el

\footnotetext{
134 Vid. DTS/01, pág. 62 y DTS/02, pág. 181.

135 Vid. DTS 0/2 pág. 292.
} 
95\% varón marroquí. Estas característica son comunes a la siguiente medida ${ }^{136}$.

MEDIDA

4.4.2. Desarrollo de un programa de primera acogida y acogida residencial para menores extranjeros.

- Una vez ofrecida la medida de protección necesaria para garantizar la guarda y custodia de estos menores, desde la Consejería de Asuntos Sociales y en colaboración de centros residenciales de atención al menor, así como de otras entidades implicadas, se promueve le desarrollo de programas específicos que favorecen la integración del menor en los distintos ámbitos sociales, como son: Programa de Primera Acogida, donde ingresan de forma inmediata los menores extranjeros no acompañados y Programa de de Acogida Residencia para menores extranjeros no acompañados que procedan del Programa de Primera Acogida. Los datos nos ofrecen una media mensual de 225 menores atendidos desde los Centros Residenciales y un total de 83.334 estancias en el año $2002^{137}$.

\section{MEDIDA}

\subsubsection{Programa de integración social y personal.}

MEDIDA

\subsubsection{Programa de educativo individual.}

\section{MEDIA}

\subsubsection{Programa de formación y reinserción profesional.}

- Cada menor atendido en centros ha tenido un programa de integración social y personal, cuyos objetivos formulados y actividades propuestas, responde a las necesidades del menor, desde el respeto a su cultura y forma de vida.

- Dentro del programa de integración social y personal, se desarrollan distintos proyectos y actuaciones. Unos de estos proyectos es el programa educativo individual. Aunque la elaboración de este proyectos es personal y adaptado a las características educativas de cada menor es habitual, en ciertos casos, complementarlo con distin-

\footnotetext{
136 Vid. DTS/02, pág. 182.

137 Vid. DTS/02, pág. 183.
} 
tas actuaciones de fomento educativo, destinadas a los menores que requieren de una serie de medidas específicas como es el aprendizaje de nuestra lengua. En el año 2002 se han realizado un 442 actuaciones de fomento educativo específicas, 5 más que las realizadas en el año 2001.

- Los Programas de formación y reinserción laboral están destinados a menores, mayores de 16 años, a fin de favorecer su acceso a mercado laboral desde una experiencia profesional. Dicho proyecto se realiza de forma individual y adaptado alas características del menor. En el año 2002 se han elaborado 215 programas de reinserción laboral, lo que implica un aumento de 5 respecto del año 2001. la media de edad de los menores ha sido de 17 años, en su mayoría varones marroquíes ${ }^{138}$.

Objetivo específico 4.5. Atención socioeducativa a los niños de 0 a 3 años de edad hijos de inmigrantes.

ÓRGANO RESPONSABLE: CONSEJERÍA DE ASUNTOS SOCIALES. D.G. DE INFANCIA Y FAMILIA

\section{MEDIDAS}

4.5.1. Atención a los menores de 0 a 3 años en horario continuado hasta los 5 de la tarde.

4.5.3. Programa de integración social para hijos de inmigrantes.

- La Red de Centros Socioeducativos Infantiles de la Junta de Andalucía ofrece servicios de atención socioeducativa a los niños de 0 a 3 años. Se está implantando, amparado en el Plan de Apoyo a las Familias andaluzas, la atención continuada desde las 7.30 a las 17:00 en los centros que lo han solicitado y reúnen las características requeridas. En el año 2002 se han beneficiado de este servicio 1.054 niños/as de 0 a 3 años, hijos de inmigrantes, lo que supone un importante aumento respecto del año 2001 en que fueron 650, lo que implica un aumento de 404 menores. Su distribución geográfica ha sido la siguiente en Almería han asistido 358 niños/as, en Cádiz 73, en Córdoba 50, en Granada 94, en Huelva 87 niños/as, 33 en Jaén, en Málaga 245 y 114 en Sevilla. Está prevista la creación renuevas plazas en zonas donde está aumentando la demanda.

138 Vid. DTS/02, pág. 183-184. 
- Para determinar el nivel de satisfacción de las familias se ha realizado una encuesta a 400 de estas familias. De estas encuestas se ha obtenido un resultado global de satisfacción respecto a los Centros, con una puntuación de 8.71 sobre 10 .

- A estos menores atendidos en Centros Socioeducativos Infantiles se les desarrolla programas educativos generales, adaptados a sus respectivas edades.

- No se ha puesto en marcha programas específicos de integración social para estos menores, ya que las actuaciones de integración social se llevan a cabo en de forma continuada a través del programa educativo individual, donde se tiene presente para su elaboración aspectos tales como la cultura, procedencia, la familia, etc. del niño $/ \mathrm{a}^{139}$.

Objetivo específico 4.6. Promover que los Cetros de Información Juvenil (C.I.J.) de las zonas con mayor incidencia de población inmigrante consigan integrar en sus respectivos grupos de corresponsales Juveniles a jóvenes inmigrantes.

\title{
ÓRGANO RESPONSABLE: CONSEJERÍA DE LA PRESIDENCIA. INSTITU- TO ANDALUZ DE LA JUVENTUD
}

\author{
MEDIDAS
}

4.6.1. Promover en el periodo 2001-2002 la extensión de la figura del Corresponsal Juvenil en aquellos C.I.J. de zonas geográficas con destacados porcentajes de población inmigrantes (principalmente comarcas del litoral andaluz y grandes ciudades).

- Se han producido contactos en la provincia de Almería con el C.I.J. de AJI-ATIME, en Puebla de Vícar, existiendo allí 2 Corresponsales. En Córdoba hay 3 (2 en Córdoba ciudad y 1 en Palma del Río). En Granada (Baza y Huétor-Tajas) se mantiene contacto a través de los servicios sociales municipales. Además el Corresponsal Juvenil tiene presencia en gran parte del territorio andaluz, en zonas donde es mayor la presencia de inmigrantes.

- Existen dificultades que no son exclusivas del fenómeno migratorio. La extensión de la red de corresponsales depende del nivel de compromiso con la realidad circundante de los jóvenes y que ellos

${ }^{139}$ Vid. DTS/02, págs. 185-186. 
se sientan protagonistas y capaces de aportar soluciones a los jóvenes inmigrantes ofreciéndose como valioso instrumento de información para la transformación social ${ }^{140}$.

- Propuestas para el bienio 2003-2004: Extender la red de corresponsales juveniles al máximo de CIJS, para así atender las nuevas necesidades que plantea el fenómeno de la inmigración ${ }^{141}$.

Objetivo específico 4.7. Facilitar el acceso de las mujeres inmigrantes a los recursos existentes para que puedan beneficiarse de ellos y mejorar así su condiciones de vida.

ÓRGANO RESPONSABLE: CONSEJERÍA DE LA PRESIDENCIA. INSTITUTO ANDALUZ DE LA MUJER.

MEDIDA

4.7.1. Facilitar información y asesoramiento psicológico, jurídico, de recursos sociales, de promoción y orientación laboral y formación de empleo.

- El Instituto Andaluz de la Mujer (IAM) cuenta con 8 Centros Provinciales de la Mujer y 165 Centro Municipales de Información a la Mujer. A través de ellos se ofrece a las mujeres que acuden información sobre los recursos existentes, así como asesoramiento, orientación psicológica, jurídica o laboral

- El IAM en colaboración con las Corporaciones Locales, cuenta con 123 Centros de Preformación para el empleo dirigidos a mujeres, independientemente de su procedencia geográfica.

- Durante el año 2002, a través de las aulas de informática se han realzado 178 cursos sobre Internet y correo electrónico. También se ha prestado un servicio de orientación universitaria a través de las Unidades de orientación para el empleo de Universitarias, así como servicios de acompañamiento a la creación y mejora de empresas a través de los centros VIVEM ${ }^{142}$.

- Propuestas para el bienio 2003-2004. Se continuará con la convocatoria de subvenciones, que permitirá aumentar la Red de Centros de Información a la mujer y servicios OPEM. También, se propone

\footnotetext{
${ }^{140}$ Vid. DTS/02, pág. 187.

141 Vid. DTS/02, pág. 293.

142 Vid. DTS/02, pág. 188.
} 
mejorar el sistema de información, incorporando incluso un nuevo indicador en esta medida relativo al numero de centros de orientación al empleo ${ }^{143}$.

MEDIDA

4.7.2. Subvención a ONGs con programas de ayuda a las mujeres inmigrantes.

- En el IAM a través de la convocatoria de ayudas destinadas a entidades sin ánimo de lucro, subvencionó 7 entidades que desarrollaron 5 programas para mujeres inmigrantes que por sus necesidades socioeconómicas y personales necesitan una atención especial, lo que implica aun aumento de 3 programas respecto del año 2001.

- La cuantía total de la subvenciones concedidas fue de $102.107,00 €$ frente a los $10.818,21 €$ del año anterior, teniendo en cuenta que en dicha cantidad se engloban el total del Objetivo $4.7^{144}$.

- Propuestas para el bienio 2003-2004: Realización del diseño y distribución de un folleto informativo sobre servicios que ofrece el Instituto Andaluz de la Mujer en al menos árabe, francés e inglés. Contemplado la posibilidad de incrementar los idiomas en los que se realiza dependiendo de la evolución de los flujos migratorios respecto a las nacionalidades de las mujeres que emigran a Andalucía ${ }^{145}$.

MEDIDA

4.7.4. Formación de mediadoras.

- En el año 2002 el IAM en colaboración con Mujeres Vecinales de Andalucía ha desarrollado un programa formativo dirigido a mujeres vecinales y mujeres inmigrantes sobre mediación intercultural para la prevención de la violencia hacia las mujeres.

- El programa se ha desarrollado en las 8 provincias andaluzas, celebrándose un total de 9 cursos, en lo que han participado 207 personas $^{146}$.

\footnotetext{
143 Vid. DTS/02, pág. 293.

144 Vid. DTS/02, págs. 188-189.

${ }^{145}$ Vid. DTS/02, pág. 293.

146 Vid. DTS/02, pág. 189.
} 
Objetivo específico 4.8. Facilitar la información y atención necesaria a las mujeres inmigrantes que en el seno de su pareja sufren violencia.

ÓRGANO RESPONSABLE: CONSEJERÍA DE LA PRESIDENCIA. INSTITUTO ANDALUZ DE LA MUJER.

\section{MEDIDA}

4.8.1. Informar y asesorar a las mujeres inmigrantes que hayan sido víctimas de violencia de género.

- El IAM a través de sus Centros Provinciales, sus Centros Provinciales de la Mujer y su teléfono 24 horas ha atendido un total de 280.115 consultas. Los datos se desglosan así: Las consultas en los Centros Provinciales de la Mujer han pasado de 32.101 en el 2001 a 46.403 en el año 2002, lo que implica aun aumento del 44,55\%. Respecto de los Centros Municipales de Información a la mujer, en el año 2001 se realizaron 202.576 consultas y 218.972 en el año 2002, lo que supone un incremento del 7,65\%. Finalmente, el Teléfono 900200999 paso de 11.969 atenciones en el año 2001 a 15.620 en el año $2002^{147}$. Por las características del servicio no procede en ese mismo instante solicitar datos de la nacionalidad.

\section{MEDIDA}

4.8.2. Acoger a las mujeres que hayan sido víctimas de violencia de género en Centros del Instituto Andaluz de la Mujer.

4.8.3. Integrarlas en programas específicos, de mujeres inmigrantes que hayan sufrido violencia de género, para facilitarles la adquisición de habilidades laborales y sociales que contribuyen a su autonomía.

- Los Servicios de acogida y atención a mujeres víctimas de malos tratos están dirigidos a toda mujer, independientemente de su nacionalidad y situación de regularización, siempre que sean víctimas de malos tratos y carezcan de medios económicos y apoyo social.

- El número de mujeres atendidas en centro para victimas de violencia de género en Andalucía durante año 2001 fueron 161 mujeres y 166 niños/as mientras que en el año 2002 ha sido de 217 y el de niño/as de 216, lo que implica aun incremento de un $34,25 \%$ y un $30,72 \%$ respectivamente.

- La mujeres inmigrantes atendidas en piso tutelados es de 9 y el niños/as asciende a 11, lo que hace un total de 20 persona en el

147 Vid. DTS/02, pág. 192. 
año 2002, mientras que en el año 2001 fueron de una mujer y un niño ${ }^{148}$.

- Todas las mujeres que lo soliciten pueden acudir a cursos de formación $^{149}$.

MEDIDA

4.8.4. Ayudas económicas para facilitar la integración social posterior.

- El IAM cuenta con una línea de ayudas económicas para la acogida al programa de atención a mujeres víctimas de la violencia de los malos tratos que carezcan de recursos económicos o sean inferiores al SMI.

- En el caso de las mujeres inmigrantes, cuando no cuentan con ningún tipo de documentación acreditativa, no pueden solicitar estas ayudas hasta que se gestiones y resuelve la solicitud de documentación. Este trámite se prolonga en el tiempo, evitando la fluidez administrativa propia en la gestión de este tipo de ayudas. Dado que esta situación es frecuente pues los compañeros retiene la documentación como medio de presión para evitar que les abandonen, han disminuido las ayudas durante el año 2002. Así mientras en el 2001 se concedieron 27 ayudas, en el año 2002 fueron $26^{150}$.

\section{MEDIDA}

\subsubsection{Programas de formación para el empleo.}

- Durante el año 2002 se ha desarrollado la 3a edición del Programa Cualifica en las 8 provincias andaluzas. En esta edición han participado 13 mujeres inmigrantes y han finalizado 11. La especial situación en que se encuentran estas mujeres hace que en algunos casos tengan que abandonar el programa al tener que ser trasladadas por que han sido localizadas por sus agresores ${ }^{151}$.

\footnotetext{
148 Vid. DTS /01, pág. 67 y DTS/02, págs. 192-93.

${ }^{149}$ Vid. DTS/02, págs. 194.

${ }^{150}$ Vid. DTS/02, págs. 194.

151 Vid. DTS/02, págs. 195.
} 
Objetivo específico 4.9. Asesorar, informar y acoger a mujeres inmigrantes que hayan sido víctimas de explotación sexual, para facilitarles la salida de esa situación poniendo en juego los recursos pertinentes.

ÓRGANO RESPONSABLES: CONSEJERÍA DE PRESIDENCIA (INSTITUTO ANDALUZ DE LA MUJER). CONSEJERÍA DE GOBERNACIÓN. CONSEJERÍA DE JUSTICIA Y ADMINISTRACIÓN PÚBLICA. CONSEJERÍA DE ASUNTOS SOCIALES.

\section{MEDIDA}

4.9.1. Atender a mujeres extranjeras víctimas del tráfico de personas para ser prostitutas.

- El Instituto Andaluz de la Mujer a través de su convocatoria de Ayudas a Entidades sin ánimo de lucro que desarrollan programas dirigidos a mujeres con especiales dificultades socioeconómicas, en el año 2002 concedió a 4 Entidades ayudas para desarrollar sus programas de acogida y atención integral a mujeres víctimas del tráfico de personas con fines de explotación social. Los programas financiados son: Programa de la Cruz Roja para atención y acogida a mujeres víctimas de tráfico de personas con fines de explotación social con cobertura regional y que cuenta con un equipo multidisciplinar para ofrecer una tención integral a las mujeres acogidas y que ha atendido a 21 mujeres. También se concedieron subvenciones a APRAMP, CARDINJ, AMMAR que dentro de los programas que desarrollan también atienden a mujeres extranjeras y que han atendido a 8,37 y 7 mujeres respectivamente ${ }^{152}$.

- Propuestas para el bienio 2003-2004: Se propone continuar con la convocatoria de ayudas a entidades sin ánimo de lucro que desarrollan programas dirigidos a mujeres en situación de exclusión social, adaptando la Orden que la desarrolla a las nuevas necesidades de atención social. También se continuará con la colaboración de la Cruz Roja Española para el desarrollo del programa de acogida y atención integral de las mujeres víctimas de tráfico de personas con fines de explotación social ${ }^{53}$.

152 Vid. DTS/02, págs. 196.

${ }^{153}$ Vid. DTS/02, pág. 294. 
MEDIDA

4.9.3. Formación a los Cuerpos y Fuerzas de Seguridad.

- Durante el año 2002 no se ha realizado ningún curso formativo dirigido en exclusiva a las fuerzas de Seguridad, ya que la formación de estos profesionales se planifica a la demanda de estos.

MEDIDA

4.9.4. Colaboración con ONGs que realicen programas dirigidos a la eliminación de este grave problema.

- En el año 2002 se han concedido ayudas a 7 ONGs para desarrollar programas dirigidos a mujeres víctimas del tráfico de personas, programas que tenían como objetivo ofrecer la acogida y atención, orientación sociosanitaria o formación e integración social ${ }^{154}$.

MEDIDA

4.9.5. Campaña de sensibilización social.

- El Encuentro Internacional sobre Tráfico de Mujeres y Explotación Sexual celebrado los días 23 y 24 de septiembre de 2002 en Málaga cumple un doble objetivo, formación y sensibilización. El objetivo último de este Encuentro -en el que participaron 300 personas procedentes de distintos contexto profesionales- era la sensibilizar a la sociedad y abrir el debate a los distintos ámbitos profesionales: Justicia, Salud, Fuerzas y Cuerpos de Seguridad, Servicios Sociales, Medios de Comunicación. Para desarrollar este objetivo se contó con expertos nacionales e internacionales ${ }^{155}$.

Objetivo específico 4.10. promover la participación social de la población inmigrante, con especial atención a los menores inmigrantes, haciendo de la práctica deportiva un instrumento de adquisición de valores tales como la solidaridad, la colaboración, el diálogo, la tolerancia, la no-discriminación y la igualdad.

ÓRGANO RESPONSABLE: CONSEJERÍA DE TURISMO Y DEPORTES.

MEDIDAS

${ }^{154}$ Vid. DTS/02, págs. 197.

155 Vid. DTS/02, págs. 197. 
4.10.1. Concesión de subvenciones a las ONGs, Ayuntamientos, Patronatos Municipales de Deporte, clubes deportivos y demás personas jurídicas sin ánimo de lucro.

4.10.2. Promoción de los programas deportivos que favorezcan la integración social de la población inmigrante.

4.10.3. Fomento de la integración, en el tejido asociativo deportivo andaluz, de la población inmigrante.

- En el año 2002, la Consejería de Turismo y Deporte, mediante la convocatoria de subvenciones ha colaborado mediante un total de $19.230,55 €$ en la financiación de los programas deportivos de 17 entidades locales donde asistieron un total de 2.174 participantes ${ }^{156}$ y un total de $10.575,2 €$ de subvención a 10 clubes deportivos, ONGs u otras personas jurídicas sin ánimo de lucro, donde se cuantificaron un total de 389 participantes ${ }^{157}$. En total han participado 27 entidades, la cuantía financiada ha sido de $29.805,75 €$ y han sido 2.563 participantes, mientras que en el año 2001 fueron 26 entidades, la cantidad financiada fue de 26.961, $41 €$ y participaron 1.074 inmigrantes.

- Cabe señalar que aunque se ha ejecutado casi en totalidad la cantidad presupuestada, el bajo nivel de demanda no ha cubierto las expectativas de la misma, incidiendo en la distribución de los recursos previstos. También se ha producido algunas incidencias que han repercutido en la gestión de ayudas, como son: Falta de documentación, renuncias posteriores a la solicitud, falta de requisitos, etc. ${ }^{158}$.

- Propuestas para el bienio 2003-2004: Se pretende seguir con la misma línea de trabajo. Sin embargo, tras la evaluación del primer bienio, para mejorar posteriores evaluaciones por cuestiones técnicas, se propone modificar la redacción de las medidas para el cumplimento del objetivo 4.10; concretamente desaparecería la medida 4.10.1 en su forma actual, y las medidas 4.10 .2 y 4.10 .3 pasarían a ser las medidas 4.10.1 y 4.10.2. respectivamente con una nueva redacción ${ }^{159}$.

\footnotetext{
${ }^{156}$ Vid. datos desglosado por provincias en Tabla 4.10.1.1. FINANCIACIÓN DE PROGRAMAS DEPORTIVOS EN ENTIDADES LOCALES, en DTS/02, págs. 199.

157 Vid. datos desglosados en TABLA 4.10.1.2 FINANCIACIÓN DE PROGRAMAS DEPORTIVOS DE CLUBES DEPORTIVOS, ONGS Y OTRAS PERSONAS JURÍDICAS SIN ÁNIMO DE LUCRO, en DTS/02, pág. 199.

158 Vid. DTS/01, pág. 69 y DTS/02, págs. 198.-200.

${ }^{159}$ Vid. DTS/02, pág. 294.
} 


\section{5. Área de Intervención DE VIVIENDA}

- El acceso a una vivienda digna es una de las necesidades básicas inherentes a las personas y a las familias. Por ello, desde el Área de intervención de Vivienda se establecen medidas encaminadas a favorecer que la población inmigrante acceda a la vivienda en iguales condiciones que la población autóctona, ya sean temporeros o inmigrantes residentes en zonas urbanas. La ausencia de unas condiciones mínimas de habitabilidad es, en muchos casos, origen de situaciones de exclusión.

Objetivo específico 5.1. Favorecer la promoción de viviendas y alojamientos en condiciones adecuadas para trabajadores inmigrantes temporeros en el ámbito de la Comunidad Autónoma de Andalucía, así como apoyar el acceso de la población inmigrante para la obtención de créditos hipotecarios destinados a la adquisición de viviendas.

\section{ÓRGANOS RESPONSABLE: CONSEJERÍA DE OBRAS PÚBLICAS Y TRANSPORTES.}

MEDIDA

5.1.1. Ayudas a fondo perdido por un valor equivalente al $30 \%$ del valor de la ejecución de la promoción, así como la subsidiación del $50 \%$ de la cuota del préstamo hipotecario.

- A través del Decreto 2/2001 se regulan y convocan ayudas a la promoción de viviendas en alquiler destinados a alojar trabajadores temporales en municipios de alta movilidad laboral. Dicho Decreto tiene como finalidad el fomento de la promoción de viviendas en arrendamiento y de toros alojamientos integrados por "unidades habitaciones" que constituyen la fórmula intermedia entre vivienda individual y residencia colectiva.

- Las actuaciones objeto de dicho Decreto se desarrollan conforme al Plan Andaluz de Vivienda y Suelo y se realiza a través de los Ayuntamientos, que actúan como promotores públicos, y otras entidades y organizaciones que lo hacen como promotores privados, todo ello bajo la supervisión y control de la Comisión de Evaluación y Seguimiento integrada en la Junta de Andalucía.

- Finalmente, hay que destacar las dificultades existentes para la puesta en marcha de las promociones: suele haber problemas urbanísticos en la cesión del suelo, la documentación presenta deficiencias, escaso número de solicitudes presentadas por promotores públicos o privados. 
- En el año 2002, se encuentran en distintas fases de ejecución un total de 24 solicitudes de ayudas para la promoción de ayudas a promociones para temporeros, con un total de 1.468 plazas. De este total de 24 promociones 21 fueron presentadas en el año 2001 / 1.319 plazas) y las 3 restantes (149 plazas) en el año $2002^{160}$.

- Propuestas para el bienio 2003-2004. Debido a la modificación del Decreto para el año 2003, se propone modificar la medida en los porcentajes de ayuda hasta los siguientes tramos: Ayudas a fondo perdido por un valor equivalente al 35\% (antes 30\%) del valor de la ejecución de la promoción, así como la subsidiación de $50 \%$ de la cuota del préstamo hipotecario durante los cinco primeros años y del $40 \%$ el resto hasta los veinticinco años ${ }^{161}$.

Objetivo específico 5.2. Promover el alojamiento temporal o normalizado de la población migrante.

\section{ÓRGANO RESPONSABLE: CONSEJERÍA DE ASUNTOS SOCIALES. D.G.} DE BIENESTAR SOCIAL

\section{MEDIDA}

5.2.1. Apoyo al alojamiento normalizado de aquellos inmigrantes y sus familias asentados de forma regular y estable en Andalucía e intermediación para el acceso a la vivienda.

- La contribución de la D.G. de Bienestar Social ha sido fundamental a la hora de apoyar el acceso a la vivienda de los población inmigrante, para ello se ha subvencionado distintas asociaciones cuyo objeto es la mediación en materia de vivienda e integración social, así como la intermediación en el alquiler de pisos para inmigrantes. Las actuaciones se han realizado en las provincias de Almería, Jaén, Málaga y Sevilla y la cuantía de las subvenciones ha ascendido a un total de $60.575,91 €$

- También se ha firmado 2 convenios de colaboración, concretamente uno entre el Instituto de Migraciones y Servicios Sociales la Consejería de Asuntos Sociales de la Junta de Andalucía para el desarrollo de actuaciones conjuntas en materia de acogida básica de inmigrantes, y otro entre el Ministerio de Trabajo y Asuntos Sociales

\footnotetext{
160 Vid. datos desglosados por provincias en DTS/02, págs. 204-205.

161 Vid. DTS/02, pág. 295.
} 
y la Consejería de Asuntos Sociales de la Junta de Andalucía para el desarrollo de actuaciones conjuntas en materia de atención a inmigrantes, refugiados, solicitantes de asilo y desplazados ${ }^{162}$.

MEDIDA

5.2.2. Refuerzo del alojamiento temporal en zonas donde se desarrollan campañas agrícolas de temporada.

- Durante el año 2002 se ha concedido un subvención total de $848,202,33 €$ a distintas entidades públicas, ONGs u otras entidades sin ánimo de lucro para el refuerzo de alojamiento (servicios de ducha, lavandería, comida, dormitorio) que se han distribuido entre 34 centros con un total de 935 plazas, distribuidos por todas las provincias andaluzas excepto Málaga. Mientras que en el año 2001, fueron 32 los centros con un total de 488 plazas, lo que indica el esfuerzo de adaptación a los nuevos entornos que se está realizando desde la Junta de Andalucía.

- También se tuvo que hacer frente a una situación imprevista en la provincia de Huelva debido a que gran parte de los inmigrantes que acudieron a la recogida de la fresa se encontraron que no había trabajo inmediato, por lo que se encontraron sin recursos económicos para subsistir. Este hecho llevo a la Junta de Andalucía poner en marcha el Plan Humanitario de Emergencia Social destinado a proporcionar atención básica a estos inmigrante. Para ello se firmo un Convenio de Colaboración con CÁRITAS DIOCESANA DE HUELVA a la que se le concedieron $180.210,00 €$ y con la CRUZ ROJA DE HUELVA a la que se concedieron 26.520,00€.

- Además se concedió una subvención de carácter supraprovincial por importe de 30.050,61 € a COAG "Andalucía" para financiar el Proyecto de alojamiento para trabajadores temporeros inmigrantes ${ }^{163}$.

- Finalmente, se ha subvencionado con 284.614,00 € la Rehabilitación, equipamiento y reformas de albergues localizados principalmente en Jaén para la recogida de aceituna, en Huelva para la fresa, en Granada para las hortalizas y en Almería para la alojamiento de temporeros, lo que supone un aumento respecto los $14 \mathrm{del}$ año 2001, en el que se repartieron subvenciones por un total de $301.227,14 €^{164}$.

${ }^{162}$ Vid. DTS/02, pág. 206.

163 Vid. DTS/02, págs. 207-210. 
- Propuestas para el bienio 2003-2004: Incluir la redacción de una nueva medida (5.2.7) que recoja las actuaciones de la Dirección General en esta materia ${ }^{165}$.

\section{MEDIDA}

5.2.3. Primera acogida en zonas costeras fronterizas.

- La primera acogida en zonas costeras fronterizas se realiza en Cádiz, en concreto en Tarifa y municipios limítrofes, aunque se extiende puntualmente a toda la costa gaditana.

- Durante el año 2002, la Red de Acogida de la Diputación de Cádiz ha realizado actuaciones en la playas gaditanas y ha atendido a 3.892 personas, para lo que contó con una subvención de 18.030,36€ y la Red de Acogida de la asociación CARDINJ ha gestionado 10 centros de acogida para lo que ha contado con una subvención de 45.166,06 €. En total fueron atendidas 4.978 personas entre las dos redes de acogida ${ }^{166}$.

\section{MEDIDA}

\subsubsection{Apoyo al alojamiento en pisos tutelados por Entidades Colaboradoras y} por Corporaciones Locales.

- Durante el año 2002, se ha subvencionado con un total $669.780 € 8$ pisos tutelados gestionados por entidades colaboradoras y 12 por corporaciones locales, siendo la distribución geográfica de estos recursos las provincias de Almería, Huelva, Málaga y Sevilla, como lugares de acogida, así como un proyecto de atención en origen, concretamente una casa de acogida de menores en Tetuán (Marruecos) ${ }^{167}$.

\section{MEDIDA}

5.2.5. Terminar la construcción de un albergue para temporeros en Zafarraya (Granada) de 80 plazas.

5.2.6. Construcción de un albergue de temporeros en Jaén capital de 50 plazas. - Ambos proyectos fueron terminados en el año $2001^{168}$.

\footnotetext{
${ }^{164}$ Vid. DTS/02, pág. 212.

165 Vid. DTS/02, pág. 296.

166 Vid. DTS/02, pág. 210.

${ }^{167}$ Vid. datos concretos sobre lugares de distribución de estos pisos tutelados, DTS/02, págs.

168 Vid. DTS/02, pág. 211.
} 210-211. 


\section{6. Área de Intervención SOCIO-CULTURAL}

Avanzamos hacia una sociedad andaluza intercultural y multiétnica que necesita de la aportación de hombre y mujeres de todas las culturas. Desde esta área se establecen mecanismos que favorecen la creación de espacios óptimos para la práctica y difusión de las diferentes cultural, la interacción entre las mismas basada en la comprensión y aceptación mutua, teniendo en cuenta la cultura constituida por un grupo de creencias, conocimiento, arte, valores derechos, moral, etc.

Objetivo específico 6.1 ofrecer y asegurar el acceso de la población inmigrante y minorías éticas y lingüísticas a un servicio bibliotecario al mismo nivel que el resto de los ciudadanos, facilitándoles materiales y servicios adecuados a sus necesidades, favoreciendo el conocimiento de su cultura por parte del resto de los sus usuarios de las bibliotecas municipales y fomentando el uso de la Biblioteca Pública como lugar de encuentro e intercambio cultural.

\section{ÓRGANO RESPONSABLE. CONSEJERÍA Y RESULTADOS OBTENIDOS}

MEDIDA

6.1.1. Puesta en marcha de cinco bibliotecas interculturales con fondos específicos (libros, música, videos CDs, materiales infantiles adaptados, revistas, periódicos...).

- Continuando con las actuaciones realizadas en el año 2001, en el año 2002 se han realizado diversas actuaciones para la puesta en marcha de una de las bibliotecas interculturales proyectadas, en concreto, la ubicada en el Albaycín, en la provincia de Granada.

- Las otras cuatro bibliotecas continúan en fase de diseño, siendo el bienio 2003.04 el momento de la puesta en marcha de los proyectos ${ }^{169}$.

- Propuestas para el bienio 2003-2004: Inauguración de la Biblioteca Pública del Albaycín; Realización de convenios de colaboración con los Ayuntamientos que participan en el proyecto, de modo que pueda garantizarse la continuidad del mismo; Convenios de colaboración con las bibliotecas públicas municipales del Albaycín (Granada) y Lepe (Huelva); Adquisición de la colección documental para las bibliotecas de Almería y Lepe; Establecimiento de un calendario

169 Vid. DTS/02, págs. 215-216. 
de reuniones sobre bibliotecas multiculturales para planificar las actuaciones en las bibliotecas de Almería, Huelva y Lepe; Realización de un estudio y establecimiento definitivo de los parámetros bibliotecarios que han de regir las prestaciones del servicio en las bibliotecas multiculturales: tipo de señalización, disposición de los fondos dentro de la colección global de la biblioteca, etc ${ }^{170}$.

\section{MEDIDA}

6.1.2. Localización de las zonas geográficas de actuación haciendo hincapié en las ciudades donde la población inmigrante y minorías étnicas y lingüísticas significativas.

- Durante el año 2002 se ha continuado realizando un estudio demográfico de la población extranjera en Granada, Almería. Huelva, Lepe (Huelva), La Mojonera (Almería) y Alcalá la Real (Jaén). Para determinar las características de la población residente en estos municipios se ha tenido en cuenta, entre otras variable, la procedencia de la población extranjera así como los grupos de edad y sexo. Para ello se analizaron distintas fuentes, tales como D.G. de Policía del Ministerio del Interior y el Anuario de Extranjería; el Censo de Población, el padrón Municipal, el Ministerio de Trabajo y Asuntos Sociales... ${ }^{171}$

- Propuestas para el binomio 2003-2004: Se procederá a la elaboración de un estudio sobre usuarios de las bibliotecas que integren a las distintas minorías culturales determinado su tipología y necesidades ${ }^{172}$.

\section{MEDIDA}

6.1.4. Realización de cursos de formación de los responsables bibliotecarios que van a desarrollar el programa en las bibliotecas.

- Aun no habiendo sido posible la realización de los cursos de formación que recoge esta medida, en el año 2002 se ha realizado algunas actuaciones tales como preparación de los contenidos formativos, selección del profesorado que impartirá el curso de formación y selección de los bibliotecarios municipales que podrían asistir al curso ${ }^{173}$.

\footnotetext{
${ }^{170}$ Vid. DTS/02, pág. 296.

171 Vid. DTS/02, pág. 216.

172 Vid. DTS/02, pág. 297.

173 Vid. DTS/02, pág. 216.
} 
- Propuestas para el bienio 2003-2004: realización de los cursos de formación ${ }^{174}$.

MEDIDA

6.1.5. Formación de la colección, haciendo especial hincapié en los fondos infantiles y juveniles e incorporando toda clase de soportes.

- En el año 2002 se han adquirido los fondos para la Biblioteca del Albaycín. La adquisición de fondos documentales va en función de las características de la población donde se va a poner en marcha la biblioteca, en este caso gira sobre el Al-Andalus. Hay que resaltar la dificultad para la obtención de estos fondos debido a los pocos proveedores a nivel nacional en este tipo de colecciones ${ }^{175}$.

- Propuestas para el bienio de 2003-2004: Adquisición de fondos para las bibliotecas de Almería, Huelva, Lepe, La Mojonera y Alcalá la Real, con ello se pretende mantener la colección viva ${ }^{176}$.

MEDIDA

6.1.6. Creación de una página Web sobre recursos electrónicos de interés para poblaciones multiculturales.

- En el año 2002 se ha realizado el estudio y diseño de páginas Webs sobre recursos multiculturales, analizándose contenidos, estructuras, enlaces, sistemas de comunicación con usuarios/as y otros aspectos de interés.

- Se ha realizado el diseño y dotación de contenidos de la página Web con recursos de información para minorías étnicas, lingüísticas y culturales de Andalucía ${ }^{177}$.

- Propuestas para el bienio 2003-2004: finalización del estudio, contenido y epígrafes de la página. Por otro lado se pondrá en marcha la página en Internet, haciéndola accesible desde el servicio de la $\mathrm{Bi}$ blioteca de Andalucía. Finalmente se procederá a la actualización de los contenidos y enlaces, así como de los resultados disponibles ${ }^{178}$.

\footnotetext{
${ }^{174}$ Vid. DTS/02, pág. 297.

175 Vid. DTS/02, pág. 217.

176 Vid. DTS/02, pág. 297.

177 Vid. DTS/02, pág. 217.

178 Vid. DTS/02, pág. 297.
} 


\section{MEDIDA}

6.1.7. Difusión de los servicios bibliotecarios mediante la edición de hojas y folletos informativos y guías de uso en las distintas lenguas de origen del usuario.

- Se ha diseñando un folleto explicativo para la difusión de las bibliotecas multiculturales en Andalucía y se ha traducido a los siguientes idiomas: árabe, ruso, francés e inglés.

- También se han traducido las guías informativas de las bibliotecas provinciales de Huelva y Almería y se ha recomendado a las biblioteca municipales que también lo hagan ${ }^{179}$.

- Propuestas para el bienio 2003-2004: Elaboración de un plan de actividades para las bibliotecas multiculturales, así como la puesta en común del plan de actividades con las bibliotecas integradas en el proyecto ${ }^{180}$.

Objetivo específico 6.2. promover la integración de jóvenes inmigrantes en Asociaciones Juveniles andaluzas ya existentes.

ÓRGANO RESPONSABLE: CONSEJERÍA DE LA PRESIDENCIA. INSTITUTO ANDALUZ DE LA JUVENTUD.

MEDIDA

6.2.1. Divulgación entre los colectivos de jóvenes inmigrantes de las asociaciones juveniles existentes, de las actividades organizadas y de la manera de establecer contacto con las mismas.

\section{MEDIDA}

6.2.3 Sensibilización de las asociaciones juveniles para que promuevan, acepten y faciliten la incorporación de los jóvenes inmigrantes a las mismas como una vía de conocimiento, intercambio y enriquecimiento mutuo

6.2.4. Facilitación de ayudas económicas a través de la correspondiente convocatoria pública a las asociaciones que promuevan la participación de los jóvenes inmigrantes en todo tipo de actividades culturales.

- Teniendo en cuenta la importancia del tejido asociativo en la integración de los jóvenes en Andalucía, independientemente de su procedencia, y desde la experiencia acumulada durante el año 2001, el año 2002 se ha realizado las siguientes actividades.

\footnotetext{
179 Vid. DTS/02, pág. 218.

180 Vid. DTS/02, pág. 297.
} 
- A las personas y colectivos interesados se le ha facilitado una relación de las asociaciones y actuaciones que vienen realizando y que ha sido subvencionadas por el IAJ

- Se ha subvencionado aquellas asociaciones con proyectos que contribuían a la participación de jóvenes en la vida social. En concreto se han subvencionado 39 asociaciones de ámbito regional de las cuales 3 actúan específicamente con colectivo de jóvenes inmigrantes.

- Mediante las actuaciones en materia de sensibilización -que no programas específicos, ya que se considera que todas las asociaciones son objeto de programa de sensibilización- se han subvencionado 279 proyectos de asociaciones, de las cuales 39 son de ámbito regional y 240 de ámbito provincial

- El número estimado de jóvenes inmigrantes asociados se estima entorno a 2700 según se desprende de las memorias presentadas por las diversas asociaciones.

- Fueron subvencionadas las asociaciones de aquellas asociaciones que presentaron proyectos que promovían la participación de jóvenes inmigrantes, tanto en asociaciones de inmigrantes -se subvencionaron 3 en el año 2002, frente a 5 del año 2001- como aquellas cuyos miembros no son inmigrantes pero cuyas actuaciones van dirigidas a este colectivo ${ }^{181}$.

- Propuestas para el binomio 2003-2004: Para realizar la difusión de la Red de Centros de Información Juvenil entre los colectivos de jóvenes inmigrantes como medio de acceder a una información sobre la oferta sociocultural existente en su entorno, se propone mejorar la información sobre los objetivos que se pretenden conseguir con su ejecución en los colectivos objeto de la medida. Se propone también realizar una Campaña de Sensibilización desde el IAJ a las asociaciones para que dirijan sus actuaciones hacia la integración de los inmigrantes ${ }^{182}$.

Objetivo específico 6.3. Promover la participación de los jóvenes inmigrantes en los programas europeos.

ÓRGANO RESPONSABLE: CONSEJERÍA DE LA PRESIDENCIA. INSTITUTO ANDALUZ DE LA JUVENTUD.

\footnotetext{
181 Vid. DTS/02, págs. 219-221.

182 Vid. DTS/02, pág. 297.
} 


\section{MEDIDA}

6.3.1. Información y motivación entre la comunidad de inmigrantes andaluces, a través de sesiones informativas del Programa de la Juventud mediante acciones entre el Instituto Andaluz de la Juventud y los Centros de Información Juveniles de Andalucía.

- Las actuaciones específicas de información dirigidas a la comunidad de inmigrantes andaluces del programa Comunitario de Juventud no pueden ser determinas de forma directa dada su amplitud. No obstante se subvencionaron 7 encuentros informativos, aunque ninguno de ellos tuvo como destinarlos exclusivos a los jóvenes inmigrantes. En estos encuentros han participado 198 personas según datos aportado en las memorias de gestión ${ }^{183}$.

Objetivo específico 6.4. Fomentar el asociacionismo de las mujeres inmigrantes para promover su participación y facilitar su integración en las asociaciones de mujeres existentes en Andalucía como medio de acceso al conocimiento de la cultura de la sociedad de acogida e integración en la misma.

ÓRGANO RESPONSABLE: CONSEJERÍA DE LA PRESIDENCIA. INSTITUTO ANDALUZ DE LA MUJER.

\section{MEDIDAS}

6.4.1 Divulgación, entre los colectivos de mujeres inmigrantes de las asociaciones de mujeres existentes, de las actividades por ella organizadas y de la manera de establecer contacto con las mismas.

6.4.2. Difusión de la Red de Centros de Información de la Mujer.

6.4.3. Potenciación de los programas de las asociaciones de mujeres que favorezcan la integración de mujeres inmigrantes.

6.4.4. Facilitar ayudad económicas, a través de la correspondiente convocatoria pública, a las asociaciones de mujeres.

6.4.5. Formación en género a las agentes mediadoras interculturales.

6.4.6. Fomentar las redes de ayudas mutuas entre mujeres.

- El IAM a través de sus Centros Provinciales cuenta con un área de participación social que ofrece, asesoramiento y apoyo a aquellos colectivos de mujeres que quieran asociarse, además de fomentar el encuentro entre asociaciones de mujeres. En este contexto ha desarrollado el programa "Encuentros de Asociaciones de Mujeres, conociendo Andalucía”.

183 Vid. DTS/02, pág. 221. 
- El IAM cuenta con 8 Centros Provinciales de Información a la Mujeres, sitos en las capitales provinciales, al mismo tiempo, en el año 2002 ha sido 165 las corporaciones locales subvencionadas que tiene Centros Municipales de Información a la Mujer. Junto con estos centros, el IAM cuenta con el Servicio Telefónico 24 horas que ofrece información sobre programas y servicios del IAM todos los días del año y a cualquier hora. También se han remodelado la información de la página Web del Instituto Andaluz de la Mujer, para que sea más accesible a las mujeres inmigrantes.

- En el año 2002 el IAM ha subvencionado 11 asociaciones de mujeres integradas totalmente por inmigrantes o donde participan mujeres inmigrantes.

- Durante el año 2002 se han realizado en las 8 provincias andaluzas un total de 9 cursos de formación en mediación intercultural para la prevención y atención a mujeres víctimas de malos tratos, en los que se ha formado un total de 207 personas.

- El IAM fomenta a través de sus programas de participación social la creación de asociaciones de mujeres. Así en el año 2002 se ha colaborado con 11 asociaciones de mujeres inmigrantes que dentro de sus actividades han potenciado el desarrollo de redes de ayuda mutua, frente a las 7 que colaboraron en el año $2001^{184}$.

\section{7. Área de Intervención de ATENCIÓN JURÍDICA}

Una de las funciones traspasadas por el Estado mediante Real Decreto 142/1997, de 31 de enero, en materia de provisión de medios materiales y económicos para el funcionamiento de la Administración de Justicia, es el concerniente al reconocimiento del derecho a la asistencia gratuita y la gestión de las indemnizaciones de las actuaciones correspondientes a la defensa por Abogado y representación por Procurador de los Tribunales en turno de oficio ante los órganos judiciales con sede en la C.A. de Andalucía, y la asistencia letrada al detenido o preso cuando el lugar de custodia este situado en territorio de la C.A. de Andalucía. Dichas funciones ha sido asignadas a la Consejería de Justicia y Administración Pública por Decreto 139/200, de 31 de enero.

${ }^{184}$ Vid. DTS/02, págs. 222-225. 
Objetivo específico 7.1. Posibilitar el ejercicio del derecho a la tutela judicial efectiva de los extranjeros y prestación de asistencia legal.

ÓRGANO RESPONSABLE: CONSEJERÍA DE JUSTICIA Y ADMINISTRACIÓN PÚBLICA. D.G. DE INSTITUCIONES Y COOPERACIÓN CON LA JUSTICIA.

MEDIDA

7.1.1. Creación de un punto avanzado a desplazados extranjeros en Tarifa y Campo de Gibraltar, demandantes de asilo, mediante la suscripción de un Convenio específico entre la Consejería de Justicia y Administración Publica y la Comisión Española de Ayuda al Refugiado (CEAR/Sur).

- En el año 2001 se creo el Punto Avanzado a desplazados extranjeros en Tarifa-Campo de Gibraltar, mediante la suscripción de un convenio entre la Consejería de Justicia y Administración Pública y CEAR/Sur. Desde ese punto se atendió a 53 demandas de asilo y 800 demandas genéricas contando para ello con 1 letrado en ejercicio y 3 letrados voluntarios. En el año 2002 se atendió a 1132, contando para ello con 4 letrados adscritos al Punto Avanzado.

- En el año 2002 el número de asistencias realizadas a extranjeros detenidos en comisarías de policía y juzgados han sido 166 y no se ha realizado recurso alguno en vía administrativa en materia de extranjería desde el Punto Avanzado. Por el contrario se han presentado 157 recursos en vía contencioso-administrativa ${ }^{185}$.

- Propuestas para el bienio 2003-2004: ampliación de los Puntos Avanzados en aquellos municipios que en estos momentos estén recibiendo un número mayor de desplazados. Además se pretende ampliar la atención jurídica a Granada y Almería ${ }^{186}$.

\section{MEDIDA}

7.2.2. Incremento y revisión del número de Letrados adscritos al turno de oficio y al servicio de asistencia letrada al detenido.

- Dentro del turno de oficio y el servicio de asistencia letrada al detenido de las distintas provincias andaluzas se ofrece prestación jurídica con objeto de cubrir el derecho a la tutela judicial efectiva de aquellas personas que no son de nacionalidad española.

\footnotetext{
185 Vid. DTS/01, pág. 82 y DTS/02, pág. 227.

${ }^{186}$ Vid. DTS/02, pág. 298.
} 
- En el año 2002, desde el turno de oficio y asistencia letrada al detenido se han realizado 7.838 recursos en vía administrativa, en materia de extranjería, frente a los 8.384 recursos presentado en el año 2001. Respecto de los recursos en vía contenciosa administrativa en el año 2002 se tramitaron 3.143 expedientes frente a los 3.148 que se tramitaron en el año $2001^{187}$.

- El número de letrados adscritos al turno de oficio y servicio de asistencia letrada al detenido se ha incrementado en 13 personas en el año $2002^{188}$.

Objetivo específico 7.2. Posibilitar el asesoramiento jurídico e información integral a inmigrantes.

ÓRGANO RESPONSABLE: CONSEJERÍA DE JUSTICIA Y ADMINISTRACIÓN PÚBLICA. D.G. DE INSTITUCIONES Y COOPERACIÓN CON LA JUSTICIA.

MEDIDAS

7.2.1. Diseño de una Red de Atención Jurídica Integrada para inmigrantes.

7.2.2. Creación de un Servicio de Orientación Jurídica a extranjeros en colegios de Abogado de Málaga y Sevilla.

- El Servicio de Orientación Jurídica a extranjeros del Colegio de Abogados de Sevilla (SAOJI) comenzó su funcionamiento en mayo de 2001. Desde ese momento ha venido funcionando con normalidad y ha servido de experiencia para poner e marcha el Servicio de Orientación Jurídica a extranjeros del Colegio de Abogados de Málaga (SOJE), que entró en funcionamiento en enero de 2002, momento en el que se puso un marcha un curso de acceso a la especialidad de extranjería de 25 horas de duración para los letrados/as adscritos.

- Igual que ocurrió en el año 2001, el Servicio de Orientación Jurídica a extranjeros, las atenciones que se han realizado han sido de diversa índole, siendo las consultas sobre el permiso de trabajo y residencia las más frecuentes, seguidas de las consultas sobre expulsión.

187 Vid. datos desglosados por provincias en GRÁFICOS 7.1.2. 1 RECURSOS EN VÍA ADMINISTRATIVA EN ANDALUCÍA SEGÚN PROVINCIAS. AÑO 2002 y 7.1.2.2 RECURSOS EN VÍA CONTENCIOSO-ADMINISTRATIVAS SEGÚN PROVINCIA. AÑO 2002, en DTS/02, pág. 229.

188 Vid. DTS/01, pág. 82 y DTS/02, pág. 228. 
El total de consultas atendidas por SOEJI en el año 2002 han sido 501 y desde el SOJE $970^{189}$.

\section{8. Área de Intervención de FORMACIÓN E INVESTIGACIÓN}

El carácter dinámico del hecho migratorio requiere un sistema de seguimiento, estudio e investigación de los diversos factores y condicionantes que producen estos cambios, incluso que posibiliten conocer las previsiones y tendencias de la inmigración. Conocer la realidad de la inmigración a tiempo real permite estructurar, priorizar o canalizar actuaciones en todos los ámbitos intervinientes en este fenómeno, dado el carácter transversal de esta área respecto de las demás áreas del Plan.

Objetivo específico 8.1. conocer la realidad de la inmigración en Andalucía, de los factores que determinan y sus repercusiones, así como de su evolución en el ámbito autonómico, provincial y local.

\section{ÓRGANO RESPONSABLE: CONSEJERÍA DE GOBERNCIÓN. D.G. DE CO- ORDINACIÓN DE POLÍTICAS MIGRATORIAS.}

\section{MEDIDA}

8.1.1. Promoción de la actividad investigadora sobre el fenómeno de la inmigración.

- La D.G. de Coordinación de Políticas Migratorias ha promovido y subvencionado la realización de 15 actuaciones de estudio e investigación durante el año 2002, 7 desde el Servicio de Estudios y Planificación y 8 desde el Servicio de Coordinación y Relaciones Institucionales, frente a 12 estudios e investigaciones promovidas y subvencionadas en el año $2001^{190}$.

\section{MEDIDA}

8.1.2. Desarrollo y coordinación del Observatorio Permanente Andaluz de las Migraciones (OPAM) con la función de aglutinar y difundir información cuantitativa y cualitativa existente sobre el fenómeno y su evolución.

\footnotetext{
189 Vid. DTS/01, pág. 83 y Vid datos desglosados en TABLA 7.2.2.1, en DTS/02, pág. 230.

190 Vid. DTS/01, págs. 89-90 y DTS/02, págs. 235-237.
} 
- En el marco de esta medida, durante el año 2002 se ha realizado un análisis estadístico de datos sobre la población extranjera en Andalucía, provenientes de diversas fuentes (Ministerio del Interior, INE, IEA) y referidos sobre todo, al año 2001.

- Asimismo se ha realizado la edición del Boletín OPAM, en soporte papel y digital, intentado con ello llegar al mayor número posible de personas interesadas en las cuestiones abordadas en dicho documento ${ }^{191}$.

MEDIDA

8.1.3. Convenio de de colaboración con el Instituto de Estadísticas de Andalucía para favorecer el acceso a fuentes de información sobre el fenómeno de la inmigración.

- Se continúan manteniendo relaciones entre el IEA y la D.G. de Coordinación de Políticas Migratorias, para favorecer el acceso a fuentes de información sobre el fenómeno de la inmigración, estando pendiente la formalización de dicho convenio.

MEDIDA

8.1.4. Realización de estudios de evolución de actuaciones desarrolladas en el ámbito de la inmigración.

- Se ha firmado un convenio de colaboración entre la Consejería de Gobernación de la Junta de Andalucía y la Universidad de Sevilla para la valoración inicial y elaboración del modelo de evaluación externa del programa ARENA, el 30 de septiembre de 2002, como modelo e evolución de actividades desarrolladas en el ámbito de la inmigración ${ }^{192}$.

- Propuestas para el bienio 2003-2004: realizar la evaluación externa del OPEMEI-INTERREG III MARRUECOS-ESPAÑA ${ }^{193}$.

Objetivo específica 8.2. Difundir la información disponible sobre las características del fenómeno inmigratorio y los factores relacionados con él.

ÓRGANO RESPONSABLE: CONSEJERÍA DE GOBERNACIÓN. D.G. DE COORDINACIÓN DE POLÍTICAS MIGRATORIAS.

\footnotetext{
191 Vid. DTS/02, pág. 237.

192 Vid. DTS/02, pág. 238.

193 Vid. DTS/02, pág. 297.
} 


\section{MEDIDA}

8.2.1. Creación de una página web para difundir información relativa al ámbito de competencias de la D.G. de Coordinación de Políticas Migratorias, en la que tendrá especial entidad al Observatorio Permanente Andaluz de las Migraciones (OPAM).

- El objetivo propuesto para el año 2002 ha sido la creación de la página web para difundir el ámbito de competencias de la D.G. de Coordinación de Políticas Migratorias, en la que tendrá especial entidad el OPAM, pero no pudo realizarse en su totalidad debido a cuestiones de diversa índole ${ }^{194}$.

- Propuestas para el bienio 2003-2004: Se pondrá en marcha, a través de la página de la Consejería de Gobernación, la página web del OPAM, con nuevos modelos de comunicación más flexibles y que permitirán al ciudadano y a los investigadores, así como a cualquier personas que necesite información en materia de inmigración, obtener ésta de forma rápida y fiable ${ }^{195}$.

MEDIDA

8.2.3. Publicación de los resultados de investigación de interés sobre el fenómeno de la inmigración.

- Durante el año 2002 se ha realizado una importante labor divulgadora de actividades investigadoras en materia de inmigración en la C.A. de Andalucía, con edición y publicación de los textos producidos en los diferentes eventos que tienen lugar en el mundo de la investigación en el fenómeno migratorio en Andalucía ${ }^{196}$.

Objetivo específico 8.3. Favorecer el intercambio y el enriquecimiento mutuo entre personas que intervienen y/o investigan en el ámbito de la inmigración.

ÓRGANO RESPONSABLE: CONSEJERÍA DE GOBERNAGIÓN. D.G. DE COORDINACIÓN DE POLÍTICAS MIGRATORIAS.

\section{MEDIDA}

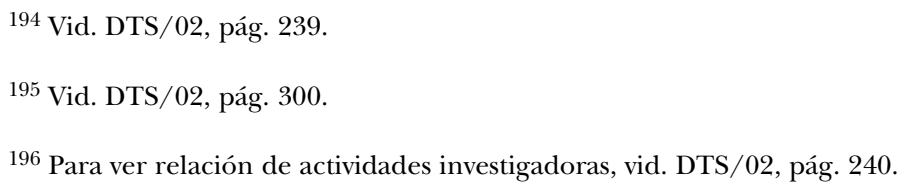


8.3.1. Organización de encuentros que posibiliten el intercambio de experiencias investigadoras o de intervención en el ámbito de la inmigración.

- Durante el año 2002 se han promovido 4 actuaciones relacionadas con encuentros que permitan el intercambio de expertos e investigadores en el campo de las migraciones:

- III Congreso de la Inmigración en España, celebrado en Granada en el mes de noviembre, que contó con 750 participantes y fue organizado por todas universidades pública andaluzas.

- II Seminario de Investigadores sobre la Inmigración Extranjera, celebrado en Almería en el mes de abril, con asistencia de 70 investigadores y 16 personas vinculas a la administración autonómica responsables de políticas migratorias.

- I Seminario Internacional de Comunicación y Migración, celebrado en Sevilla en el mes de diciembre.

- VI Congreso de Inmigración Africana, celebrado en Almería en el mes de abril ${ }^{197}$.

MEDIDA

8.3.2. Creación de un Grupo de Expertos en materia de inmigración que puedan enriquecer con su conocimiento las políticas dirigidas a favorecer $\underline{\text { la integración de la población inmigrantes en la sociedad andaluza. }}$.

- En el año 2002 se llevo a cabo la creación de un grupo de expertos, integrado por miembros de Universidades, IESA y la Dirección General de Coordinación de Políticas Migratorias en el marco del convenio de colaboración con el Instituto de Estudios Sociales de Andalucía ${ }^{198}$.

Objetivo específico 8.4. Análisis y estudio de los procesos de integración social de la inmigración y formación de profesionales en materia de intermediación intercultural.

ÓRGANO RESPONSABLE: CONSEJERÍA DE ASUNTOS SOCIALES. D.G. DE BIENESTAR SOCIAL.

MEDIDAS

${ }^{197}$ Vid. DTS/02, págs. 240-241.

198 Vid. DTS/02, pág. 241. 
8.4.1. Financiación de programas de investigación y análisis sobre la inmigración y las experiencias en integración social.

8.4.2. Formación en Intervención y Mediación Intercultural para profesionales.

8.4.3. Publicación de los estudios más significativos realizados en esta materia.

- A lo largo del año 2002 se han financiado 6 investigaciones, habiendo para ello suscrito 3 Convenios, concretamente, con la Universidades de Almería, Cádiz y Jaén. Estos datos nos permiten señalar que se van a estudiar situaciones en relación con la inmigración en los territorios de Andújar, Bajo Guadalquivir, Sevilla, Cádiz, Almería y Jaén. Estos datos permiten señalar que se ha duplicado el número de investigaciones financiadas en el año 2001.

- Durante el año 2002 se ha realizado un curso de Intervención y Mediación Intercultural por la Universidad de Granada, para la obtención del Titulo de Experto Universitario en Derecho de Extranjería, que fue dotado con 12.020, $24 €$ y en e que han participado 40 profesionales.

- Además se ha realizado las siguientes publicaciones:

- 500 ejemplares del estudio "La inmigración en el paraíso. Integración en la comarca de Doñana”, realizado por Mercedes Gordo Márquez. Univ. de Huelva. Presupuesto fue de 7.722,80€

- 500 ejemplares del estudio "Integración social y empleo de Inmigrantes. El Programa Integra-Diversidad" Sus autores fueros Manuel García, Manuel Martínez y Francisco Santolaya. Universidad de Sevilla. El presupuesto fue de 3.744,31 $€^{199}$.

Objetivo específico 8.5. Conocimiento de la realidad de la población inmigrante con una perspectiva de género.

ÓRGANO RESPONSABLE: CONSEJERÍA DE GOBERNACIÓN. D.G. DE COORDINACIÓN DE POLÍTICAS MIGRATORIAS. CONSEJERÍA DE LA PRESIDENCIA. INSTITUTO ANDALUZ DE LA MUJER. CONSEJERÍA DE EMPLEO Y DESARROLLO TECNOLÓGICO. CONSEJERÍA SALUD. CONSEJERÍA DE ASUNTOS SOCIALES.

MEDIDA

8.5.1. Realización de una larga serie de investigaciones

- En el ejercicio 2002 se han llevado a cabo las siguientes actuaciones, en el marco de la medida 8.5.1, por parte de la Dirección General de Coordinación de Políticas Migratorias:

199 Vid. DTS/02, pág. 242-243. 
- Convenio de colaboración con la Universidad de Sevilla para la realización de un estudio sobre "Mujeres inmigrantes y prostitución" ubicado el universo de referencia de las muestra en la provincia. Investigación, que se está realizando por el Departamento de Antropología Social de la Universidad de Sevilla.

- Estudio sobre "Mujeres inmigrantes y servicio doméstico en la ciudad de Granada", investigación que se está realizando a cargo de la Universidad de Granada.

- En este mismo año 2002, el IAM consciente del grave problema que afecta a las mujeres víctimas del tráfico de personas con fines de explotación sexual, ha puesto en marcha un estudio sobre la prostitución de mujeres en Andalucía. Este año se ha desarrollado el diseño de la investigación, planificando la obtención de resultados para el año 2003.

- También se ha publicado un estudio sobre "Servicio doméstico en Andalucía: Oferta y Demanda"200.

Objetivo específico 8.7. Mejorar la formación en materia de inmigración de profesionales que desarrollan su trabajo en contacto directo con inmigrantes o bien contribuyen a difundir conocimientos y crear opiniones y actitudes en la población (docentes, periodistas, etc.).

ÓRGANO RESPONSABLE: CONSEJERÍA DE GOBERNACIÓN. D.G. DE COORDINACIÓN DE POLÍTICAS MIGRATORIAS.

\author{
MEDIDA
}

8.7.1. Organización de actividades formativas dirigidas a profesionales de atención directa a inmigrantes y otros.

Desde la D.G. de Coordinación de Políticas Migratorias se han realizado diversas actividades formativas dirigidas a distintos profesionales de atención directa a personas inmigrantes y otros colectivos como son: periodistas, mediadores, empresarios, empleados públicos, trabajadores sociales de ONGs, así como universitarios y público en general. En relación con la ejecución de actuaciones relacionadas con esta medida, en el año 2002 se han realizado 17 acciones formativas, lo que implica un importante aumento respecto del año 2001, así mismo se han realizado acciones nuevas y de mayor alcance y se ha implicado a un mayor número de universidades y entidades locales y sin áni-

${ }^{200}$ Vid. DTS/02, págs. 244-245. 
mo de lucro de toda Andalucía y se ha aumentado considerablemente el número de personas que han participado en estas medidas ${ }^{201}$.

MEDIDA

8.7.2. Elaboración de materiales formativos y de difusión dirigidos a profesionales de atención directa a inmigrantes y otros.

- El año 2002 se ha enfocado a la realización de materiales de difusión a diferencia del año 2001, donde el enfoque se realizó hacia materiales formativos y guías de actuación:

- Edición y difusión del Plan Integral para la Inmigración en Andalucía. Se editaron 3.000 ejemplares en formato texto encarpetado y 3.500 en CD-ROM.

- Publicación de la Revista Portularia. Elaborada por la Escuela de Trabajo Social de la Universidad de Huelva, esta dedicada de forma monográfica al tema de la Migraciones y la Intervención Social. 3.500 ejemplares $^{202}$.

Objetivo específico 8.8. General ideas que puedan servir a los responsables públicos locales en el área de inmigración.

ÓRGANO RESPONSABLE: CONSEJERÍA DE GOBERNAGIÓN. D.G. DE ADMINISTRACIÓN LOCAL.

MEDIDA

8.8.1. Observatorio del Mundo Local genera ideas que puedan servir a los responsables públicos locales en el tema de inmigración.

- Durante el año 2002 se ha creado el Observatorio del Mundo Local (OML). Este Observatorio se crea en el último trimestre de 2002 y se gestionará por la Universidad Pablo Olavide de Sevilla.

- Entre sus funciones tendrá en cuenta la información sobre inmigración desde el punto de vista socioeconómico de interés para la gestión local.

- Durante el año 2002 se han realizado cuatro sesiones para la puesta en marcha del Observatorio, de estas sesiones se ha obtenido como resultado la puesta en marcha de un sistema de información que contempla la variable de inmigración ${ }^{203}$.

${ }^{201}$ Vid. las acciones formativas concretas en DTS/02, págs. 246-247.

202 Vid. DTS/02, pág. 248.

${ }^{203}$ Vid. DTS/02, págs. 248-249. 
Objetivo específico 8.9. Sensibilizar a través de la formación del personal de la gerencia pública local en el área de la interculturalidad.

ÓRGANO RESPONSABLE: CONSEJERÍA DE GOBERNACIÓN. D.G. DE ADMINISTRACIÓN LOCAL.

MEDIDA

8.9.1. Programa de formación del personal de la gerencia pública local para mejorar en eficiencia y eficacia la prestación de servicios mínimos obligatorios, teniendo en cuenta en todos los módulos el área de la interculturalidad.

- La formación de cargos electos ha sido, este año 2002, acometida a través de un curso piloto. Este curso aborda temas muy diversos, entre los que se aborda de forma transversal temas relacionados con el tema migratorio.

- Se ha celebrado el Seminario "Organización del Gobierno Local. Dirección Política Estratégica” en Antequera (Málaga) centrado en el tema de la inmigración. Este curso fue valorado positivamente por sus participantes, según las encuestas realizadas a la conclusión del curso $^{204}$.

Objetivo específico 8.11. Promover contactos entre los participantes y representantes de asociaciones juveniles europeas, al objetivo de transmitir a los colectivos implicados una información clara sobre el Programa Juventud.

ÓRGANO RESPONSABLE: CONSEJERÍA DE LA PRESIDENCIA. INSTITUTO ANDALUZ DE LA JUVENTUD.

MEDIDA

8.11.1. Cursos de formación para animadores y responsables de asociaciones juveniles, cuyos programas incluirían, entre otros, contenidos relativos al ámbito de inmigración.

- IAJ, a través del área de Formación en valores, ha dedicado especial atención al tema de inmigración ya que uno de los objetivos de esta área es promover los valores de respeto a la diversidad desde los principios de igualdad, tolerancia, paz, solidaridad etc., entre los jóvenes.

${ }^{204}$ Vid. DTS/02, pág. 249. 
- En este sentido durante el año 2002, se ha continuado con el desarrollo y ejecución del Proyecto "La Educación en Valores con Jóvenes" iniciado el 2001.

- Se han realizado 19 actividades formativas en Andalucía relacionadas con el tema de la inmigración dentro de la modalidad de formación de Valores, pertenecientes al Programa Formativo anual del IAJ que se coordina desde el Servicio de Formación, Investigación y Documentación de EPSA.

- Con la puesta en marcha de este proyectos se ha conseguido crear una red de formadores en Educación de Valores con jóvenes profesionales de distintas ONGs, colectivos o asociaciones que intervienen en programas relacionados con la sensibilización y educación de valores. El número total de animadores y responsables ha ascendido a 750 Además se ha diseñado colectivamente nuevas herramientas y materiales de formación ${ }^{205}$.

- Propuestas para el bienio 2003-2004: Publicación y difusión de los materiales didácticos sobre Educación en Valores con Jóvenes, elaborados tanto en los encuentros-talleres como en las reuniones mantenidas por los miembros del grupo de cada provincia ${ }^{206}$.

Objetivo específico 8.13. Atender con garantía de especialización a los inmigrantes demandantes de asistencia jurídica gratuita.

ÓRGANO RESPONSABLE: CONSEJERÍA DE JUSTICIA Y ADMINISTRACIÓN PÚBLICA. D.G. DE INSTITUCIONES Y COOPERACIÓN CON LA JUSTICIA.

\section{MEDIDA}

8.13.1. Realización de cursos de formación y especialización en materia de extranjería en los 11 Colegios de Abogados con sede en la C.A. Andaluza.

- Durante el año 2002, se ha subvencionado por parte de la Consejería de Justifica y Administración Pública a diversos Colegios de Abogados de Andalucía. Cada uno de ellos ha recibido una cuantía para la formación en materia de extranjería dirigido a los Letrados adscritos a los servicios de asistencia letrada al detenido y a los turnos de oficio. La subvención total asciende a 12.108, $60 €$ y los co-

\footnotetext{
205 Vid. DTS/02, págs. 250-252.

206 Vid. DTS/02, pág. 301.
} 
legios participantes han sido los de Almería, Antequera, Córdoba, Huelva y Sevilla, lo que implica un incremento en la participación ya que durante el año 2001 sólo se impartieron estos curso en los Colegios de Málaga y Sevilla.

- También se ha subvencionado con 1.200,00€ a CEAR-SUR para la realización de unas "Jornadas para la puesta en común y homogeneización de los procedimientos en que intervienen sus interrogantes". Deben sumarse a dichos cursos unas jornadas sobre procedimientos en materia de extranjería ${ }^{207}$.

\section{9. Área de Intervención de SENSIBILIZACIÓN SOCIAL}

El carácter transversal esta área permite establecer medidas que concurren con la finalidad del resto de las áreas intervinientes en el Plan. La Sensibilización Social como vía para insertar en nuestra sociedad valores positivos del hecho migratorio y el rechazo a toda forma de racismo y xenofobia o cualquier tipo de discriminación, favorece la integración y cohesión social entre la población inmigrante y la población autóctona.

Objetivo específico 9.1. Propiciar en la sociedad andaluza actitudes favorables a la acogida y a la integración social de la población inmigrante, tratando de prevenir la aparición de actitudes negativas hacia el hecho migratorio, así como modificar las posibles conductas racistas y xenófobas ya existentes.

\section{ÓRGANO RESPONSABLE: CONSEJERÍAS DE GOBERNCIÓN, EDUCA- CIÓN, ASUNTOS SOCIALES Y GULTURA.}

MEDIDA

9.1.1. Difusión y transmisión de conocimientos sobre diferentes culturas que conviven en la sociedad andaluza, utilizando información veraz sobre el fenómeno de la inmigración que se contrapone con las creencias favorecedoras de actitudes negativas y prejuiciosas, así como los testimonios de los emigrantes retornados que contribuyan al desarrollo de sentimientos de empatía.

- $\mathrm{Al}$ objeto de difundir y transmitir conocimientos y valores positivos acerca del fenómeno de la inmigración la D.G. de Coordinación de Políticas Migratorias, contando con la colaboración de entidades y personas que desempeñan labores en el campo artístico o intercul-

${ }^{207}$ Vid. DTS/01, pág. 97 y DTS/02, pág. 253. 
tural y que trabajan en contacto con el mundo de la inmigración ha organizado en año 2002 un total de 7 actividades ("VI Concierto contra el Racismo"....).

9.1.2. Producción y difusión de campañas publicitarias y programas en diferentes medios de comunicación, así como en contextos de educación formal y no formal.

- La producción y difusión de campaña publicitarias se ha mantenido e incrementado en el año 2002. En concreto se han llevado acabo 4 grandes campañas publicitarias y 2 actuaciones en materia de programación a través de televisión, prensa, radio y carteles.

- La audiencia media del programa "Andalucía sin fronteras" ha sido del 10,2\% de cuota de pantalla. Asimismo la evolución del programa ha sido positiva en general, llegando a conseguir récord de audiencia del $17,8 \%$ de cuota de pantalla el día 14 de abril de $2002^{208}$.

\section{MEDIDA}

9.1.3. Apoyo y colaboración con las ONGs en la organización de tareas de sensibilización y de difusión con contenidos favorecedores del mejor conocimiento y compresión del fenómeno migratorio y de las aportaciones de los inmigrantes a la sociedad de acogida.

- Gracias a las actividades que han sido puestas en marcha para el cumplimiento del presente objetivo, se ha podido acercar a la población andaluza a manifestaciones culturales como son la música, la danza y la gastronomía de las personas procedentes de países de África y Latinoamérica que en la actualidad residen en Andalucía.

- En este contexto la D.G. de Coordinación de Políticas Migratorias ha apoyado, durante en año 2002, 78 acciones enmarcadas en el "I Festival Andino" (Sevilla), la Semana Cultural Bay-Fall "Toca el alma de África" (Granada), contratación en la provincia de Jaén de 6 mediadores interculturales. También se subvencionaron 76 proyectos de sensibilización (charlas, talleres, jornadas...)

Objetivo específico 9.2. Sensibilizar y prevenir las actitudes racistas y xenófobas.

ÓRGANO RESPONSABLE: CONSEJERÍA DE ASUNTOS SOGIALES. D.G. DE BIENESTAR SOCIAL.

208 Vid. DTS/02, págs. 258-261. 
MEDIDAS

9.2.1. Financiación de programas de sensibilización a la población en general y colectivos específicos.

9.2.2 Formación-sensibilización a profesionales que desempeñen su trabajo con el colectivo inmigrante.

9.2.3. Encuentro interculturales.

9.2.4. Producción de material divulgativo.

9.2.5. Establecimiento de planes específicos de formación par a los profesionales de los Servicios Sociales Comunitarios.

9.2.6. Formación del voluntariado Social en Programas de Inmigrantes.

- Se han realizado un elevado número de actividades de sensibilización que han tenido diversos protagonistas. Las actividades se encuadran bajo la denominación de charlas, encuentros, seminarios, actuaciones, etc, y responde a circunstancias diversas, lo que es lógico por que en materia de sensibilización, de lo que se trata es de acercarse a las personas. La cuantía de las subvenciones concedidas ha sido de $287.429,49 €$, lo que implica un importante aumento respecto del año 2001 en que subvencionaron programas por valor de 226.875,34€.

- Dado que es fundamental la sensibilización de las personas que realizan la prestación servicios para lograr los objetivos del I Plan para la Inmigración durante el año 2001 se realizaron dos actividades de formación, mientras que en el año 2002 se ha realizado 4 actuaciones dirigidas a profesionales que trabajan con colectivos de inmigrantes: Curso sobre acogidas realizado por la Cruz Roja de Almería (6.100€); Programa de interculturalidad y mediación llevado acabo por la Asociación Jiennense $(6.000 €)$; Intervención de los Servicios Sociales con inmigrantes, ejecutada por la Diputación de Sevilla $(8.669 €)$; y Cursos de Otoño: Inmigración, realizado por la Universidad de Huelva $(8.414 €)$.

- Se ha realizado diversos encuentro interculturales que permiten el acercamiento de todas las partes implicadas desde una posición de igualdad entre las culturas. En el año 2002 se ha aumentado el número de encuentros, pasando de 3 celebrados en 2001 a 6 , lo que duplica el número de actividades.

- Los materiales divulgativos permiten incrementar el acervo en materia de sensibilización, por lo que su publicación es un factor muy importante a la hora de adquirir y comparar conocimientos. La transmisión de conocimientos esta permitiendo mejorar año tras año la intervención. Durante el año 2001 se publicaron 3 materiales divulgativos $(18.833,40 €)$ mientras que en el año 2002 se ha publicado (21.197,68 €). 
- No se ha establecido ningún plan especial para la formación de profesionales de los Servicios Sociales Comunitarios, pero dentro del Plan de Formación del Ministerio de Trabajo y Asuntos Sociales se propuso y ejecutó el curso POLÍTICAS DE INMIGRACIÓN: BASES PARA LA INTERVENCIÓN SOCIAL CON INMIGRANTES, que reimpartió en Huelva del 18 al 20 de noviembre de 2002, con la participación de 30 profesionales.

- La Mancomunidad de Municipios de La Janda en Medina Sidonia (Cádiz) ha ejecutado un programa de formación de voluntariado, inmigración e interculturalidad, con un presupuesto de 6.039,39 $€^{209}$.

Objetivo específico 9.3. Contribuir a mejorar el conocimiento del fenómeno de la inmigración por parte de la sociedad en general $y$, en particular, de profesionales que trabajan en contacto directo con la población inmigrante o que contribuyen directamente a la formación de opiniones y actitudes de la población hacia esta realidad (docentes, periodistas, profesionales de la atención sanitaria...).

ÓRGANO RESPONSABLE: CONSEJERÍAS DE GOBERNACIÓN, EDUCACIÓN, SALUD Y ASUNTOS SOCIALES.

\section{MEDIDAS}

9.3.1. Organización de acciones formativas en materia de inmigración dirigidas a profesionales de los medios de comunicación y de otros ámbitos y colaboración en actividades de lamisca naturaleza organizadas por otras entidades públicas y privadas.

9.3.2. Establecimiento de los Premiso Andalucía sobre migraciones para estimular, mediante el reconocimiento público, la destacada labor desarrollada a favor de la integración social de este colectivo.

- A través de las actividades realizadas se ha conseguido formar y sensibilizar a profesionales y sociedad en general En el año 2002 se ha realizado 15 actividades frente a las 5 realizadas en el año 2001.

- Se ha convocado los Premios Andalucía sobre Inmigración destinadas a destacar la labor desarrollada a favor de la integración y que se entregan en el Teatro Central de Sevilla. En el año 2002 sólo se presentaron 21 candidaturas por lo que algunas modalidades de este premio han quedado desiertas.

${ }^{209}$ Vid. DTS/01, pág. 102 y DTS/02, págs. 263-267. 
- Propuestas para el bienio 2003-2004: Convocar los premios, aunque en el primer trimestre para que no coincida con el verano, fecha a la que se atribuye la escasa participación; Implicar más a las administraciones y entidades con responsabilidad en materia educativa, cultural e informativa para tratar de extender al máximo la convocatoria entre los posibles candidatos y animarles a participar; Cambiar la fecha de entrega de premios de diciembre a enero o febrero $^{210}$.

Objetivo específico 9.4. Prevenir posibles actitudes xenófobas y favorecer la toma de conciencia de los valores culturales para crear las condiciones que permitan la integración social de las personas inmigrantes y el enriquecimiento y desarrollo de la sociedad andaluza.

ÓRGANO RESPONSABLE CONSEJERÍA DE RELACIONES INSTITUCIONALES

MEDIDA

9.4.1. Realización de actividades divulgativas: publicaciones, conferencias, exposiciones, en colaboración con ONGs, Universidades y colectivos de enseñantes y profesionales en contacto directo con el fenómeno migratorio.

- Se ha subvencionado 7 proyectos, durante el año 2002, frente a los 4 que se subvencionaron en el año 2001. Entre las actividades subvencionadas en el año 2002 destacan: I coloquio Internacional "Los extranjeros en la España moderna" organizado por la Universidad de Málaga; Jornadas Antiglobalización "Más allá de la globalización económica" organizado por el consejo Local de Juventud de Sevilla; Acogida de niños saharauis "Vacaciones en Paz 2002"; Programa "Encuentro entre culturas" en Sevilla organizado por SIDA CONTIGO; Acciones sobre "salud social de los Inmigrantes: información, prevención y formación" organizadas por AEH-Huelva Solidaria; I Encuentro de inmigrantes moriscos, en Puebla de Cazalla y Proyecto de sensibilización para el desarrollo "El otro mundo puede ser éste", promovido por la Asociación VOZ DEL INMIGRANTE de Sevilla ${ }^{211}$.

${ }^{210}$ Vid. DTS/02, pág. 304.

211 Vid. DTS/02, págs. 271-273. 
- $\quad$ Propuesta para el bienio 2003-2004: Mencionar expresamente en la próxima actualización de las bases reguladoras para concesión de subvenciones y ayudas públicas por la Consejería de Relaciones Institucionales al I Plan de Integral para la Inmigración en Andalucía y en concreto al área, objetivo y medida en la que participa esta Consejería 212 .

\section{0. Área de Intervención de Cooperación al Desarrollo}

La cooperación para el desarrollo llevada a cabo por la Junta de Andalucía pretende contribuir a que las personas de los países menos avanzados obtengan condiciones dignas de vida, siendo su fin último la erradicación de la pobreza humana mediante la promoción de un desarrollo socio-económico y socio-cultural sostenible.

Objetivo específico 10.1. Contribuir, en la medida de los posible, a la radicación de la pobreza y a la consolidación de los procesos encaminados a asegurar un desarrollo humano sostenible. Informar a la sociedad andaluza sobre la situación desfavorecida que padecen otros pueblos y grupos sociales...

ÓRGANO RESPONSABLE: CONSEJERÍA DE LA PRESIDENCIA. D.G. DE ASUNTOS EUROPEOS Y COOPERACIÓN EXTERIOR.

\section{MEDIDA}

10.1.1. Un programa de educación para el desarrollo, sensibilización y concienciación de los diferentes agentes y de la sociedad andaluza en general sobre la tolerancia y el respeto por la diversidad cultural.

10.1.2. Posibles actuaciones de formación y capacitación en origen de recursos humanos que accederán al mercado laboral andaluz, de forma temporal y mediante un contrato de trabajo, además de formarles sobre la realidad cultural, social, política etc..de nuestra región, creando en origen servicios de orientación e información laboral para los potenciales inmigrantes a Andalucía y estudiar la posibilidad de instrumentar con la Administración competente, servicios de intermediación para la búsqueda de empleo.

- Al igual que el año 2001, en el 2002 el programa ha adoptado como referente esencial la disminución de la pobreza y cobertura de las necesidades básicas de las poblaciones más desfavorecidas en países

\footnotetext{
${ }^{212}$ Vid. DTS/02, pág. 304.
} 
que el PNUD denomina de bajo índice de desarrollo humano en América, Latina, África Subsahariana y el Magreb.

- En el año 2002 se han aprobado 173 proyectos y actuaciones de Cooperación Internacional al Desarrollo que ha recibido una financiación total por parte de la Junta de Andalucía de 18.449.217,03€. Es de destacar la elevada participación de distintos agentes e instituciones en la ejecución del Programa de Cooperación Internacional: el $65,04 \%$ de la financiación total, con el 78,03\% de los proyectos aprobados se ha canalizado a través de ONGs, Universidad de Andalucía, Administraciones Locales y Organizaciones Profesionales. Las actuaciones de Cooperación a ejecutar directamente por la Junta Andalucía supone el 34,96\% de la financiación total aprobada con el 21,975 de los proyectos ${ }^{213}$.

\section{CONCLUSIONES}

Tanto el DTS/01 como el DTS/02 finalizan con análisis general de la ejecución del Plan que permite extraer una serie de conclusiones y recomendaciones por área de intervención, de las que vamos a realizar un pequeño extracto:

- Área Socio-Educativa: se considera muy positivo la propuesta del establecimiento de la figura del Mediador/a intercultural y la inclusión de este servicio en diversas áreas de intervención.

- Área Socio-Laboral: tanto en el año 2001 como en el 2002, el principal handicap es que todavía no se han transferido las Políticas Activas de Empleo a la Comunidad Autónoma, lo que condiciona el desarrollo de las actuaciones previstas en esa área. No obstante se ha avanzado en la adaptación de los cursos de formación flexibilizando los horarios, proporción de alojamiento etc. Con todo, es necesario ampliar la oferta formativa, incluyendo cursos básicos de español, así como la incorporación de la formación lingüística en los módulos de formación. También es necesario reforzar la oferta de pre-formación y/o preparación de la población inmigrante.

- Área Socio-Sanitaria: se detecta la necesidad de agilizar el sistema utilizando el servicio de traducción para obtener mejor cobertura de las demandas y necesidades.

213 Vid. datos desglosados en DTS/02, págs. 275-283. 
- Área de Recursos Sociales: es prioritario reforzar y mejorar el sistema de Servicios Sociales Comunitarios en cuanto a la prestación de servicios para la población inmigrante, para ello se considera necesario realizar una guía de recursos en materia de inmigración, como herramienta que permita mejorar la prestación de servicios de Información, Asesoramiento y Orientación a la oblación inmigrante. También se deberá incentivar las actividades deportivas, mejorando la difusión de las convocatorias de subvenciones existentes.

- Área de Vivienda: Es necesario realizar campañas de sensibilización para facilitar el acceso de los inmigrantes a las viviendas de alquiler, así como continuar mejorando la mediación de alquileres.

- Área Cultural: Sería necesario incluir medidas nueva para fomentar el deporte como herramienta de integración, para la aproximación de las diversas culturas. También se considera oportuno aceptar las propuestas de la Consejería de Cultura para asegurar el acceso de la población inmigrante y minorías étnicas y lingüísticas a los servicios bibliotecarios.

- Área de Atención Jurídica: es necesario culminar la Red de Atención Integrada para Inmigrantes y acometer el estudio y elaboración de protocolos de actuación para los distintos supuestos y situaciones.

- Área de Formación e Investigación: Se observa un mayor acercamiento de las investigaciones a las demandas del sector público, así como la progresiva incorporación de investigadores de distintas disciplina, pero se considera necesario incrementar las investigaciones desde la perspectiva de género e incorporar investigadores de los países de origen que permita profundizar en la perspectiva cultural. Finalmente, sería interesante realizar investigaciones sobre movimientos migratorios desde la perspectiva socioeconómica.

- Ámbito Formativo: Dentro del Plan de Formación General del IAAP se ha hecho una oferta a profesionales de los distintos Centros Directivos, como un primer paso para avanzar en la inserción de la formación específica en materia de inmigración en esta planificación. Además se propone la oferta formativa para profesionales de distintos ámbitos como son: Sanitario, Laboral, Cultural y especialmente Administración Local.

- Área de Sensibilización Social: siguiendo las conclusiones y recomendaciones de DTS/01 se ha continuado emitiendo el programa "Andalucía sin Fronteras" en Canal Sur2. Además es necesario seguir realizando campaña para prevenir actitudes de racismo y xenofobia. 
- Área de Cooperación al Desarrollo: se valoran positivamente las actividades realizadas por la Consejería de la Presidencia a través de la D. G de Cooperación al Desarrollo.

- Anexo Presupuestario: la previsión de gasto realizados para el 2002 y sucesivos se elaboró incrementando en un $2 \%$ las cantidades contempladas para el 2001. Durante estos dos primeros años de ejecución, seguimiento y evaluación del I Plan Integral para la Inmigración en Andalucía, se ha comprobado cómo el incremento de población extranjera sí como la necesidad de adaptar las medidas a las nuevas demandas, hace necesario un ajuste en las previsiones iniciales contenidas en el anexo presupuestario.

\section{- Coordinación:}

- El DTS/01 pone de manifiesto la mejora que ha supuesto el modelo de Coordinación utilizado a raíz de la elaboración, aprobación y puesta en marcha del I Plan Integral para la Inmigración en Andalucía y apunta la necesidad de seguir profundizado en esa línea. Durante el año 2002 se ha continuado la mejora de la coordinación de las estructuras y mecanismos verticales y horizontales. En este sentido se han realizado estudios tendentes a desarrollar un Sistema de Información Digital que creara espacios de comunicación internos y externos. La realidad continua demostrando la necesidad de mejorar la coordinación institucional, como eje fundamental de una política migratoria acertada.

- El papel de los Ayuntamientos es clave en el proceso. Es preciso que estos cuenten con los recursos necesarios para poder cubrir la demanda que se presenta en su ámbito de competencia. También es necesario que los mismos planteen iniciativas a las ofertas que tanto la Junta de Andalucía como otras Administraciones realizan o pueden realizar en un marco de colaboración adecuado y necesario.

- También es necesario mejorar las campañas de difusión de servicios, programas y medidas contempladas en este I Plan.

- Como conclusión final se propone una mayor participación en la toma de decisiones, una disminución de las desigualdades que contribuyan a una mayor cohesión social, y por último, aprovechar las innovaciones tecnológicas que se están produciendo continuamente, para ponerlas al servicio de I Plan Integral para la Inmigración en Andalucía como instrumento de planificación de políticas migratorias ${ }^{214}$.

${ }^{214}$ Vid. DTS/01, pág. 117-120 y DTS/02, págs. 319-322. 